\title{
Erythrocytapheresis, a treatment modality in hereditary hemochromatosis
}

Citation for published version (APA):

Rombout-Sestrienkova, E. (2016). Erythrocytapheresis, a treatment modality in hereditary hemochromatosis. [Doctoral Thesis, Maastricht University]. Datawyse / Universitaire Pers Maastricht. https://doi.org/10.26481/dis.20161208er

Document status and date:

Published: 01/01/2016

DOI:

10.26481/dis.20161208er

Document Version:

Publisher's PDF, also known as Version of record

\section{Please check the document version of this publication:}

- A submitted manuscript is the version of the article upon submission and before peer-review. There can be important differences between the submitted version and the official published version of record.

People interested in the research are advised to contact the author for the final version of the publication, or visit the DOI to the publisher's website.

- The final author version and the galley proof are versions of the publication after peer review.

- The final published version features the final layout of the paper including the volume, issue and page numbers.

Link to publication

\footnotetext{
General rights rights.

- You may freely distribute the URL identifying the publication in the public portal. please follow below link for the End User Agreement:

www.umlib.nl/taverne-license

Take down policy

If you believe that this document breaches copyright please contact us at:

repository@maastrichtuniversity.nl

providing details and we will investigate your claim.
}

Copyright and moral rights for the publications made accessible in the public portal are retained by the authors and/or other copyright owners and it is a condition of accessing publications that users recognise and abide by the legal requirements associated with these

- Users may download and print one copy of any publication from the public portal for the purpose of private study or research.

- You may not further distribute the material or use it for any profit-making activity or commercial gain

If the publication is distributed under the terms of Article $25 \mathrm{fa}$ of the Dutch Copyright Act, indicated by the "Taverne" license above, 


\section{Erythrocytapheresis, a treatment modality in hereditary hemochromatosis}

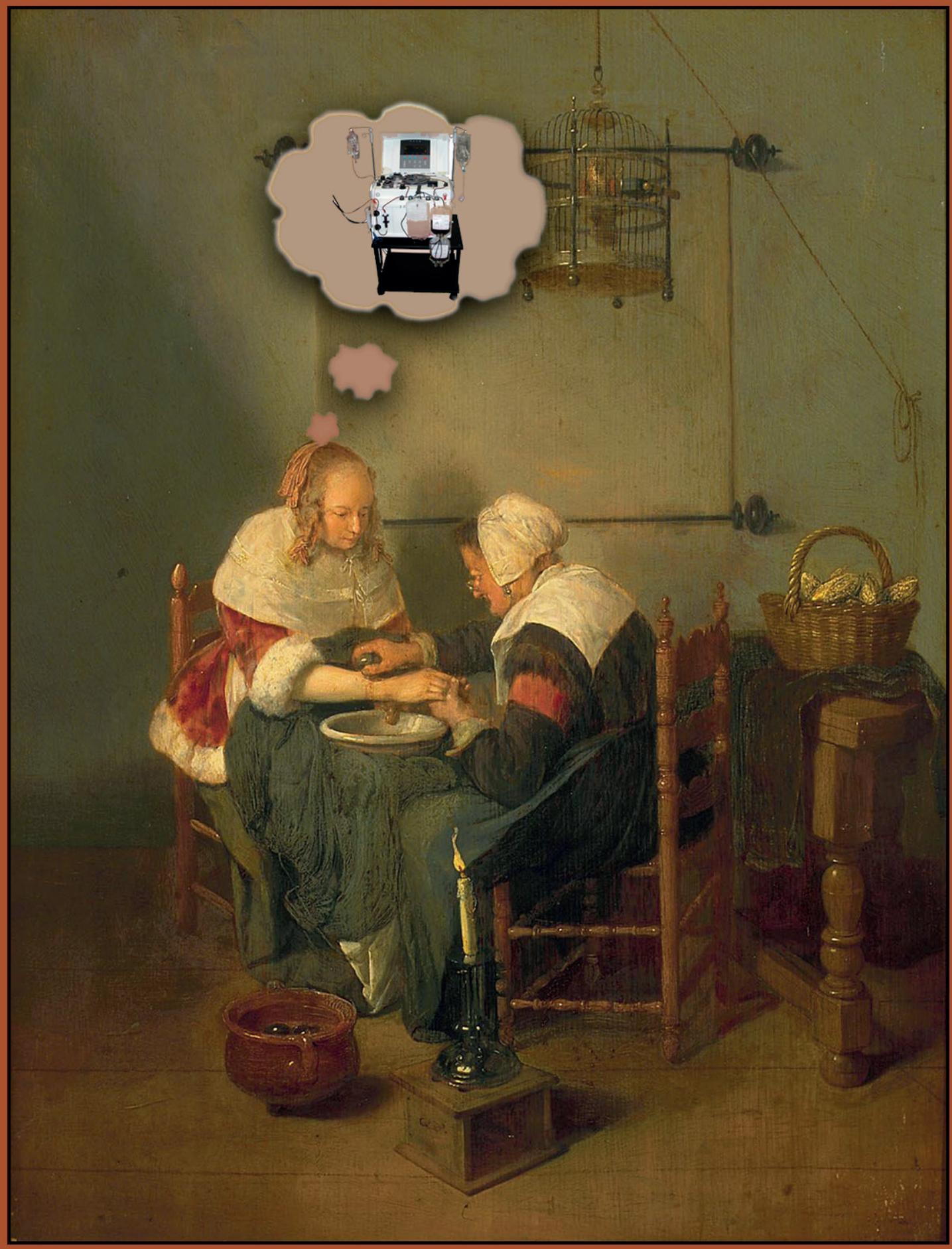

Eva Rombout - Sestrienkova 
(C) Eva Rombout-Sestrienkova, Maastricht 2016

No part of this book may be reproduced or transmitted in any form or by any means, without prior permission in writing by the author, or when appropriate, by the publishers of the publications.

Layout: Tiny Wouters

Cover design: Ferdie Rombout

Production: Datawyse | Universitaire Pers Maastricht

ISBN: $\quad 9789461596109$

Reproduction of this thesis was financially supported by: $\mathrm{MUMC}^{+}$, Sanquin Blood Supply, DruDevO, TERUMO BCT, and Haemonetics BV 


\title{
Erythrocytapheresis, a treatment modality in hereditary hemochromatosis
}

\author{
PROEFSCHRIFT \\ ter verkrijging van de graad van doctor aan de Universiteit Maastricht, \\ op gezag van de Rector Magnificus, Prof. dr. Rianne M. Letschert, \\ volgens het besluit van het College van Decanen, \\ in het openbaar te verdedigen op \\ donderdag 8 december 2016 om 14.00 uur
}

door

Eva Rombout-Sestrienkova 


\section{Promotor}

Prof. dr. A.A.M. Masclee

\section{Copromotores}

Dr. G.H. Koek

Dr. M.G.J. van Kraaij, Sanquin, Amsterdam

\section{Beoordelingscommissie}

Prof. dr. O. Bekers, voorzitter

Prof. dr. A. Brand, LUMC, Leiden

Prof. dr. P. Brissot, Université Rennes, France

Dr. W. Hameeteman

Prof. dr. H.C. Schouten 
Pre môjho otecka

Aan mijn vader 



\section{Contents}

Chapter 1 Introduction, outline and aims of the thesis 9

Chapter 2 Therapeutic erythrocytapheresis versus phlebotomy in the initial 25 treatment of hereditary hemochromatosis - A pilot study

Chapter 3 Erythrocytapheresis versus phlebotomy in the initial treatment of HFE hemochromatosis patients: results from a randomized trial

Chapter 4 Course of iron parameters in HFE-Hemochromatosis patients during initial treatment with erythrocytapheresis compared to phlebotomy

Chapter 5 Predicting the number of treatments in naïve hereditary hemochromatosis patients treated by phlebotomy or erythrocytapheresis

Chapter 6 Erythrocytapheresis versus phlebotomy in the maintenance treatment of HFE hemochromatosis patients; results from a randomized cross-over trial

Chapter 7 End-stage cardiomyopathy because of hereditary 99 hemochromatosis successfully treated with erythrocytapheresis in combination with left ventricular assist device support

Chapter 8 General discussion and summary

Samenvatting

Valorisation

Dankwoord

Curriculum vitae

List of publications 


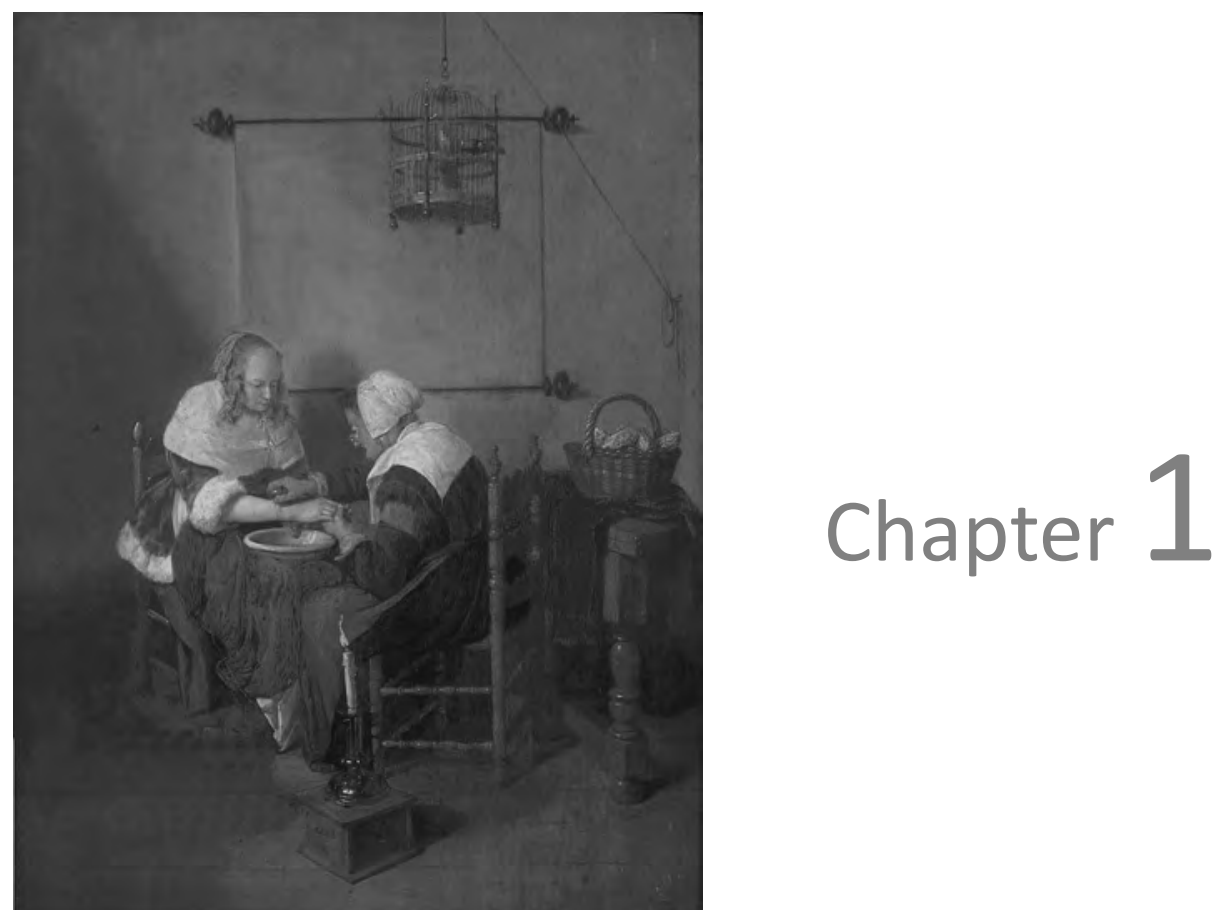

\section{Introduction, outline and aims of the thesis}

This chapter is a part of the authoritative review: "How we manage patients with hereditary haemochromatosis" Eva Rombout-Sestrienkova, Marian van Kraaij, Ger H Koek Br J Haematol 2016, Epub ahead of print 



\section{Introduction}

Hereditary hemochromatosis $(\mathrm{HH})$ is a term used for a group of genetic disorders characterized by an increased iron absorption. This may lead to a progressive accumulation of iron in tissues and organs resulting in impairment of organ structure and function, especially of liver, pancreas, heart, pituitary gland and probably joints. The disease has been described first time as "bronze diabetes" by Trousseau in $1865^{1}$ and as diabetes mellitus associated with hypertrophic cirrhosis of the liver and dark brownish skin pigmentation by Troisier in 1871. The first pathological finding in a patient with hemochromatosis was reported in 1882 by Hanot and Chauffard (TroisierHanot-Chauffard syndrome). ${ }^{2}$ Von Recklinghausen introduced the name hemochromatosis in $1889 .^{3}$ The first suggestion of the role of an inborn error of iron metabolism as its pathogenesis was made in 1953 by Sheldon. ${ }^{4}$ Just in 1996 Federer $^{5}$ discovered mutations in the HFE gene by most patients with a phenotypic $\mathrm{HH}$.

The prevailing mechanism in most types of $\mathrm{HH}$ is deficiency of hepcidin, originally identified as an antimicrobial peptide by Park et al., ${ }^{6}$ and then shown to play a major role in iron homeostasis. ${ }^{7,8}$ Hepcidin is synthesised mainly in hepatocytes and controls plasma iron concentration by binding to ferroportin, the only known cellular iron exporter. After binding, ferroportin is degraded reducing both intestinal absorption of iron from enterocytes and iron release from hepatocytes and macrophages. Increased plasma iron or cellular iron stores, as well as inflammation, generate a negative feedback that leads to a restriction of iron release into plasma and blockade of dietary iron absorption, through increased hepcidin production. Both hypoxia and increased erythroid demand generate a positive feedback, leading to increased flow of iron into plasma mediated by a decreased hepcidin production. The effects of inflammation, hypoxia and erythroid activity on hepcidin production are independent of the normal homeostatic feedback mediated by iron.

\section{HH classification}

Four main types of $\mathrm{HH}$ can be distinguished according to which of the proteins involved in iron homeostasis is affected.

Type 1, also called HFE- related $\mathrm{HH}$, caused by mutations in the HFE gene, is the most frequent form of genetic iron overload and results in a decreased production of hepcidin. The most common causal mutation, is a $\mathrm{G}$ to $\mathrm{A}$ transition at nucleotide 845 of the HFE gene, resulting in cysteine to tyrosine substitution at amino acid 282, referred as p.C282Y (Type 1a). ${ }^{9}$ This form is mainly present in populations of north European origin where one in 200-300 individuals are homozygous for this mutation. Although the prevalence of homozygosity for the p.C282Y mutation is high, the penetrance of disease is relatively low. Between 1-33\% of the homozygotes carriers develop clinical manifestations related to iron overload. ${ }^{10,11}$ Such a wide range is caused by the different ways in which homozygotes are identified, e.g. in population- or patient- 
based studies, as well as by the influence of other genetic and non-genetic factors, e.g. certain bone morphogenic protein (BMP) 2 variants ${ }^{12}$ and alcohol consumption. ${ }^{13}$ Allen et al. ${ }^{11}$ found gender differences with much lower penetrance in females versus males (1.2\% versus $28.4 \%)$. This has been attributed to physiological iron loss during menstruations and pregnancies and an antioxidant effect of the oestrogen. With the discovery of hepcidin, however, the lower penetrance in females has also been attributed to naturally occurring higher hepcidin levels as this was observed in female mice, ${ }^{14}$ and in $\mathrm{C} 282 \mathrm{Y}$ homozygous women with body mass index (BMI) $\geq 28{ }^{15}$

Another known genetic subtype is the p.H63D mutation that does not cause a significant iron overload, but may act as cofactor for iron overload phenotypic expression, ${ }^{16,17}$ mostly in combination with $\mathrm{p} . \mathrm{C} 282 \mathrm{Y}$, classified as compound heterozygosity (p.C282Y/p.H63D) (Type $1 b)^{9}$ with a prevalence of $2 \%$ in populations of north European origin. Only $0.5-2.0 \%$ of people with this specific type of hemochromatosis develop clinical symptoms of iron overload. Porto et al. ${ }^{18}$ concluded that this genotype is insufficient to result in hemochromatosis and that these patients need additional risk factors for iron overload or liver disease. HFE genotype type $1 \mathrm{c}$, e.g. p.S65C, etc., does not substantially affect the phenotype. ${ }^{9}$ However, there are sparse clinical and epidemiological data available on this genotype.

The other $\mathrm{HH}$ genotypes are not related to the HFE gene and have a very low prevalence.

Type $2 \mathrm{HH}$ is associated with mutations in the hemojuvelin (type $2 \mathrm{~A}$ ) or the hepcidin gene (type 2B) respectively. As in type $1 \mathrm{HH}$, hepcidin deficiency is the prevailing mechanism. Type $2 \mathrm{HH}$ is the most severe form, occurring in younger individuals and therefore called juvenile hemochromatosis.

Type $3 \mathrm{HH}$ is associated with mutations in the transferrin receptor 2 gene (TFR2), causing hepcidin deficiency.

Ferroportin disease, or type $4 \mathrm{~A} \mathrm{HH}$, is the only autosomal dominant form and is associated with mutations in the ferroportin gene. In this type the production of hepcidin is normal, but the export function of ferroportin is lost. This leads to intracellular iron retention with low levels of plasma iron as well as low levels of transferrin saturation (TS). In this type of $\mathrm{HH}$ the spleen is the most affected organ, because of high ferroportin activity at macrophage level. ${ }^{19,20}$ In type 4B the hepcidin concentration is also normal, but the receptor function of ferroportin is altered, with similar consequences for iron accumulation as in type $1 \mathrm{HH}$. The mutation in ferroportin gene in type $4 \mathrm{~B}$ leads to insensitivity of ferroportin to hepcidin, resulting in excessive iron efflux from cells to plasma. $^{21}$

Another form of a very rare and serious inherited iron overload disease, is aceruloplasminemia, caused by the absence of the feroxidase enzyme ceruloplasmin, resulting in iron accumulation in most organs, including the central nervous system. 


\section{Iron overload mechanisms}

Hepcidin production is decreased in type 1, 2 and $3 \mathrm{HH}$. Hepcidin deficiency allows hyperabsorption of dietary iron into plasma from duodenal enterocytes and increased release of recycled iron from splenic and liver macrophages and hepatocytes. This results in a chronic elevation of plasma iron, which exceeds the iron-binding capacity of circulating transferrin and results in the presence of iron in a non-transferrin-bound form (NTBI). Various parenchymal cells especially in the liver, pancreas and heart avidly take up NTBI. A special NTBI component, called labile plasma iron (LPI), is involved in the Haber-Weis and Fenton reactions, leading to production of reactive oxygen species in the cells, resulting in tissue oxidative damage and vital organ dysfunction.

\section{Diagnosis}

An increase in serum ferritin (SF) concentration with a concomitant increase in the TS is suggestive of $\mathrm{HH}$. When TS is low or normal, iron overload might be based on type 4A $\mathrm{HH}$, although this pattern is most commonly seen as part of an acute phase response. TS levels $\geq 75 \%$ are highly suggestive for presence of highly toxic LPI. ${ }^{20}$

In published cohorts approximately $77-78 \%$ of men and $47-52 \%$ of women, who were homozygous for the p.C282Y mutation, had elevated SF and TS at baseline and $37 \%$ of males and $3 \%$ of females had SF $>1000 \mu \mathrm{g} / \mathrm{l}$ at baseline. ${ }^{11,22}$ The predicted probability for SF to increase to $>1000 \mu \mathrm{g} / \mathrm{I}$ after 12 years with baseline SF between 300-1000 $\mu \mathrm{g} / \mathrm{I}$ was $13-35 \%$ in males and $16-22 \%$ in females. ${ }^{11}$

In patients with consistently elevated SF and increased TS, after excluding hematological or inflammatory diseases, genetic tests should be performed. The first step in populations of north European origin is testing for the p.C282Y mutation. ${ }^{18}$ Testing for p.H63D mutation can be considered as an optional complementary test. Genetic testing for other variants of $\mathrm{HH}$ is indicated in patients that test negative for p.C282Y homozygosity but have proven iron overload, demonstrated by magnetic resonance imaging (MRI) or liver biopsy. For patients testing positive for p.C282Y homozygosity genetic screening is indicated in their adult first-degree relatives. ${ }^{18}$

A liver biopsy is no longer required to confirm the diagnosis of $\mathrm{HH}$ or to assess iron load, but is still recommended to stage the degree of fibrosis when SF is $>1000 \mu \mathrm{g} / \mathrm{l}^{23}$ However, transient elastography, having a specificity of about $80 \%$, has become a suitable non-invasive alternative for liver biopsy. ${ }^{24}$ Currently, MRI techniques are used to evaluate body iron excess before treatment, ${ }^{25}$ and are probably accurate enough to rule out iron overload in the liver and other organs. ${ }^{26}$ To date, it is not clear whether MRI can be used to control the results of iron depletion after treatment. Prospective studies and standardized MRI protocols are needed to determine the role of MRI in the management of $\mathrm{HH}$. 


\section{Clinical manifestations}

The manifestation of HFE HH, usually occurring in middle-aged patients, is diverse because iron deposition can occur in multiple tissues and may vary from only genetic abnormalities (genotype), through biochemical abnormalities, such as increased SF and TS (biochemical phenotype) to severe organ damage (clinical phenotype). The traditional HH stigmata of bronze diabetes, arthropathy and liver cirrhosis, were found in early reports before the discovery of HFE gene. Nowadays chronic fatigue, joint pains, abdominal complaints and moderately elevated transaminases are typical early clinical features. ${ }^{27,28}$ The most common sign on physical examination is hepatomegaly. ${ }^{10}$

\section{Organ damage}

The principal target of iron overload is the liver. Iron is initially preferentially stored in hepatocytes and with severe overload (SF>1000 $\mu \mathrm{g} / \mathrm{l}$ ) also in bile ductular and Kupffer cells. Iron-induced activation of stellate cells may stimulate fibrogenesis and cause cirrhosis, $^{29}$ ultimately even leading to hepatocellular carcinoma (HCC). Concomitant diseases such as alcoholic liver disease, non-alcoholic fatty liver disease and chronic viral hepatitis, which can be present in up to $15 \%$ of $\mathrm{HH}$ patients, will increase the risk of liver injury and development of cirrhosis. ${ }^{30}$ Cirrhosis and HCC are the major causes of death in patients with untreated $\mathrm{HH}$. The quantity of iron stored in the liver is the major known predictor of cirrhosis. However, recent cohort data showed that in some patients cirrhosis may already occur at lower levels of iron overload, while other individuals with severe iron overload do not have cirrhosis, ${ }^{30}$ indicating that other factors besides iron overload may be responsible for the development of cirrhosis and HCC.

Other complications of advanced $\mathrm{HH}$ are (i) diabetes, caused by iron-overload in the pancreas, (ii) cardiomyopathy and arrhythmias caused by heart siderosis, (iii) impotence and hypogonadotropic hypogonadism caused by iron overload in the pituitary gland and testes, and (iv) destructive arthropathy/arthritis with primary involvement of the $2^{\text {nd }}$ and $3^{\text {rd }}$ metacarpophalangeal joints, interphalangeal joints, hips and knees.

Some manifestations such as weakness, skin pigmentations and hepatic fibrosis may regress with appropriate treatment, while others such as cirrhosis, cardiomyopathy, diabetes and arthropathy are irreversible, although certain aspects of these complications might be improved with treatment (increased liver enzymes, daily insulin requirements). ${ }^{31,32}$ Early diagnosis and treatment are therefore important if morbidity and mortality are to be reduced. 


\section{Treatment}

Once $\mathrm{HH}$ is diagnosed, therapy is straightforward and effective, based on the removal of excess body iron. The treatment consists of two phases, the depletion phase with the goal of lowering SF to target values, and the maintenance treatment with the goal of maintaining stable target SF values.

Despite absence of randomized controlled trials, the benefit of iron depletion has been well documented and established by case series from clinically diagnosed $\mathrm{HH}$ patients. Life expectancy of $\mathrm{HH}$ patients on therapy equals that of the non-HH population when this disorder is diagnosed before the onset of cirrhosis and diabetes. ${ }^{31-35}$ Since about $90 \%$ of all $\mathrm{HH}$ cases are associated with homozygosity for the p.C282Y mutation ${ }^{36}$ the focus in this thesis will be on the treatment of type $1 \mathrm{HH}$.

\section{Timing: when should treatment be started?}

After the diagnosis of $\mathrm{HH}$ has been established, either surveillance or treatment is recommended according to the European and American guidelines. ${ }^{37,23}$ Where the SF level is within the normal range, yearly follow-up is advised. Where the SF level is elevated, pre-emptive treatment is recommended to reduce SF to target levels. This includes treatment of asymptomatic individuals with homozygous $\mathrm{HH}$ and increased iron stores. All current recommendations are based on expert opinion as there are no studies providing evidence-based data about optimal timing to start treatment.

Whether patients with mild hyperferritinemia (SF 300-1000 $\mu \mathrm{g} / \mathrm{l}$ ) need treatment is currently under debate. Bardou-Jacquet et al. ${ }^{38}$ followed 1085 p.C282Y homozygotes who were treated according to current recommendations. The subgroup with mild hyperferritinemia (SF 300-1000 $\mu \mathrm{g} / \mathrm{l}$ ) treated with iron depletion had a better survival than the general population, due to a decreased cardiovascular and extrahepatic cancer related mortality. In treated patients only those with SF higher than $2000 \mu \mathrm{g} / \mathrm{I}$ had increased mortality compared to the general population, mainly related to liver disease. These results suggest a beneficial effect of early and sustained management of patients with even mild iron excess, which opposes earlier studies ${ }^{39,40}$ that advise surveillance instead of therapy. However, the results of Bardou-Jacquet study cannot clarify whether treatment of $\mathrm{HH}$ patients with mild hyperferitinemia favours surveillance, since $\mathrm{HH}$ patients were compared to the general population. A randomized controlled study comparing either surveillance or treatment of $\mathrm{HH}$ patients with mild hyperferritinemia may give better insight into the optimal SF level to start iron removal treatment.

\section{What are target SF levels for depletion phase?}

According to the 2010 EASL guideline for $\mathrm{HH}$, the target level of SF is less than 50 $\mu \mathrm{g} / \mathrm{l}{ }^{37}$ However new data from the literature suggest that excessive iron depletion 
down to iron-deficient levels may be counter-productive and may lead to increased intestinal iron absorption through hepcidin suppression caused by lowering SF levels. ${ }^{41-43}$ It has long been known that iron absorption is increased at low SF levels: $42 \%$ versus $12 \%$ when the mean SF were 14 and $538 \mu \mathrm{g} / \mathrm{l}$ respectively. ${ }^{44}$

The Current Practice Guidelines developed by the AASLD advises a target SF levels between $50-100 \mu \mathrm{g} / \mathrm{I}^{23}$ Although several national guidelines still mention a target SF level of less than $50 \mu \mathrm{g} / \mathrm{I}$ most experts now state that SF levels close to $50 \mu \mathrm{g} / \mathrm{l}$ are the optimal target level. ${ }^{17,20}$

\section{What are target SF levels for maintenance phase?}

The same target SF levels as for the depletion phase $(50-100 \mu \mathrm{g} / \mathrm{I})$ are recommended for the maintenance therapy. Some experts recommend surveillance rather than treatment for patients with SF below the upper limit of normal value, given the information that non-haem absorption is markedly increased at lower levels of iron stores leading to more frequent maintenance treatments. ${ }^{41}$ More data are needed to confirm this recommendation.

\section{Methods for iron depletion}

There are three different types of iron depletion used by HH patients: phlebotomy, erythrocytapheresis and oral or parenteral chelators. Chelators are only used in selected patients i.e. without appropriate access to peripheral veins and in case of severe anemia.

\section{Phlebotomy}

Since 1950 phlebotomy is the most widely accepted treatment for $\mathrm{HH}^{45}$ The effect of the treatment is simple: repeated withdrawal of red blood cells (RBC's) reduces the iron that is present in hemoglobin $(\mathrm{Hb})$. This stimulates erythropoiesis and thereby mobilises iron stored in organs and in this way eliminates excessive stored iron.

\section{Treatment regime in the depletion phase}

Once weekly, if tolerated, on average $450-500 \mathrm{ml}$ of whole blood $(7 \mathrm{ml} / \mathrm{kg}$ ), containing 200-250 mg of iron is removed until SF is decreased to target levels. ${ }^{23,37,46}$ Although on average SF decreases by $30 \mu \mathrm{g} / \mathrm{I}$ per phlebotomy, the total number of procedures needed is highly variable and depends mainly on iron reserve status. ${ }^{47}$ In a study of Adams, with $77 \mathrm{HH}$ patients with a mean SF of $2.554 \mu \mathrm{g} / \mathrm{l}$, the mean duration of phlebotomy therapy was 1.4 years (range $0.44-3.6$ years) with a treatment frequency 
of once every 1.38 weeks. $^{48}$ In a survey of McDonnell et al., ${ }^{49}$ the mean duration of treatment in the depletion phase was 14 months with a total number of procedures between 28 and 43 .

\section{Treatment regime in the maintenance phase}

In the maintenance phase the phlebotomy frequency is reduced to 2-6/year. After initial therapy not all patients re-accumulate iron at the same speed as was shown in a study of Adams et al in which 21 homozygous $\mathrm{HH}$ patients were followed with a mean of 4.0 years. ${ }^{50}$ Manet et al. ${ }^{51}$ point to the iron reabsorption index (IRI), expressed as milligrams of iron removed per day of treatment, as a potential valuable phenotypic indicator for daily iron over-absorption, which may guide the clinician in balancing phlebotomy interval and volume. Recently Verhaegh et al. ${ }^{52}$ suggested that modified iron avidity index (IAI) might be a fairly good predictor at identifying patients needing more than 3 phlebotomies per year. The calculated IAI consists of SF at diagnosis, divided by age at diagnosis minus 20 when male, or plus 20 when female. However, the correlation between IAI and number of phlebotomies was only moderate and the usefulness of IAI has to be confirmed in prospectively conducted studies.

\section{How should treatment be monitored?}

The SF level, known to be directly related to total body iron $(1 \mu \mathrm{g} / \mathrm{l}$ of SF corresponded to $7.5 \mathrm{mg}$ of body iron), ${ }^{53}$ is used to monitor effectiveness of treatment. The frequency of measurements depends upon SF values: every three months in the initial stage of depletion treatment and more frequently as SF approaches the normal range. ${ }^{23,37}$ In the maintenance phase of treatment the frequency of SF measurement is decreased to once every 6 months.

It should be taken into account that SF test suffers from low specificity, as elevated SF values can be the result of a range of inflammatory, and neoplastic conditions. However in the group of patients with a secure diagnosis of $\mathrm{HH}$, it is a sensitive and specific marker to monitor therapy taking into account that in certain situations increased SF may result from other causes.

Regular measurements of $\mathrm{Hb}$ should be performed before each phlebotomy, to avoid reducing the $\mathrm{Hb}$ to $<80 \%$ of the starting value. When anemia is present, phlebotomy should be postponed until the anemia has resolved.

\section{Side effects of phlebotomy treatment}

The most common side effects of phlebotomy treatment are fatigue, fainting, pain at the venous access site, hematomas and anemia. Overall, $52 \%$ of patients during the induction phase of treatment and $37 \%$ in the maintenance phase report negative experiences related to treatment and $16 \%$ of patients would even decide to stop phlebotomy treatment if alternative options became available. ${ }^{54}$ 
Patient compliance with phlebotomy treatment was evaluated in a study by Hicken et al. ${ }^{55}$ During depletion phase $76 \%$ of patients complied to weekly $(33 \%)$ or bi-weekly (43\%) schedules. In the first year of maintenance therapy $84 \%$ of patients complied with therapy, subsequent compliance decreasing by $6.8 \%$ annually.

\section{Erythrocytapheresis}

A more recent alternative for $\mathrm{HH}$ treatment is erythrocytapheresis, a technique that selectively removes RBC's and returns valuable blood components such as plasma proteins, clotting factors, platelets, etc. to the patient. This makes treatment particularly suited for patients suffering from hypoproteinemia and/or thrombocytopenia.

With erythrocytapheresis it is possible to remove up to $1000 \mathrm{ml} \mathrm{RBC}$ 's per single procedure, compared to $200-250 \mathrm{ml} \mathrm{RBC}$ 's per phlebotomy. Another advantage is the possibility for substitution of the removed RBC's volume with saline, albumin or other colloid solutions. This results in fewer hemodynamic changes compared to phlebotomy, making this treatment particularly well suited for patients with cardiac diseases.

Two different approaches are used when applying erythrocytapheresis in daily practice.

In an individualized approach based on sex, body weight, total blood volume (TBV), and actual hematocrit (Hct), erythrocytapheresis allows for a more sophisticated and accurate adjustment for the volume of removed RBC's. ${ }^{56-67}$ This approach showed a higher efficiency of erythrocytapheresis compared to phlebotomy, with a reduction in the number of needed treatment procedures and a reduction in the treatment duration.

Another therapeutic approach has been applied by groups of Sundic ${ }^{68}$ and Stefashyna. ${ }^{69}$ They choose to remove a standard volume of RBC's in each patient (400 $\mathrm{ml}$ and $360 \mathrm{ml}$ respectively), which also led to a reduction in total number of treatments, but without a reduction in the treatment duration. This approach lacks a potential advantage of erythrocytapheresis: since a fixed volume has been used instead of personalized removal of RBC's, making it relatively more expensive and therefore less competitive with phlebotomy. Also Stefashyna et al used their approach in a selected population of patients in order to be able to use the removed RBC's for transfusion purposes. However, if patients with $\mathrm{HH}$ will be accepted as blood donors, it would be presumably more cost effective when 2,3 or even 4 RBC's units could be removed through erythrocytapheresis, depending on TBV and $\mathrm{Hb}$ of the patients. 


\section{Outline, aims and focus of the thesis}

In the current thesis our aim is to study, in an evidence based way, the role of erythrocytapheresis in both the depletion and maintenance phase of type $1 \mathrm{HH}$ treatment and to compare advantages and dis-advantages of this treatment method with standard phlebotomy treatment.

We hypothesize that treatment of type $1 \mathrm{HH}$ with erythrocytapheresis is a more efficient and effective treatment, with less treatment procedures, leading to less adverse events, and better compliance of patients when compared to treatment with phlebotomy. A $50 \%$ decrease in the number of treatment procedures was chosen as the relevant difference to detect.

Chapter 2 describes a pilot study that was undertaken to study the feasibility of erythrocytapheresis in the depletion phase of $\mathrm{HH}$ treatment. Chapter 3 presents results of a randomized clinical trial (RCT) comparing erythrocytapheresis with phlebotomy in the depletion phase of $\mathrm{HH}$ treatment. Chapter 4 describes the time course of iron parameters with a special focus on serum hepcidin, based on a small observational study, executed during the depletion phase of treatment with erythrocytapheresis and phlebotomy. Chapter 5 presents the prediction rule that estimates the number of treatment procedures needed for the depletion phase of $\mathrm{HH}$ treatment by either using phlebotomy or erythrocytapheresis, based on a retrospective data analysis in 97 newly diagnosed type $1 \mathrm{HH}$ patients. In chapter 6 the effectiveness of erythrocytapheresis versus phlebotomy is compared during the maintenance phase of therapy, studied in a two-treatment arms, cross-over RCT. Chapter 7 describes a patient with end-stage cardiomyopathy due to type $1 \mathrm{HH}$ who was treated with erythrocytapheresis in combination with left ventricular assisted device support. Finally, in the general discussion (Chapter 8), the results of the studies presented in this thesis are summarizes with focus on potential implications for future treatments of patients with $\mathrm{HH}$. 


\section{References}

1. Trousseau A. (1865) Glycosurie, Diabète sucré. Clinique Médical de l'Hôtel-Dieu de Paris. 2nd edition, vol. 2. Bailière, Paris. 1865:663-98.

2. Chauffard A, Hanot VC. Cirrhose hypertrophique pigmentaire dans le diabète sucré ", Revue de médecine, Paris, vol. 2, 1882:385-403.

3. Von Recklinghausen FD. Hämochromatose. Tageblatt der Naturforschenden Versammlung (1889), Heidelberg, 1890:324.

4. Sheldon J. Haemochromatosis. Oxford University Press, London, UK.1935.

5. Feder JN, Gnirke A, Thomas W, Tsuchihashi Z, Ruddy DA, Basava A, Dormishian F, Domingo R, Jr, Ellis MC, Fullan A, Hinton LM, Jones NL, Kimmel BE, Kronmal GS, Lauer P, Lee VK, Loeb DB, Mapa FA, McClelland E, Meyer NC, Mintier GA, Moeller N, Moore T, Morikang E, Prass CE, Quintana L, Starnes SM, Schatzman RC, Brunke KJ, Drayna DT, Risch NJ, Bacon BR, Wolff RK. A novel MHC class I-like gene is mutated in patients with hereditary hemochromatosis. Nature Genetics. 1996;13:399-408.

6. Park $\mathrm{CH}$, Valore EV, Waring AJ, Ganz T. Hepcidin, a urinary antimicrobial peptide synthesized in the liver. J Biol Chem. 2001;276(11):7806-10.

7. Pigeon C, Ilyin G, Courselaud B, Leroyer P, Turlin B, Brissot P, Loreal O. A new mouse liver-specific gene, enconding a protein homologous to human antimicrobial peptide hepcidin, is overexpressed during iron overload. J Bio Chem. 2001;276:7811-9.

8. Ganz T. Hepcidin, a key regulator of iron metabolism and mediator of anemia of inflammation. Blood. 2003;102:783-8.

9. Powell LW, Seckington RC, Deugnier Y. Haemochromatosis. Lancet 2016;388(10045):706-16.

10. Pietrangelo A. Hereditary hemochromatosis: pathogenesis, diagnosis, and treatment. Gastroenterology. 2010;139:393-408.

11. Allen KJ, Gurrin LC, Constantine CC, Osborne NJ, Delatycki MB, Nicoll AJ, McLaren CE, Bahlo M, Nisselle A, Vulpe CD, Anderson GJ, Southey MC, Giles GG, English DR, Hoppe, JL, Olynyk JK, Powell LW, Gertig DM. Iron-overload-disease in HFE hereditary hemochromatosis. New Engl J Med. 2008; 358:221-230.

12. Milet J, Dehais V, Bourgain C, Jouanolle AM, Mosser A, Perrin M, Morcet J, Brissot P, David V, Deugnier $\mathrm{Y}$, Mosser J. Common variants in the BMP2, BMP4, and HJV genes of the hepcidin regulation pathway modulate HFE hemochromatosis penetrance. Am J Hum Gen. 2007;81:799-807.

13. Fletcher LM, Dixon JL, Purdie DM, Powell LW, Crawford DH. Excess alcohol greatly increases the prevalence of cirrhosis in hereditary hemochromatosis. Gastroenterology. 2002;122:281-9.

14. Krijt J, Cmejla R, Sykora V, Vokurka M, Vyoral D, Necas E. Different expression patern of hepcidin genes in the liver and pancreas of C57BL/6N and DBA/2N mice. J Hepatol. 2004;40:891-896.

15. Desgrippes R, Lainé F, Morcet J, Perrin M, Manet G, Jezequel C, Bardou-Jacquet E, Ropert M, Deugnier $\mathrm{Y}$. Decreased iron burden in overweight $\mathrm{C} 282 \mathrm{Y}$ homozygous women: Putative role of increased hepcidin production. Hepatology. 2013;57(5):1784-92.

16. Moirand R, Jouanolle AM, Brissot P, Le Gall JY, David V, Deugnier Y. Phenotypic expression of HFE mutations: a French study of 1110 unrelated iron-overloaded patients and relatives. Gastroenterology. 1999; 116:372-7.

17. Kanwar P, Kowdley KW. Diagnosis and treatment of hereditary hemochromatosis: an update. Expert Review of Gastroenterology \& Hepatology. 2013;7:517-530.

18. Porto G, Brissot P, Swinkels DW, Zoller H, Kamarainen O, Patton S, Alonso I, Morris M, Keeney S. EMQN best practice guidelines for the molecular genetic diagnosis of hereditary hemochromatosis (HH). Eur J Hum Genet. 2016;24:479-495.

19. Schimanski LM, Drakesmith H, Merryweather-Clarke AT, Viprakasit V, Edwards JP, Sweetland E, Bastin JM, Cowley D, Chinthammitr Y, Robson KJ, Townsend AR. In vitro functional analysis of human ferroportin (FPN) and hemochromatosis-associated FPN mutations. Blood. 2005;105(10):4096-102.

20. Brissot P. Optimizing the diagnosis and the treatment of iron overload diseases. Expert Rev Gastroenterol Hepatol. 2016;10:359-370.

21. Drakesmith H, Schimanski LM, Ormerod E, Merryweather-Clarke AT, Viprakasit V, Edwards JP, Sweetland E, Bastin JM, Cowley D, Chinthammitr Y, Robson KJ, Townsend AR. Resistance to hepcidin is conferred by hemochromatosis-associated mutations of ferroportin. Blood. 2005;106(3):1092-7. 
22. Adams PC, Reboussin DM, Barton JC, Acton RT, Speechley M, Leiendecker-Foster C, Meenan R, Passmore L, McLaren CE, McLaren GD, Gordeuk V, Dawkins F, Eckfeldt JH. Serial serum ferritin measurements in untreated HFE C282Y homozygotes in the Hemochromatosis and Iron Overload Screening Study. Int J Lab Hematol. 2008;30:300-305.

23. Bacon BR, Adams PC, Kowdley KV, Powell LW, Tavill AS. Diagnosis and management of hemochromatosis: 2011 practice guideline by the American Association for the Study of Liver Diseases. Hepatology. 2011;54:328-43.

24. Legros L, Bardou-Jacquet $E$, Latournerie $M$, Guillygomarc'h A, Turlin B, Le Lan C, Désille $Y$, Lainé $F$, Moirand R, Brissot P, Deugnier Y, Guyader D. Non-invasive assessment of liver fibrosis in C282Y homozygous HFE hemochromatosis. Liver International. 2015;35:1731-1738.

25. Gandon Y, Olivié D, Guyader D, Aubé C, Oberti F, Sebille V, Deugnier Y. Non-invasive assessment of hepatic iron stores by MRI. Lancet. 2004;363:357-362.

26. Sarigianni M, Liakos A, Vlachaki E, Paschos P, Athanasiadou E, Montori VM, Murad MH, Tsapas A. Accuracy of magnetic resonance imaging in diagnosis of liver iron overload: A systemic review and meta-analysis. Clin Gastro Hep. Doi:10.1016/j.agh.2014.05.027.

27. Swinkels DW, Aalbers N, Elving LD, Bleijenberg G, Swanink CM, van de Meer JW. Primary hemochromatosis: a missed cause of chronic fatigue syndrome? Neth J Med. 2002;60:429-433.

28. Janssen $\mathrm{MCH}$, Swinkels DW. Hereditary haemochromatosis. Best Pract Res Clin Gastroenterol. 2009;23:171-183.

29. Barton JC, Edwards CQ, Phatak PD, Britton RS, Bacon BR. Iron toxicity. In: Barton JC, Edwards CQ, Phatak PD, Britton RS, Bacon BR. Handbook of Iron Overload Disorders. Cambridge, England: Cambridge University Press, 28-33.

30. Barton JC. Hemochromatosis and iron overload: from bench to clinic. Am J Med Sci. 2013;346:403-412.

31. Bomford A, Williams R. Long term results of venesection therapy in idiopathic haemochromatosis. QJM. 1976;45:611-623.

32. Falize L, Guillygomarc'h A, Perrin M, Lainé F, Guyader D, Brissot $P$, Turlin B, Deugnier Y. Reversibility of hepatic fibrosis in treated genetic hemochromatosis: a study of 36 cases. Hepatology. 2006;44:472477.

33. Milman N, Pederson $\mathrm{P}$, á Steig $\mathrm{T}$, Byg KE, Gradual N, Fenger K. Clinically overt hereditary hemochromatosis in Denmark 1948-1985: epidemiology, factors of significance for long-term survival, and causes of death in 179 patients. Ann Hematol. 2001;80:737-744.

34. Niederau C, Fisher R, Pursuchel A, Stremmel W, Haussinger D, Strohmayer G. Long-term survival in patients with hereditary hemochromatosis. Gastroenterology. 1996;110:1107-1119.

35. Wojcik JP, Speechley MR, Kerstesz AE, Chakrabarti S, Adams PC. Natural history of C282Y homozygotes for hemochromatosis. Can J Gastroenterol. 2002;16:297-302.

36. Burke W, Imperatore G, McDonnel SM, Baron RC, Khoury MJ. (2000) Contribution of different HFE genotypes to iron overload disease: a pooled analysis. Genet Med. 2000;2:271-7.

37. European Association for the Study of the liver. EASL clinical practice guidelines for HFE hemochromatosis. J Hepatol. 2010;53:3-22.

38. Bardou-Jacquet E, Morcet J, Manet G, Laine F, Perrin M, Jouanolle AM, Guyader D, Moirand R, Viel JF, Deugnier Y. Decreased cardiovascular and extrahepatic cancer-related mortality in treated patients with mild HFE hemochromatosis. J Hepatol. 2015;62:682-689.

39. Gurrin LC, Osborne NJ, Constantine CC, McLaren CE, English DR, Gertig DM, Delatycki MB, Southey MC, Hopper JL, Giles GG, Anderson GJ, Olynyk JK, Powell LW, Allen KJ.; Healthlron Study Investigators. The natural history of serum iron indices for HFE C282Y homozygosity associated with hereditary hemochromatosis. Gastroenterology. 2008;135:1945-1952.

40. Allen KJ, Bertalli NA, Osborne NJ, Constantine CC, Delaticky MB, Nisselle AE, Nicoll AJ, Gertig DM, Mc Laren CE, Giles CG, Hopper JL, Anderson GJ, Olynyk JK, Powell LW, Gurrin LC, for the Healthron Study Investigators. HFE C282Y homozygotes with serum ferritin concentrations below $1000 \mu \mathrm{g} / \mathrm{l}$ are at low risk of hemochromatosis. Hepatology. 2010;52(3):925-933.

41. Van Dijk BA, Laarakkers CM, Klaver SM, Jacobs EM, van Tits LJ, Janssen MC, Swinkels DW. Serum hepcidin levels are innately low in HFE- related haemochromatosis but differ between C282Yhomozygotes with elevated and normal ferritin levels. Br J Haematol. 2008;142:979-85. 
42. Girelli D, Trombini P, Bust F, Campostrini N, Sandri M, Pelucchi S, Westerman M, Ganz T, Nemeth E, Piperno A, Camaschella C. A time course of hepcidine response to iron challenge in patients with HFE and TFR2 hemochromatosis. Haematologica. 2011;94:500-506.

43. Piperno A, Girelli D, Nemeth E, Trombini P, Bozzini C, Poggiali E, Phung Y, Ganz T, Camaschella C. Blunted hepcidine response to oral iron challenge in HFE-related hemochromatosis. Blood. 2007;110:4096-100.

44. Lynch SR, Skikne BS, Cook JD. Food iron absorption in idiopathic hemochromatosis. Blood. 1988;74:2187-2193.

45. Davis WD. Jr, Arrowsmith WR. The effect of repeating bleeding in hemochromatosis. J Lab Clin Med. 1950;36:814-815.

46. Adams PC, Barton JC. How I treat hemochromatosis. Blood. 2010;116:317-325.

47. Harrison SA, Bacon BR. Hereditary hemochromatosis, update for 2003. J Hepatol. 2003;38:14-23.

48. Adams PC. Factors affecting the rate of iron mobilization during venesection therapy for genetic hemochromatosis. Am J Hematol. 1998;58:16-19.

49. McDonnel SM, Grindon AJ, Preston BL, Barton JC, Edwards CQ Adams PC. A survey of phlebotomy among persons with hemochromatosis. Transfusion. 1999;39:651-656.

50. Adams PC, Kertesz AE, Valberg LS. Rate of iron reaccumulation following iron depletion in hereditary hemochromatosis. Implications for venesection therapy. J Clin Gastroenterol. 1993;16:207-10.

51. Manet G, Bardou-Jacquet E, Perin N, Morcet J, Sinteff JP, Laine F, Moirand R, Deugnier Y. The iron reabsorption index: a new phenotypic and pathophysiological descriptor in HFE hemochromatosis. Eur J Gastroenterol Hepatol. 2013;25:1321-1329.

52. Verhaegh PLM, Moris W, Koek GH, van Deursen CThBM. The modified iron avidity index: a promising phenotypic predictor in HFE-related haemochromatosis. Liver Int. 2016 DOI:10.1111/liv.13121

53. Basset ML, Halliday JW, Ferris RA, Powell LW. Diagnosis of hemochromatosis in young subjects: predictive accuracy of biochemical screening tests. Gastroenterology. 1984;87:628-33.

54. Brissot P, Ball S, Rofail D, Cannon H, Wu Jin V. Hereditary hemochromatosis: patient experiences of the disease and phlebotomy treatment: Transfusion. 2011;51:1331-1338.

55. Hicken BL, Tucker DC, Barton JC. Patient compliance with phlebotomy therapy for iron overload associated with hemochromatosis. Am J Gastroenterol. 2003;98(9):2072-7.

56. Conte D, Brunelli L, Bozzani A, et al. Erythrocytapheresis in idiopathic haemochromatosis. Br Med J. (Clin Res Ed) 1983;286:939.

57. Zoller WG, Kellner H, Spengel FA. Erythrocytapheresis. A method for rapid extracorporeal elimination of erythrocytes. Results in 65 patients. Klin Wochenschr. 1988;66:404-9.

58. Conte D, Mandelli C, Cesana M, et al. Effectiveness of erythrocytapheresis in idiopathic hemochromatosis. Report of 14 cases. Int J Artif Organs. 1989;12:59-62.

59. Kellner H, Zoller WG. Repeated isovolemic large-volume erythrocytapheresis in the treatment of idiopathic hemochromatosis. Z Gastroenterol. 1992;30:779-83.

60. Kohan A, Niborski R, Daruich J, et al. Erythrocytapheresis with recombinant human erythropoietin in hereditary hemochromatosis therapy: a new alternative. Vox Sang. 2000;79:40-5.

61. Muncunill J, Vaquer P, Galmes A, et al. In hereditary hemochromatosis, red cell apheresis removes excess iron twice as fast as manual whole blood phlebotomy. J Clin Apher. 2002;17:88-92.

62. Mariani R, Pelucchi S, Perseghin P, et al. Erythrocytapheresis plus erythropoietin: an alternative therapy for selected patients with hemochromatosis and severe organ damage. Haematologica. 2005;90:717-8.

63. Fernandez-Mosteirin N, Salvador-Osuna C, Garcia-Erce JA, et al. Comparison between phlebotomy and erythrocytapheresis of iron overload in patients with HFE gene mutations. Med Clin. (Barc) 2006; 127:409-12.

64. Wijermans $\mathrm{P}$, van Egmond L, Ypma $\mathrm{P}$, et al. Isovolemic erythrocytapheresis technique as an alternative to conventional phlebotomy in patients with polycythemia rubra vera and hemochromatosis. Transfus Apher Sci. 2009; 40:137.

65. Poullin P, Lefevre PA. Effectiveness of therapeutic erythrocytapheresis to achieve iron depletion in hereditary type 1 hemochromatosis: Report of 30 cases. Transfusion Clinique et Biologique. 2011;18: 553-8.

66. Řeháček V, Bláha $M$, Jirušová $H$, Černohorská J, Papoušek P. Therapeutic erythrocytapheresis in the initial treatment of hereditary hemochromatosis. Acta Medica. 2012;55(4):180-185. 
67. Evers D, Kerkhoffs JL, Van Egmond L, Schipperus MR, Wijermans PW. The efficiency of therapeutic erythrocytapheresis compared to phlebotomy: A mathematical tool for predicting respons in hereditary hemochromatosis, polycythemia vera, and secondary erythrocytosis. J Clin Apher. 2014;29:133-138.

68. Sundic T, Hervig T, Hannisdal S, et al. Erythrocytapheresis compared with whole blood phlebotomy for the treatment of hereditary hemochromatosis. Blood Transfus. 2014;12 Suppl 1:s.84-9.

69. Stefashyna O, Stern M, Infanti L, Holbro A, Tichelli A, Buser A, O’Meara A. Pattern of care of blood donors with early-uncomplicated hereditary haemochromatosis in a Swiss blood donation centre. Vox Sanguinis. 2014;106:111-117. 


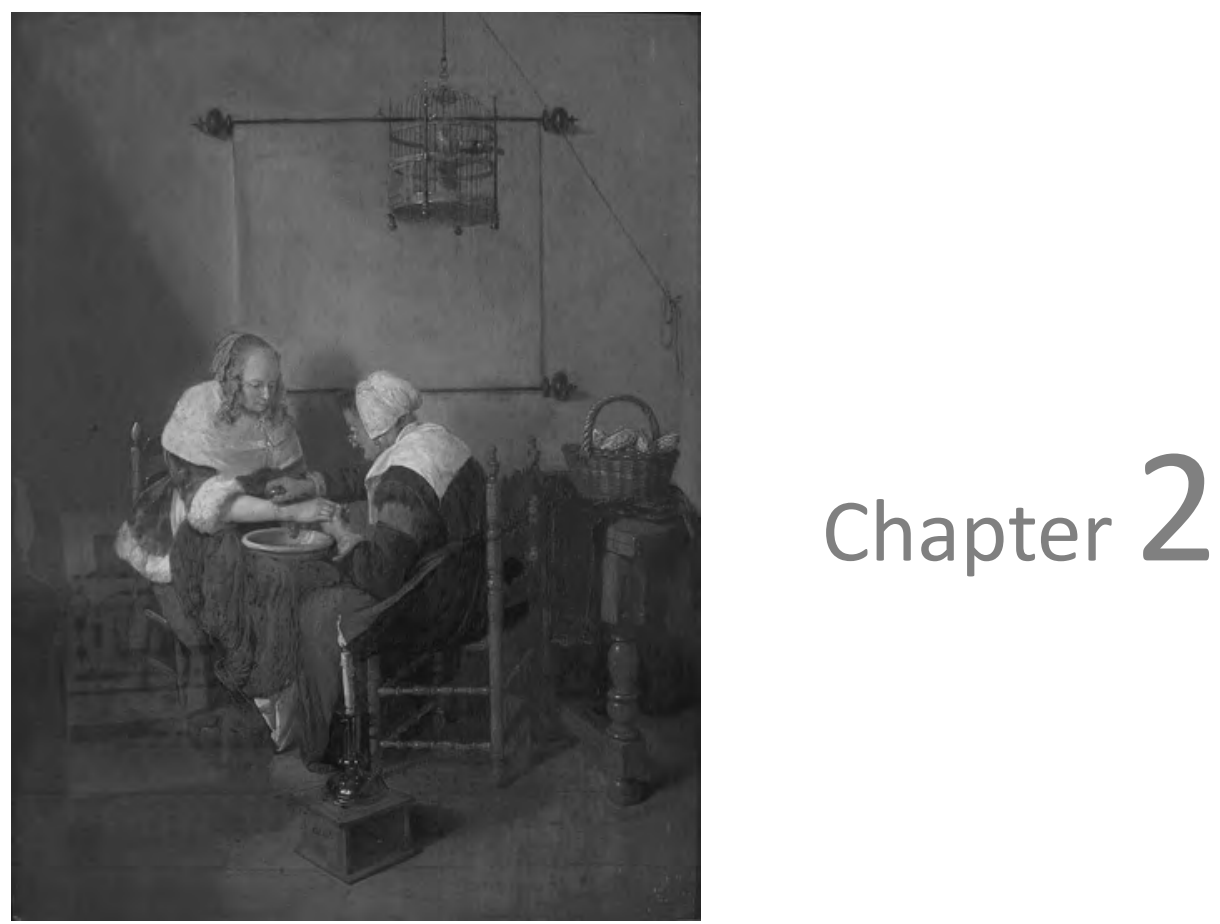

Therapeutic erythrocytapheresis versus phlebotomy in the initial treatment of hereditary hemochromatosis - a pilot study

Eva Rombout-Sestrienkova, Paulus AH van Noord, Cees ThBM van Deursen, Bob JPH Sybesma, Ans EL Nillesen-Meertens, Ger H Koek 


\section{Abstract}

Hereditary Hemochromatosis $(\mathrm{HH})$ is a genetic disorder of iron metabolism, resulting in excessive iron overload. Currently, phlebotomy is the standard effective treatment that prevents progression of tissue damage. Aim of the therapy is to reach ferritin levels between 20-50 $\mu \mathrm{g} / \mathrm{l}$. In patients with total iron stores of more than $30 \mathrm{~g}$, intensive treatment by means of even weekly phlebotomies during 2-3 years is required to reach this aim.

More recently mechanical removal of erythrocytes through therapeutic erythrocytapheresis (TE) has become a new therapeutic modality. By means of TE, up to $1000 \mathrm{ml}$ erythrocytes per session can be removed, depending on patient characteristics, compared to $250 \mathrm{ml}$ erythrocytes per phlebotomy. Thus, TE potentially offers a more efficient method of removing iron overload with less procedures in a shorter treatment period.

In a pilot study between 2002 and 2005, results from a group of $\mathrm{HH}$ patients treated with TE $(\mathrm{N}=6)$ were compared to the results of a historical control group of $\mathrm{HH}$ patients $(\mathrm{N}=6)$ treated with phlebotomy. The results showed a reduction of almost $70 \%$ in both the total number and the duration of treatments in the TE group. Although, the procedure costs compared on the basis of a single TE session were higher, the total costs for the whole treatment were comparable or cheaper with the use of TE. Future prospective studies are needed to compare both therapies in a randomized setting. 


\section{Introduction}

$\mathrm{HH}$ is a common genetic disorder in which the iron absorption is increased from the normal $1-2 \mathrm{mg} /$ day to $4 \mathrm{mg} /$ day. After many years this increase can lead to deposition of excessive amounts of iron in parenchymal cells, resulting in impaired organ function, especially with regard to the liver, pancreas, heart, joints and pituitary gland.

The gene involved in the most common form of $\mathrm{HH}$ was discovered in 1996 and is called the HFE gene. ${ }^{1}$ The most common mutations responsible for clinical manifestation of the disease are a substitution of cysteine with tyrosine at position 282 (C282Y), or a substitution of histidine with aspartic acid at position 63 (H63D). ${ }^{1-3}$ The prevalence of homozygotes varies globally between $0.25 \%$ and $0.50 \%$. The prevalence of heterozygotes varies between $10 \%$ and $15 \%$ of the population. In $1-20 \%$ of the homozygote carriers, clinical manifestations of $\mathrm{HH}$ develop during their lifetime. The prevalence among the heterozygote carriers is much lower, as only $0.13 \%$ develops clinical manifestations. ${ }^{4-6}$

Clinical manifestations are diverse and not always specific for $\mathrm{HH}$. The most common initial symptoms are asthenia (46\%), arthralgia (44\%) and aminotransferase increase $(45 \%){ }^{7}$ In an advanced stage of the disease, the clinical manifestations include various degrees of hepatomegaly (95\%), cirrhosis, hepato-cellular carcinoma, congestive heart failure (15\%), diabetes mellitus (30-65\%), destructive arthropathy (25-50\%), hypogonadotrophic hypogonadism, impotence, arrhythmias and excessive skin pigmentation. $^{8}$

One of the earliest manifestations of disturbed iron metabolism is an increase in the plasma iron concentration with a concomitant increase in the transferrin saturation (TS).

\section{Treatment}

Once $\mathrm{HH}$ is diagnosed, the therapy is simple, straightforward and effective since it is based on the removal of the excess of body iron by removing blood. The effect of the therapy is monitored by the iron saturation and ferritin levels. Initial therapy starts by trying to normalize the serum ferritin concentration to $\leq 50 \mu \mathrm{g} / \mathrm{l}$ and/or the transferrin saturation to $50 \%$ or less. After achieving these target levels, the initial treatment is followed by a lifetime maintenance treatment in order to preserve these target levels of the iron concentration, as mentioned above. ${ }^{9}$

Up to now the standard treatment to achieve this result is phlebotomy, which is a simple and effective, but time-consuming, therapy. The frequency of phlebotomy, which can be performed up to once or twice a week, is determined by the hematocrit, the hemoglobin concentration, the degree of iron overload, the presence of organ dysfunction, and the limitations imposed by other conditions such as coronary heart disease. ${ }^{10}$ In severe cases (ferritin higher than $1000 \mu \mathrm{g} / \mathrm{l}$ ) the patient starts blood letting treatments once or twice a week, whereby usually $500 \mathrm{ml}$ of whole blood is 
removed. This equals approximately $250 \mathrm{mg}$ of iron. Weekly phlebotomies for a period of 1-2 years (a total of 50-100 phlebotomies) may be required. After the serum ferritin concentration and transferrin saturation are normalized, the maintenance therapy is continued with phlebotomies every 2-6 months during the remaining lifetime of the patient. Despite all safety criteria, many adverse events occur during this treatment such a vasovagal reactions, hematomas, fatigue and injuries of the vascular wall. After a whole blood donation of $500 \mathrm{ml}$, one-third of healthy blood donors develop one or more adverse events, such as bruises (23\%), sore arm (10\%), fatigue (8\%) and vasovagal reactions (7\%). ${ }^{11}$ When presented for treatment with phlebotomy, $\mathrm{HH}$ patients often already have concomitant diseases that would put them at a greater risk of complications while undergoing blood letting compared to regular blood donors. Up to today there are at least two published cases of fatal complications after phlebotomy treatment in $\mathrm{HH}$ patients. ${ }^{12,13}$

Phlebotomy cannot be used in patients with severe cardiac disease, anemia, or hypoproteinemia. For these patients, chelation therapy provides the only means of effectively removing iron. At this moment the only commercially available iron chelator is deferoxamine. However, this therapy is known for its potentially even more serious local and systemic side-effects. ${ }^{10}$

In the last 15 years, automated therapeutic erythrocytapheresis (TE) became available, which seems to offer a good alternative for $\mathrm{HH}$ treatment. ${ }^{14-24}$ During a single TE procedure up to $1000 \mathrm{ml}$ of red blood cells can be removed, equaling $800 \mathrm{mg}$ of iron, depending on the estimated circulating blood volume. Thus, almost up to four times more iron can be removed per treatment, compared to conventional treatment with phlebotomy. A TE procedure preserves the valuable blood components of the patient, such as plasma proteins, platelets, clotting factors and leucocytes, which make this approach also viable option for patients with hypoproteinemia or thrombocytopenia. During a TE procedure the patient receives compensation for the removed volume by saline or protein solutions, which makes this approach particularly viable for $\mathrm{HH}$ patients with severe cardiac disease.

If the blood volume is assumed to be $70 \mathrm{ml} / \mathrm{kg}$, the following formula is used to estimate the volume of red cells to be removed in apheresis procedure (VR). ${ }^{25}$

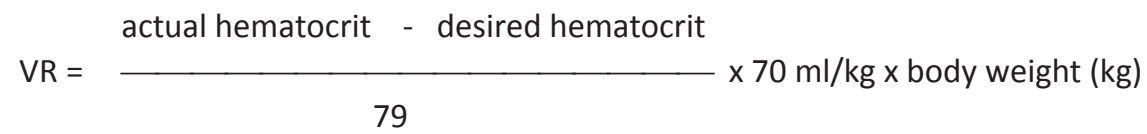

To investigate the benefits of TE in comparison to phlebotomy, a pilot study was performed among newly diagnosed patients with $\mathrm{C} 282 \mathrm{Y}$ homozogote $\mathrm{HH}$. 


\section{The Pilot study}

\section{Subjects and methods}

Between January 2002 en October 2005 six subsequent HH patients, homozygote for $\mathrm{C} 282 \mathrm{Y}$, who were referred to our blood bank, were treated with automated TE. The inclusion criteria were: age $18-80$, transferrin saturation $>50 \%$, serum ferritin $>700 \mu \mathrm{g} / \mathrm{I}$ and hemoglobin concentration $\geq 120 \mathrm{~g} / \mathrm{l}$ for female and $\geq 128 \mathrm{~g} / \mathrm{l}$ for male or a hematocrit of $\geq 34 \%$.

The group consisted of four men and two women between the age of 39 and 77 years (Table 2.1). For all six patients TE was their first therapy. All six patients suffered from increased aminotransferase, arthralgia and fatigue. Patient No. 6 suffered from heart failure and patient No. 2 suffered from liver cirrhosis. None of the patients suffered from diabetes mellitus or skin pigmentation.

Table 2.1 Characteristics of both groups.

\begin{tabular}{lcccc}
\hline Therapy & Patient No & Sex & $\begin{array}{c}\text { Age } \\
(\text { Year })\end{array}$ & $\begin{array}{c}\text { Ferritin initial } \\
(\mu \mathrm{g} / \mathrm{l})\end{array}$ \\
\hline TE & 1 & $\mathrm{M}$ & 58 & 1951 \\
TE & 2 & $\mathrm{~F}$ & 56 & 2541 \\
TE & 3 & $\mathrm{~F}$ & 63 & 908 \\
TE & 4 & $\mathrm{M}$ & 52 & 798 \\
TE & 5 & $\mathrm{M}$ & 39 & 1480 \\
TE & 6 & $\mathrm{M}$ & 77 & 1419 \\
& & & & 541 \\
Mean & & & 58 & 3743 \\
& & & & 703 \\
phlebotomy & 7 & $\mathrm{M}$ & 49 & 2121 \\
phlebotomy & 8 & $\mathrm{~F}$ & 58 & 378 \\
phlebotomy & 9 & $\mathrm{~F}$ & 60 & 592 \\
phlebotomy & 10 & $\mathrm{~F}$ & 44 & 1346 \\
phlebotomy & 11 & $\mathrm{M}$ & 51 & 0,91 \\
phlebotomy & 12 & & 53 & \\
& & & 0,46 & \\
Mean & & & 57 & \\
P value & & & & \\
\hline
\end{tabular}

All procedures were performed in donor centers of Sanquin Blood Banks by apheresis research nurses using $\mathrm{MCS}^{+}$equipment (Haemonetics Corporation, Braintree, Massachusetts, USA). Before each procedure a physical examination was performed by one of the blood bank physicians. Blood was collected in ACD-A solution at a ratio of $12: 1$ by puncturing an antecubital vein. About 1/3-1/2 of the estimated removed erythrocyte volume was replaced with $0,9 \mathrm{~g} / \mathrm{dl} \mathrm{NaCl}$. The mean initial hematocrit before each procedure was $42 \%$ (34-45\%). Minimal hematocrit of $34 \%$ was required to start TE. The minimal targeted post procedure hematocrit was $30 \%$. The mean 
hematocrit after TE was 32\%. Only one female patient (No. 2) was treated until a hematocrit of $26 \%$ was reached without adverse events. Red cell indices and serum ferritin were measured immediately before and after each TE. The initial treatment was finished when ferritin levels had returned to normal (50-100 $\mu \mathrm{g} / \mathrm{l})$. The removed volume of erythrocytes per treatment was individually determined and based on the total estimated blood volume of each patient and the hemoglobin level. The treatment interval between two procedures was determined in the same way. In practice the mean value of removed erythrocytes in each procedure varied between 450-724 ml per individual patient, which was equal to 360-579 g of removed iron (the hematocrit of removed erythrocytes was $0,80 \%$ ). Most of the patients best tolerated an interval period of fourteen days (Table 2.2).

Table 2.2 Characteristics of treatments in both groups.

\begin{tabular}{|c|c|c|c|c|c|}
\hline $\begin{array}{l}\text { Patient } \\
\text { No. }\end{array}$ & $\begin{array}{l}\text { Ferritin } \\
\text { Final } \\
(\mu \mathrm{g} / \mathrm{l})\end{array}$ & $\begin{array}{c}\text { No } \\
\text { procedures }\end{array}$ & $\begin{array}{l}\text { Treatment } \\
\text { duration } \\
\text { (months) }\end{array}$ & $\begin{array}{l}\text { Estimated removal of } \\
\text { iron per procedure } \\
(\mathrm{mg})\end{array}$ & $\begin{array}{c}\text { Estimated total } \\
\text { removal of iron } \\
(\mathrm{mg})\end{array}$ \\
\hline \multicolumn{6}{|c|}{ Therapeutic erythrocytapheresis (TE) group } \\
\hline 1 & 71 & 16 & 9 & 498 & 7974 \\
\hline 2 & 47 & 18 & 6 & 360 & 6480 \\
\hline 3 & 45 & 8 & 4 & 413 & 3303 \\
\hline 4 & 32 & 5 & 2,7 & 579 & 2896 \\
\hline 5 & 90 & 6 & 2 & 493 & 2957 \\
\hline 6 & 39 & 6 & 5,3 & 448 & 2688 \\
\hline Mean & 54 & 9,8 & 4,8 & 465,2 & 4383 \\
\hline \multicolumn{6}{|c|}{ Phlebotomy group } \\
\hline 7 & 52 & 40 & 10 & 230 & 9200 \\
\hline 8 & 66 & 22 & 11 & 205 & 4510 \\
\hline 9 & 29 & 26 & 13 & 205 & 5330 \\
\hline 10 & 26 & 27 & 13 & 230 & 6210 \\
\hline 11 & 32 & 48 & 24 & 205 & 9840 \\
\hline 12 & 57 & 29 & 22 & 230 & 6670 \\
\hline Mean & 43,7 & 32 & 15,5 & 217,5 & 6960 \\
\hline$P$ value & 0,38 & 0,001 & 0,005 & 0,16 & 0,07 \\
\hline
\end{tabular}

The results of this group were compared to the results of a historical control group of six $\mathrm{HH}$ patients, which were also homozygote for $\mathrm{C} 282 \mathrm{Y}$, and had been treated with standard phlebotomy in the regional hospital between 1998 en 2001. The demographics of the phlebotomy group were comparable to those of the TE group (Table 2.1). The phlebotomy group consisted of three men and three women between the age of 44 and 60 years. All patients also suffered from increased aminotransferase, arthralgia and fatigue. None had symptoms of heart failure or diabetes mellitus. The initial values of ferritin varied between $378-3743 \mu \mathrm{g} / \mathrm{l}$, with a mean value of $1346 \mu \mathrm{g} / \mathrm{l}$. The phlebotomies were performed once every one to three weeks by hospital nurses in the short stay unit of the hospital. In each procedure $500 \mathrm{ml}$ of whole blood was 
taken. To estimate the absolute amounts of iron removed in this group we applied the following formula: Phlebotomy males: $500 \mathrm{ml} \times 0,46$ (Ht range 0.41-0.51) x number of procedures; Phlebotomy females: $500 \mathrm{ml} \times 0.41$ (Ht range 0.36-0.47) $\times$ number of procedures.

\section{Results}

\section{TE group}

At the end of the initial treatment in the TE group the serum ferritin levels varied between 32 en $90 \mu \mathrm{g} / \mathrm{l}$, with a mean value of $54 \mu \mathrm{g} / \mathrm{l}$ (Table 2.2).

The total number of treatments needed in the TE group varied between 5 and 18 with a mean value of 9.8. The mean value of total treatment duration was 4.8 months, ranging between 2 and 9 months. The estimated mean values of removed total iron per patient varied between 2688 and $7974 \mathrm{mg}$, with a mean value of $4383 \mathrm{mg}$ (Figure 2.2).

\section{Phlebotomy group}

At the end of the initial treatment in the phlebotomy group (Table 2.2) the serum ferritin levels varied between 26 and $66 \mu \mathrm{g} / \mathrm{l}$, with a mean value of $43,7 \mu \mathrm{g} / \mathrm{l}$. The total number of treatments varied between 22 and 48 , with a mean value of 32 . The total duration of initial treatment varied between 10 en 24 months with a mean value of 15,5 months. The estimated mean values of the total amount of removed iron per patient varied between 4510 and $9840 \mathrm{mg}$, with a mean value of $6960 \mathrm{mg}$ (Figure 2.2).

\section{Comparison between Phlebotomy and TE groups}

Patient groups, summarised in Table 2.1, were comparable in regards to age, clinical presentation and laboratory values. The treatment groups largely differed in the number of treatments and duration of therapy. The reduction in the total number of treatments in the TE group was $69,4 \%$, with a reduction in treatment duration of $69 \%$ (Table 2.2, Figure 2.1).

\section{Adverse events}

As to the assessment of adverse events a strict protocol was followed during the TE procedures. All recorded adverse events in the TE group were light to very mild. In a total of 59 procedures, eight $(13,6 \%)$ very mild cases of citrate reaction and three $(5,1 \%)$ mild cases of dizziness were seen. Given that the phlebotomy group was a historical control group, adverse events had not been documented and unfortunately could not be traced retrospectively, and were thus unavailable for comparison. 


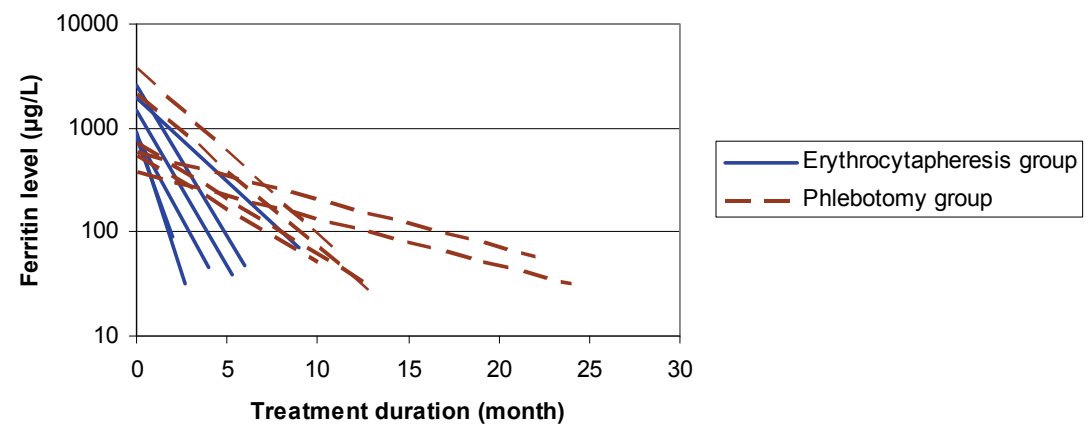

Figure 2.1 Treatment duration and decrease of ferritin level in both groups.

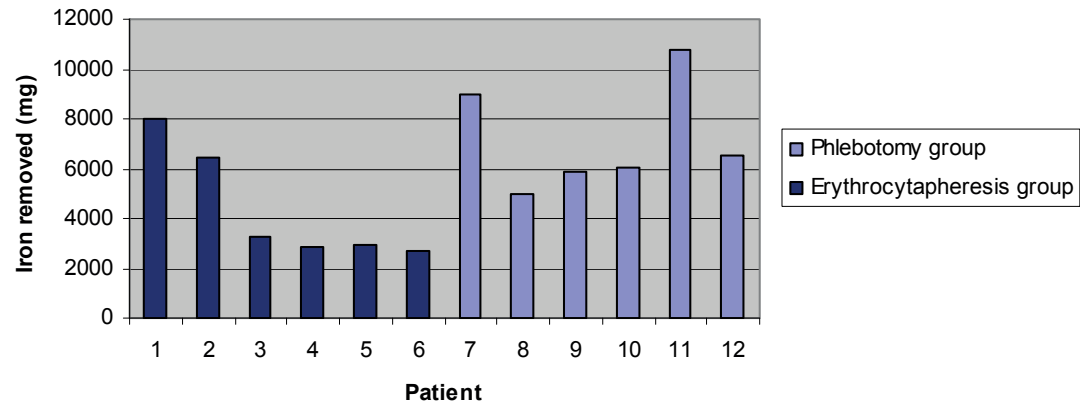

Figure 2.2 Iron removed per patient.

\section{Costs based on Dutch healthcare reimbursement rates}

In scattered publications that included some cost aspects, it is concluded that TE is probably much more expensive than phlebotomy treatment, ${ }^{15,17,18}$ which may be true when compared per single procedure. A more valid comparison, however, should be based on the total number of treatments required to reach normal ferritin levels.

As a first attempt to estimate reductions in costs, we compared the costs of this type of therapy as performed in the Sanquin Blood Banks.

Based on costs as determined by the Sanquin Blood Banks, the reimbursement price charged by Sanquin for TE is $€ 600$, which is about three times the price for phlebotomy, which is $€ 200$. Although, the cost of a single TE procedure was higher, the total cost of the treatment turn out to be the same or even lower when applying TE. For example the total price charged by a mean number of ten procedures in the TE group is $€ 6000$ and the total price charged by a mean number of 32 procedures by the phlebotomy group is $€ 6400$. The additional socio-economic costs related to the 
greater number of phlebotomies are not taken into account, due to the availability of a little information.

\section{Discussion}

The results of this pilot study indicate that TE compared to phlebotomy in the initial therapy of $\mathrm{HH}$ patients was both safe and highly efficient. Both the number of procedures as well as the duration of the therapy was reduced by $70 \%$ through TE in order to reach comparable ferritin levels between $26-90 \mu \mathrm{g} / \mathrm{l}$.

Few investigators studied the efficacy and safety of TE procedures, but had not compared the TE therapy to phlebotomy.

No adverse side effects were observed in a study among 65 patients treated with TE. ${ }^{21}$ Several studies limited to TE have also concluded that TE is an effective and safe method in obtaining iron depletion in $\mathrm{HH}$ patients. ${ }^{18,19,23,24}$ In combination with recombinant human erythropoietin TE offers better results, even in complicated patients. $^{14,17}$

Some additional advantages of TE in comparison to phlebotomies should be mentioned. TE offers the possibility to compensate for loss of circulating volume during a procedure. An isovolemic method of therapy is therefore potentially safer than phlebotomy with its related induced hypovolemia, especially with respect to older and/or cardiovascular unstable patients.

The fine-tuning in TE by modulating cycle duration and target hematocrit, allows continuation of scheduled treatment sessions, whereas this is not possible in phlebotomies where started procedures can only be aborted or rescheduled. In this way TE also allows better monitoring of anemias and adjustments per procedure, another feature not available in phlebotomy.

TE also preserves the valuable blood components of the patient, such as plasma proteins, platelets, clotting factors and leucocytes, potentially relevant to patients with hypoproteinemia and/or thrombocytopenia.

The TE patients also spontaneously expressed their content with regard to the reduced number of procedures. This can be an important issue, because only one-third of $\mathrm{HH}$ patients tolerate and adhere to weekly phlebotomy. Furthermore, there is a constant rate of decline in the percentage of patients which comply with maintenance therapy. ${ }^{26}$

An additional advantage is that TE can be performed with a needle which is one to two gauges smaller than the needles used in blood letting. This can lead to decreased incidence of hematomas, arterial puncture or nerve injury in automated collection. ${ }^{27}$ In order to appreciate these results in a better way, some limitations of this study should be mentioned. A historical comparison of two small groups has limitations as to the conclusions that could be made. The two groups, however, seemed comparable at baseline (Table 2.1). We therefore consider that a general conclusion about safety and 
efficiency of TE holds. The large efficiency gain with TE in the order of a factor 3 is not only statistically significant but is also clinically relevant.

\section{Conclusions}

TE seems a more effective method of removing iron excess when compared to phlebotomies in newly diagnosed $\mathrm{HH}$ patients. The total number of required TE procedures per whole treatment had significantly decreased and the treatment duration itself was distinctly shorter (both almost 70\%) when compared to phlebotomies. Furthermore, TE appears to be a better tolerated type of treatment applicable to a wider range of patients, including more complicated and older patients. Considering the whole treatment, TE seems to be at least as safe as and probably safer than phlebotomies. In The Netherlands TE can be a cost effective initial treatment for HH patients.

Future studies, preferably of a randomized type, are needed to evaluate the differences in the two therapeutic modalities in more detail. 


\section{References}

1. Feder JN, Gnirke A, Thomas W, Tsuchihashi Z, Ruddy DA, Basava A, et al. A novel MHC class I-like gene is mutated in patients with hereditary haemochromatosis. Nat Genet 1996;13:399-408.

2. Risch N. Haemochromatosis, HFE and genetic complexity (letter). Nat Genet 1997;17:375-6.

3. Burke W, Imperatore G, McDonnel SM, Baron RC, Khoury MJ. Contribution of different HFE genotypes to iron overload disease: a pooled analysis. Gen Med 2000;2:271-7.

4. Powell LW, Subramaniam VN, Yapp TR. Haemochromatosis in the new millennium. J Hepatol 2000;32:48-62.

5. Beutler E, Felitti VJ, Koziol JA, Ho NJ, Gelbart T. Penetrance of 845G> A (C282Y) HFE hereditary haemochromatosis mutation in the USA. Lancet 2002;359:211-8.

6. Asberg A, Hveem K, Thorstensen K, Ellekjter E, Kannelonning K, Fjosne U, et al. Screening for hemochromatosis: high prevalence and low morbidity in an unselected population of 65,238 persons. Scand J Gastroenterol 2001;36:1108-15.

7. Marx JJM. Prevention in organ failure in hereditary haemochromatosis. The Netherlands $\mathrm{J}$ of Medicine 2002;60;11: 419-22.

8. Powel LW. Hereditary hemochromatosis and iron overload diseases. J of Gastroenterol and Hepatol 2002;17: S191-5.

9. Barton JC, McDonnell SM, Adams PC, Brissot P, Powell LW et al. Management of hemochromatosis. Hemochromatosis management working group. Ann Intern Med 1998;129:932-9.

10. Kirking H. Treatment of chronic iron overload. Clinical pharmacy 1991;10:775-83.

11. Newman BH. Blood donor complications after whole-blood donation. Curr Opin Hematol 2004;11: 339-45.

12. Jaquet Ph, Codaccioni JL, Fabre M, Marquier A. Accident mortel apres deux saignees au cours du traitement d' une hemochromatose. Diabete 1967;15:70-2.

13. Hofstetter JR. Dangers du traitement de I'hemochromatose par saignees. Gastro-enterologia 1957;87:186-90.

14. Kohan A, Niborski R, Daruich J, Rey J, Bastos F, Amerise G et al. TE with recombinant human erythropoietin in hereditary hemochromatosis therapy: a new alternative. Vox Sang 2000;79:40-5.

15. Valbonesi M, Bruni R. Clinical aplication of therapeutic TE (TEA). Transfusion Science 2000;22:184-94.

16. Waalen J, Beutler E. Hereditary hemochromatosis:screening and management. Current Hematol Reports 2006;5:34-40.

17. Mariani R, Pellucchi S, Perseghin P, Corenghia Ch, Piperno A. TE plus erythropoetin: an alternative therapy for selected patients with hemochromatosis and severe organ damage. Haematologica 2005;90:717-18.

18. Kellner H, Zoller WG. Repeated isovolemic large-volume TE in the treatment of idiopathic hemochromatosis. Z.Gastroenterol 1992;30:779-83.

19. Conte D, Mandelli C, Cesana M, Ferrini R, Marconi M, Bianchi A. Effectiveness of TE in idiopathic hemochromatosis. Report of 14 cases. Int J Artif Organs 1989;12:59-62.

20. Grima KM. Therapeutic apheresis in hematological and oncological diseases. J of Clinical Apheresis 2000;15:28-52.

21. Zoller W, Kellner H, Spengel FA. TE: A method for rapid extracorporeal elimination of erythrocytes. Results in 65 patients. Klin Wochenschr 1988;88:404-9.

22. Rombout E, van Deursen C, Nillessen A, van Noord P.A.H. Therapeutic erythrocytapheresis versus phlebotomy in hereditary hemochromatosis therapy: An ongoing study in a donor center. Transfusion and Apheresis Science 2005;33:213.

23. Cesana M, Mandelli C, Tiribelli C, Bianchi PA, Conte D. Concominant primary hemochromatosis and beta-thalassemia trait: iron depletion by erythrocytaphereis and desferrioxamine. Am J Gastroenterol 1989;84:150-2.

24. Fraquelli M, Mandelli C, Cesarini L, Barisani D, Bianchi PA, Conte D. Survival and development of neoplasms in 56 patients with idiopathic hemochromatosis. Ann Ital Med Int 1992;7:26-9.

25. Brittenham GM. Disorders of iron metabolism: Iron deficiency and overload. In: Hoffman R, Benz EJ, Shattil SJ, et al. Hematology, basis principles and practice. New York: Churchill Livingstone; 1995: 492-523. 
26. Hicken BL, Tucker DC, Barton JC. Patient compliance with phlebotomy therapy for iron overload associated with hemochromatosis. Am J Gastroenterol 2003;98:2072-7.

27. Popovsky MA. Safety of RBC apheresis and whole blood donation in allogeneic and autologous blood donors. Transfusion and Apheresis Science 2006;34:205-11. 


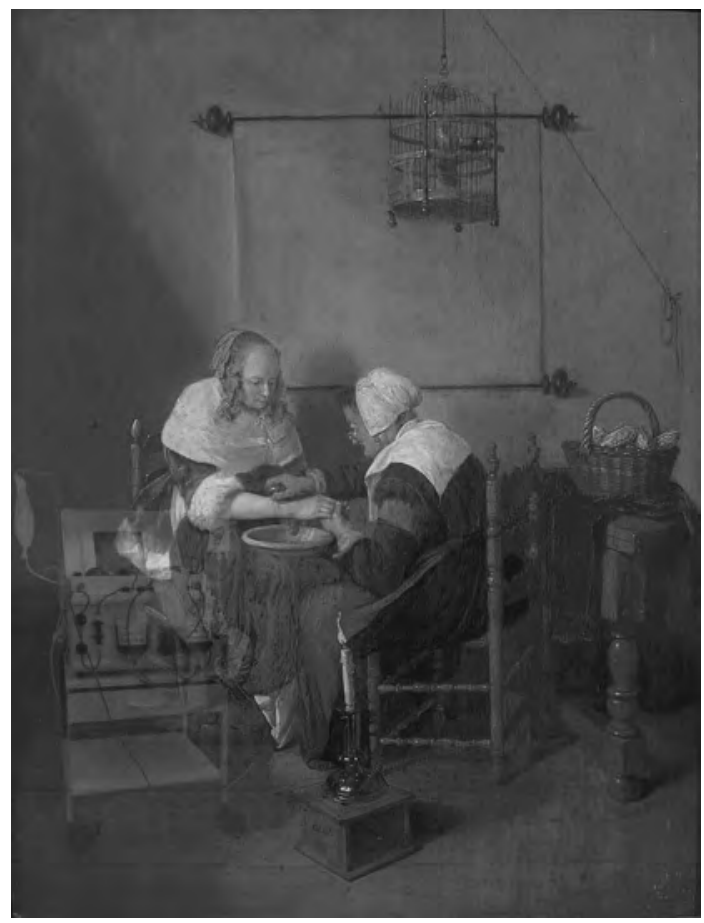

\section{Chapter 3}

\section{Erythrocytapheresis versus phlebotomy in the initial treatment of HFE hemochromatosis patients: results from a randomized trial}

Eva Rombout-Sestrienkova, Fred HM Nieman, Brigitte AB Essers, Paulus AH van Noord, Mirian $\mathrm{CH}$ Janssen, Cees ThBM van Deursen, Laurens $\mathrm{P}$ Bos, Ferdinand Rombout, Rogier van den Braak, Peter W de Leeuw, Ger H Koek 


\section{Abstract}

\section{Background}

Standard treatment of newly diagnosed HFE hemochromatosis patients is phlebotomy. Erythrocytapheresis provides a new therapeutic modality that can remove up to three times more red blood cells per single procedure and could thus have a clinical and economic benefit.

\section{Study design and methods}

To compare the number of treatment procedures between erythrocytapheresis and phlebotomy needed to reach the serum ferritin (SF) target level of $50 \mu \mathrm{g} / \mathrm{l}$, a two-treatment arms, randomized trial was conducted in which 38 newly diagnosed patients homozygous for C282Y were randomly assigned in a 1:1 ratio to undergo either erythrocytapheresis or phlebotomy. A $50 \%$ decrease in the number of treatment procedures for erythrocytapheresis compared to phlebotomy was chosen as the relevant difference to detect.

\section{Results}

Univariate analysis showed a significantly lower mean number of treatment procedures in the erythrocytapheresis group (9 vs. 27 , ratio: $0.33,95 \%$ confidence interval $[\mathrm{CI}]$ 0.25-0.45, MannWhitney $\mathrm{p}<0.001)$. After adjustments for the two important influential factors initial SF level and body weight, the reduction ratio was still significant $(0.43,95 \% \mathrm{Cl}, 0.35-0.52, p<0.001)$. Cost analysis showed no significant difference in treatment costs between both groups. The costs resulting from productivity loss were significantly lower for the erythrocytapheresis group.

\section{Conclusion}

Erythrocytapheresis is highly effective treatment to reduce iron overload and from a societal perspective might potentially also be a cost saving therapy. 


\section{Introduction}

Standard treatment for HFE hemochromatosis (HFE-HC) is removal of an excess in body iron by phlebotomy. Serum ferritin (SF) level is used as a marker for the amount of iron overload and to monitor the effectiveness of phlebotomy. The advised target SF level is $50 \mu \mathrm{g} / \mathrm{I}^{1-4}$ or less. Phlebotomy is inexpensive and easy to perform but in patients with high initial SF concentrations up to 100 procedures are required., ${ }^{5,6}$ In a large survey in hemochromatosis patients, $15 \%$ of patients treated with phlebotomy expressed a negative opinion about this therapy. The primary negative aspects were venous access problems, traveling time, waiting time and duration of the procedure. ${ }^{7,8}$ In an online survey performed in the United States, France, Ireland and the United Kingdom, $16 \%$ of the patients would definitely decide not to receive phlebotomy, if alternative options were available and $52 \%$ of induction treatment patients experienced side effects always or most of the time after phlebotomy. ${ }^{9}$

The past 15 years erythrocytapheresis has also been used as a therapeutic modality and has been evaluated in non-randomized studies. ${ }^{10-20}$ With erythrocytapheresis up to $800 \mathrm{ml}$ red blood cells (RBCs) per single procedure can be removed compared to 200-250 ml of RBCs per phlebotomy, which means that erythrocytapheresis potentially offers a more efficient method to remove iron overload with fewer procedures in less time. Up to now, however, no randomized trials have been performed to evaluate the effectiveness of erythrocytapheresis compared to phlebotomy. Therefore, the aim of this study was to compare in a randomized, prospective way erythrocytapheresis with the standard of care phlebotomy and to test the hypothesis that erythrocytapheresis significantly reduces the number of treatment procedures.

\section{Materials and methods}

\section{Study design}

We conducted a two-treatment- arms, randomized, clinical trial, involving 38 newly diagnosed patients with HFE-HC, homozygous for C282Y. Participants were randomly assigned in a 1: 1 ratio to erythrocytapheresis or phlebotomy treatment. The primary outcome measure was the number of treatment procedures to reach the SF target level of $50 \mu \mathrm{g} / \mathrm{l}$ or less. Secondary outcomes were the total duration of treatment, the occurrence of side effects, change in iron status and liver function, health related quality of life and costs. A $50 \%$ decrease in the number of treatment procedures for erythrocytapheresis compared to phlebotomy was chosen as the relevant difference to detect. The ethics committee of each participating hospital approved of the study. 


\section{Participants}

Between December 2005 and November 2008 all newly diagnosed HFE-HC patients were referred from four hospitals in the region of Sanquin Blood Bank South East Division (The Netherlands). Inclusion criteria were as follows: Homozygous for C282Y mutation, age between $18-80$ years, weight $50 \mathrm{~kg}$ or more, transferrin saturation greater than $50 \%$, SF greater than $450 \mu \mathrm{g} / \mathrm{l}$ and hemoglobin $(\mathrm{Hb})$ concentration $7.5 \mathrm{mmol} / \mathrm{l}$ or more $(120 \mathrm{~g} / \mathrm{l})$ in women and $8.0 \mathrm{mmol} / \mathrm{l}$ or more $(128 \mathrm{~g} / \mathrm{l})$ in men. Exclusion criteria were as follows: malignancy, serious cardiac arrhythmias, heart failure and epilepsy.

All participants gave written informed consent and were randomized to erythrocytapheresis or phlebotomy treatment by an independent person working as quality assurance manager at Julius Center for Health Sciences and Primary Care, University Medical Center Utrecht. He was contacted by phone upon enrollment of each new patient.

\section{Treatment procedures}

\section{Phlebotomy}

Per single treatment procedure $500 \mathrm{ml}$ whole blood (equals $200-250 \mathrm{ml}$ of RBCs) was withdrawn once weekly, after puncturing a superficial vein of the forearm with a 16-gauge $(1.6 \mathrm{~mm})$ straight needle, using a mixing device and a collection bag (Compo Guard and Compo Select T 3941, respectively, Fresenius SE, Bad Homburg, Germany). Under the assumption that each $\mathrm{ml}$ of RBCs equals $1 \mathrm{mg}$ of iron ${ }^{21}$ the absolute amount of iron removed in this group was estimated by the formula:

$\mathrm{Fe}_{\text {removed }}=$ blood volume withdrawn $\mathrm{x}$ mean pre-procedure hematocrit $(\mathrm{Hct})$ of each individual patient.

\section{Therapeutic erythrocytapheresis}

Per single treatment procedure 350 to $800 \mathrm{ml}$ of RBCs was withdrawn once every 2 weeks, after puncturing a superficial vein of the forearm with a 16-gauge $(1.6 \mathrm{~mm})$ straight needle. We used an erythrocytapheresis collection device (Model 944 and $\mathrm{MCS}^{+}$equipment Haemonetics Corporation, Braintree, MA). The removed RBC volume was determined by the total estimated blood volume (based on sex, weight, and height) and Hct of each individual patient and the minimal targeted post-procedure Hct set at $30 \%$. The total blood volume was calculated according:

Men: $2740 \times \sqrt{\frac{\text { height }(\mathrm{cm}) \times \text { weight }(\mathrm{kg})}{3600}}$, Women: $2370 \times \sqrt{\frac{\text { height }(\mathrm{cm}) \times \text { weight }(\mathrm{kg})}{3600}}$ 
A 2-week interval was in agreement with results from our pilot study ${ }^{13}$ indicating an optimal return of $\mathrm{Hb}$ values within those 2 weeks. During first treatment $30 \%$ of the estimated removed RBC volume was replaced with isotonic saline. Depending on how well the patient tolerated the first treatment procedure, $0 \%$ to $50 \%$ of the estimated removed $\mathrm{RBC}$ volume was replaced by saline in all subsequent treatment sessions. The absolute amount of iron removed in this group was calculated according to

$\mathrm{Fe}_{\text {removed }}=\mathrm{RBCs}$ volume withdrawn $\times 0.80$.

The correction factor 0.80 was based on the actual Hct of removed RBCs.

All phlebotomy and erythrocytapheresis procedures were performed in one blood donor center of Sanquin Blood Supply, by two certified research nurses experienced in therapeutic procedures, using standard equipment available in blood donor centers.

\section{Monitoring of treatment}

In blood samples taken before and immediately after each procedure, the values of $\mathrm{Hb}$, Hct, MCV, white blood cells (WBCs), platelets (PLTs), serum iron, SF, transferrin, and transferrin saturation were assessed. Treatment was discontinued when a SF level of $50 \mu \mathrm{g} / \mathrm{l}$ or less, as measured in a blood sample taken at least 1 week after any treatment, was reached. Health related quality of life was assessed at baseline, halftime and at end of treatment by means of the EQ-VAS or "feeling thermometer", which is a 20-cm 100-point visual vertical analog scale, portrayed as similar to a thermometer, on which the respondent rates his or her health state at the visit between 0 (worst imaginable health) to 100 (best imaginable health). ${ }^{22}$

\section{Statistical analysis}

\section{Sample size calculation}

From earlier phlebotomy studies it was clear that the number of treatment procedures in newly diagnosed HFE-HC patients could vary between 10 to 60 with a median between 30 to 40 . In a restricted, earlier conducted erythrocytapheresis study ${ }^{13}$ the median for a much more homogeneous population was about 10 with a range between 5 and 20. With a two-sided $\alpha$ level of 0.05 and a $1-\beta$ power of 0.95 the number of patients needed for each arm is 18 . To allow for possible non-adherence numbers needed have been set at 19 for each arm and thus 38 patients had to be included in the study.

\section{Data analysis}

The main outcomes of this study were the number of treatment procedures the patient must undergo as well as the treatment duration in weeks. Interval and ratio variables are tested for normality of distribution by the Wilk-Shapiro test. If normally 
distributed, means and standard deviations (SDs) are presented; if not, the score range is provided. Univariate analysis on baseline differences in metric, normally distributed (clinical) data between both groups (phlebotomy and erythrocytapheresis) is done with the t-test or Fisher's exact test, in non-normally distributed data with the MannWhitney test. Multiple analysis is done with logistic regression analysis using both classes in preferential numbers of treatment as a dichotomous outcome variable.

Despite randomization of the participants the univariate analysis showed a significant difference of the mean initial SF level between both treatment arms. Based on this knowledge we corrected for the initial SF level by multiple linear regression analysis to analyze differences in means between standard phlebotomy and erythrocytapheresis. A p-value of less than 0.05 is considered significant. All data analysis is done with computer software (SPSS-pc version 16.0, Inc., Chicago, IL).

\section{Cost analysis}

The cost analysis included treatment costs and costs related to the loss of productivity. A cost price calculation of both treatment procedures was performed by Sanquin Blood Supply's financial department based on the actual personnel time and use of material per single procedure. Productivity loss was measured by asking patients to report the hours they were absent from work. The costs related to the hours of work lost were valued based on the friction cost method which calculates the hours of work lost until another employee can take over. ${ }^{23-24}$ Since there was no information available about full-time or part-time characteristics of the patient's job, we calculated productivity costs as follows: the number of working hours absent multiplied by the gross national wage per hour multiplied by 0.8 elasticity factor. This elasticity factor reflects the fact that the decrease in productivity is not proportional to the reduction in annual labor. ${ }^{23}$ Uncertainty intervals $\left(2.5^{\text {th }}\right.$ and $97.5^{\text {th }}$ percentiles) for the mean differential costs were calculated by the bootstrap method. ${ }^{25}$ All costs are presented in euros $(1 €=1.30 \$$ ) for the year 2009 .

\section{Results}

A total of 38 patients were randomly assigned to one of the two treatment arms. There were no dropouts. Baseline patient characteristics are summarized in Table 3.1. The demographics, hematological and biochemical parameters as well as perceived health status, assessed by means of the EQ-VAS visual analogue scale, were not significantly different between groups. However, the initial SF concentrations were significantly lower in the erythrocytapheresis group.

In two patients treated with phlebotomy the volume of blood withdrawn per treatment procedure was reduced to 300 to $400 \mathrm{ml}$ because of dizziness during or immediately after the procedure. In two other patients, who complained about fatigue 
in the days after treatment, the time interval was extended by one week. In the erythrocytapheresis group two female patients needed extension of the 2-week interval by 1 week due to slowly restored $\mathrm{Hb}$ values after treatment procedure.

Table 3.1 Baseline and end of treatment characteristics.*

\begin{tabular}{|c|c|c|c|c|c|c|}
\hline \multirow[t]{2}{*}{ Patient characteristics } & \multicolumn{2}{|c|}{$\begin{array}{c}\text { Phlebotomy } \\
\mathrm{N}=19(5+14 \stackrel{)}{ })\end{array}$} & \multicolumn{2}{|c|}{$\begin{array}{c}\text { Erythrocytapheresis } \\
\qquad \mathrm{N}=19(5+, 14 \AA)\end{array}$} & \multicolumn{2}{|c|}{$p$ value } \\
\hline & Start & End & Start & End & Start & End \\
\hline Age (years) & $52(12)$ & & $52(10)$ & & 0.96 & \\
\hline Height $(\mathrm{cm})$ & $176(9)$ & & $176(10)$ & & 0.81 & \\
\hline Weight (kg) & $82(17)$ & & $84(16)$ & & 0.74 & \\
\hline Blood volume (L) & 5153 (939) & & $5178(912)$ & & 0.93 & \\
\hline $\begin{array}{l}\text { SF } \\
(\delta: 16-250 \mu \mathrm{g} / \mathrm{l}) \\
(\uparrow: 6-125 \mu \mathrm{g} / \mathrm{l})\end{array}$ & 1676 (612-3418) & $41.7(28-50)$ & 1103 (454-3279) & $40.2(23-50)$ & $0.04+$ & $0.62+$ \\
\hline $\begin{array}{l}\text { Transferrin } \\
(\delta \circ: 1.5-3.5 \mathrm{~g} / \mathrm{l})\end{array}$ & $1.75(0.26) \ddagger$ & $2.34(0.26) \S$ & $1.69(0.26) \ddagger$ & $2.31(0.28) \ddagger$ & 0.53 & 0.81 \\
\hline $\begin{array}{l}\text { Transferrin } \\
\text { saturation } \\
\left(\delta^{\wedge} \circ: 20-45 \%\right)\end{array}$ & 87.9 (52.5-105.6) & $25.3(11.9-52.0)$ & $89.9(68.7-102.0)$ & $29.5(7.6-75.9)$ & $0.91+$ & $0.91+$ \\
\hline $\begin{array}{l}\text { Serum Iron } \\
(\hat{\delta}: 14-27 \mu \mathrm{mol} / \mathrm{l}) \\
(q: 11-25 \mu \mathrm{mol} / \mathrm{l})\end{array}$ & $35.1(8.2)$ & $13.2(8.0-24.9)$ & $36.3(6.8)$ & $14.9(4.7-37.4)$ & 0.60 & $0.95+$ \\
\hline $\begin{array}{l}\text { Hct } \\
(\text { ơ: } 0.41-0.52 \%) \\
(\text { o }: 0.36-0.48 \%)\end{array}$ & $44(4)$ & $39(3)$ & $44(4)$ & $40(4)$ & 0.76 & 0.75 \\
\hline 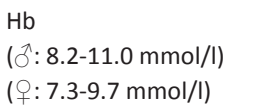 & $9.7(1.0)$ & $8.2(0.8)$ & $9.5(0.8)$ & $8.1(0.7)$ & 0.36 & 0.72 \\
\hline $\begin{array}{l}\text { MCV } \\
\left(\delta^{\wedge}+: 87-98 \mathrm{f} / \mathrm{I}\right)\end{array}$ & $95.9(4.6)$ & $95.6(3.8)$ & $94.9(3.7)$ & $94.8(6.1)$ & 0.49 & 0.64 \\
\hline $\begin{array}{l}\text { AST } \\
\left({ }^{\lambda}: 0-35 \mathrm{U} / \mathrm{I}\right) \\
(\not \circ: 0-30 \mathrm{U} / \mathrm{I})\end{array}$ & $42(16-79)$ & $23.5(7.2) \ddagger$ & $33(6-69)$ & 19.1 (7.9) & $0.25+$ & 0.09 \\
\hline $\begin{array}{l}\text { ALT } \\
(\hat{\jmath}: 0-45 \mathrm{U} / \mathrm{I}) \\
(\uparrow: 0-35 \mathrm{U} / \mathrm{I})\end{array}$ & $73.6(18-161)$ & $26.2(12.0-60.0) \ddagger$ & $50.4(12-125)$ & $23.2(8.0-77.0)$ & $0.17+$ & $0.58+$ \\
\hline $\begin{array}{l}\text { Perceived health } \\
\text { thermometer }\end{array}$ & $71(16)$ & $68(17)$ & $68(19)$ & $69(20)$ & 0.56 & 0.56 \\
\hline
\end{tabular}

* Data are reported as mean (SD) or mean (range); † using Mann-Whitney test; $¥ 1$ missing value; $§ 3$ missing values; " assessed by means of the EQ-VAS visual analogue scale.

\section{Hematologic and biochemical parameters}

After the treatment period no significant differences in hematologic and biochemical variables were observed between both treatment groups (Table 3.1). The aspartate aminotransferase (AST) levels at the end of treatment showed complete recovery in 18 of 19 patients (95\%). The alanine aminotransferase (ALT) levels at the end of treatment 
showed complete recovery in 20 of $23(87 \%)$ patients. In four patients the levels were almost normalized (one) or substantially decreased (three).

\section{Health related quality of life}

As shown in Table 3.1, no statistical significant difference in perceived health status assessed by means of the EQ-VAS visual analogue scale between both treatment groups was observed at the end of the treatment period.

\section{Iron variables}

The estimated mean total amount of removed iron (Table 3.2) was lower in the erythrocytapheresis group (3759 mg vs. 5369 mg, Mann-Whitney $p<0.001$ ). This corresponds with the lower initial SF levels in the erythrocytapheresis group. However, the mean amount of iron removed per treatment procedure was significantly higher in the erythrocytapheresis group than in the phlebotomy group (427 vs. $205 \mathrm{mg}$; $p<0.001)$.

Table 3.2 Results of the univariate comparisons between Phlebotomy and Erythrocytapheresis groups.*

\begin{tabular}{lccrr}
\hline & Phlebotomy & Erythrocytapheresis & Reduction \\
& $\mathrm{N}=19\left(5+, 14{ }^{\lambda}\right)$ & $\mathrm{N}=19\left(5+, 14 \bigcirc^{\lambda}\right)$ & factor & $\mathrm{p}$ value \\
\hline No procedures & $27(11-58)$ & $9(4-20)$ & 0.33 & $<0.001^{\dagger}$ \\
Treatment duration (weeks) & $33.7(12-79)$ & $19.6(7-37)$ & 0.58 & $0.002^{\dagger}$ \\
Treatment Interval (days) & $9(7-14)$ & $16(11-26)$ & 1,77 & $<0.001^{\dagger}$ \\
Total volume removed (ml) & $13016(5500-21000)$ & $4699(1839-11655)$ & 0.36 & $<0.001^{\dagger}$ \\
Estimated total removal of iron (mg) & $5369(2310-8820)$ & $3759(1471-9324)$ & 0.70 & $0.008^{\dagger}$ \\
Estimated removal of iron per & $205(136-230)$ & $427(294-545)$ & 2.08 & $<0.001^{\dagger}$ \\
procedure (mg) & & & & \\
\hline
\end{tabular}

* Data are reported as mean (range); † using Mann-Whitney test.

\section{Number of treatment procedures and treatment duration}

Univariate comparisons of outcome variables between the phlebotomy and erythrocytapheresis groups are depicted in Table 3.2. Because none of the six outcome variables were normally distributed, means and score ranges are given, the MannWhitney test was performed and the observed reduction factors of erythrocytapheresis versus phlebotomy are given as rates. In number of procedures the reduction rate of erythrocytapheresis versus phlebotomy is 0.33 . In treatment duration in weeks it is 0.58 and both outcomes are significantly different between the treatment groups (Mann-Whitney $p<0.001$ and $p=0.002$ respectively).

To meet the assumptions of normality to facilitate the analysis of the number of treatment procedures and the treatment duration in weeks, both have been log transformed. Linear unadjusted regression analysis on the transformed number of procedures (Table 3.3, left side) using only treatment groups as a (0-1) predicting 
factor also shows significantly lower numbers for erythrocytapheresis over phlebotomy. Calculating the antilog of the unadjusted regression coefficient provides the same observed reduction factor as in Table $3.2(0.33)$, but also its confidence interval $(95 \% \mathrm{Cl}, 0.25-0.45)$, which is well in line with the hypothetically expected reduction factor of 0.50 or less (Table 3.3, left side RF). For the number of weeks the reduction factor is $0,58(95 \% \mathrm{Cl}, 0.43-0.79)$.

The multiple regression analysis was performed to adjust for the initial SF level and patient weight. After this adjustment there is still a significant regression effect between both treatment arms (Table 3.3, right side RF). The estimated reduction factor of the mean number of treatment procedures of erythrocytapheresis over phlebotomy is $0.43(95 \% \mathrm{Cl}, 0.33-0.52)$, which just exceeds the 0,50 target in the expected upper $95 \% \mathrm{Cl}$. For treatment duration in weeks the same adjustment gave a reduction factor of $0.70(95 \% \mathrm{Cl}, 0.52-0.95)$.

Table 3.3 Results of the (multiple) linear regression analysis.

\begin{tabular}{|c|c|c|c|c|}
\hline & \multicolumn{2}{|c|}{ Unadjusted } & \multicolumn{2}{|c|}{$\begin{array}{c}\text { Adjusted for initial SF and } \\
\text { patient weight }\end{array}$} \\
\hline & $\mathrm{RF}^{*}$ & $95.0 \% \mathrm{Cl}$ for $\mathrm{RF}^{*}$ & RFt & $95.0 \% \mathrm{Cl}$ for $\mathrm{RF}^{\dagger}$ \\
\hline Number of treatment procedures & 0.33 & $0.25-0.45$ & 0.43 & $0.33-0.52$ \\
\hline Treatment duration in weeks & 0.58 & $0.43-0.79$ & 0.70 & $0.52-0.95$ \\
\hline
\end{tabular}

* Unadjusted reduction factor (RF) of the number of treatment procedures needed or treatment duration between both treatment arms. Treatment arm was defined as ' 0 ' for phlebotomy and ' 1 ' for erythrocytapheresis. + Estimated reduction factor adjusted for both initial serum ferritin and patient weight.

\section{Adverse events}

All adverse events appeared to be mild or very mild in both groups. In the erythrocytapheresis group, 3 of 19 patients (15.8\%) reported eight events (one case of very mild citrate reaction, one vasovagal collapse and six cases of mild dizziness) at a total of 171 procedures. In the phlebotomy group, 5 of 19 patients (26.3\%) reported 10 events (one short-lasting collapse and nine cases of mild dizziness) at a total of 513 procedures. This difference was not significant when expressed by number of patients $(p=0.12)$ nor when expressed as adverse events per number of required procedures (Fisher's exact $\mathrm{p}=0.09$ ).

\section{Cost analysis}

Table 3.4 gives an overview of the separate items of the cost price calculation per single procedure. The cost price for erythrocytapheresis was 3.5 fold greater compared with the cost price for phlebotomy. These higher costs are a consequence of longer personnel time of the blood bank assistant and higher costs of the collection bag and collecting equipment. 
There was no significant difference in total treatment costs between the erythrocytapheresis group and the phlebotomy group (Table 3.5). The costs resulting from the number of hours absence at work are significantly lower for the erythrocytapheresis group.

Table 3.4 Cost prices for a single treatment procedure in euros (€) for 2009.

\begin{tabular}{|c|c|c|c|c|c|c|}
\hline & \multicolumn{3}{|c|}{ Phlebotomy } & \multicolumn{3}{|c|}{ Erythrocytapheresis } \\
\hline & Resource use & Unit costs & $\begin{array}{l}\text { Costs per } \\
\text { procedure }\end{array}$ & Resource use & Unit costs & $\begin{array}{l}\text { Costs per } \\
\text { procedure }\end{array}$ \\
\hline \multicolumn{7}{|l|}{ Personal costs } \\
\hline Blood bank assistent & $0.67(h)$ & $31.90(€ / h)$ & 21,37 & $1.25(h)$ & $31.90(€ / h)$ & 39.88 \\
\hline Blood bank physician & $0.19(h)$ & $65.25(€ / h)$ & 12.40 & $0.25(h)$ & $65.25(€ / h)$ & 16.31 \\
\hline \multicolumn{7}{|l|}{ Material costs } \\
\hline Collection bag & 1 & $8.30 *$ & 8.30 & 1 & $90+$ & 90 \\
\hline \multicolumn{7}{|l|}{ Equipment costs $\ddagger$} \\
\hline Collecting equipment & $1 / 1500 \ddagger$ & 2070 (€/year)§ & 1.38 & $1 / 800||$ & 13110(€/year $)^{\text {ๆ }}$ & 16.39 \\
\hline Collecting bed & $1 / 1500 * *$ & 1150 (€/year) & 0.77 & $1 / 800+\dagger$ & 1150 (€/year) & 1.44 \\
\hline Tests costs & 2 & 1.68 & 3.36 & 2 & 1.68 & 3.36 \\
\hline Destroy costs & 1 & 0.08 & 0.08 & 1 & 0.08 & 0.08 \\
\hline $\begin{array}{l}\text { Indirect costs (building, } \\
\text { IT, overhead) }\end{array}$ & $50 \%$ of costs & 47.66 & 23.83 & $50 \%$ of costs & 167.46 & 83.73 \\
\hline Total costs & & & 71.49 & & & 251.18 \\
\hline
\end{tabular}

* Whole blood collection bag Compo Select T 3941 (Fressenius). † Apheresis collection device 944 (Haemonetics). $¥ 1500$ procedures/ equipment/ year. § Mixing device Compo Guard (Fresenius). || 800 procedures/ equipment/ year. " MCS + equipment (Haemonetics. ** 1500 procedures/ bed/ yea. †† 800 procedures/ bed/ year. $¥ \ddagger$ Depreciation costs/year (23\%), maintenance costs/year (23\%).

Table 3.5 Total mean costs of phlebotomy and erythrocytapheresis treatment in euros (€).*

\begin{tabular}{lcccc}
\hline Items & $\begin{array}{c}\text { Phlebotomy } \\
\mathrm{N}=19(5 \propto, 14 \hat{)})\end{array}$ & $\begin{array}{c}\text { Erythrocytapheresis } \\
\mathrm{N}=19(5+, 14 \hat{)})\end{array}$ & $\begin{array}{c}\text { Difference } \\
\text { in mean }\end{array}$ & UI (2.5-97.5) \\
\hline Treatment costs $(€)$ & $1898(186)$ & $2263(233)$ & +358 & $(-250$ to +927$)$ \\
Costs of lost production $(€)$ & $2669(465)$ & $775(280)$ & -1983 & $(-2927$ to -857$)$ \\
Total costs $(€)$ & $4438(599)$ & $3005(444)$ & -1433 & $(-2834$ to +114$)$ \\
\hline
\end{tabular}

* Data are reported as mean (SD). UI = uncertainty interval

\section{Discussion}

This is, to the best of our knowledge, the first randomized trial comparing phlebotomy, the standard of care, with erythrocytapheresis in the initial treatment of newly diagnosed HFE-HC patients homozygous for $\mathrm{C} 282 \mathrm{Y}$. Results from the univariate analysis support our hypothesis that erythrocytapheresis treatment reduced the total number of procedures with at least $50 \%$. The observed reduction factor of 0.33 is in agreement with the results of our pilot study. ${ }^{13}$ In addition the mean treatment duration in the erythrocytapheresis group is reduced with a factor of $0.58(p<0.001)$. 
Despite an imbalance in initial SF between both treatment arms after randomization, multivariate analysis with correction for confounders like patient weight and initial SF confirmed the conclusions from the univariate analysis. For number of treatment procedures the ratio of 0.43 as found in the multiple regression analysis was still below the ratio of 0.50 which was set in the protocol as endpoint, but just exceeds the estimated upper $95 \%$ confidence limit of 0.50 . In hindsight, we assume that a somewhat higher power and/or a by baseline SF stratified randomisation design might have led to an upper confidence level within the 0.50 or less range.

A lower mean amount of total removed iron in the erythrocytapheresis group (Table 3.2) was also a consequence of the difference in the initial SF levels between both groups. However, per single treatment procedure significantly more iron was removed in erythrocytapheresis group, suggesting that erythrocytapheresis is a much more effective treatment.

Erythrocytapheresis in symptomatic patients with initial SF levels above $1000 \mu \mathrm{g} / \mathrm{l}$ in whom phlebotomy usually takes 2 years with up to 100 or more procedures will substantially reduce the number of procedures as well as the treatment duration. The biweekly treatment regimen used by erythrocytapheresis may be easier to endure knowing that only one-third of HFE-HC patients can tolerate and adhere to weekly phlebotomy. $^{26}$

The use of apheresis equipment generally leads to a reduction of adverse events. ${ }^{27}$ This is most likely related to the saline compensation and the longer collection time during apheresis procedures, facilitating transcapillary refilling of the intravascular compartment. $^{28,29}$ However, our study showed no differences in adverse events between both therapies, although the number of patients was limited and the study was not powered to show a difference in adverse events.

Erythrocytapheresis did remove more than two times the amount of RBCs per single procedure without inducing anemia. This reflects the individual fine tuning adapted to sex, weight, the total blood volume, and actual Hct in which erythrocytapheresis allows for a much more sophisticated and accurate adjustment. In addition, erythrocytapheresis has the potential to selectively reduce the iron source and preserve valuable blood components of the patient such as plasma proteins, PLTs, clotting factors and WBCs, which make this approach also attractive for patients with hypoproteinemia or thrombocytopenia.

An advantage of phlebotomy is that it is a simple procedure that can be performed in various situations. In contrast, erythrocytapheresis needs specialized equipment and adequately trained staff. This can be overcome by using blood donor centers as treatment locations. Blood centers with apheresis equipment and trained staff are readily available in Europe, the United States, and Canada. We performed our study with MCS + equipment (Haemonetics), which uses a one-needle system and is standard available in most blood donor centers. Nevertheless it is also possible to perform these procedures with Spectra equipment (Caridian BCT, Lakewood, CO), which uses a two-needle system. 
Published data suggests that erythrocytapheresis is expensive. ${ }^{16,18}$ However, our study throws another light on this important issue. In the Netherlands, in Sanquin blood donor centers, the cost price of a single erythrocytapheresis is 3.5 times higher compared to phlebotomy. This cost difference is probably much smaller compared to other countries and healthcare settings. However, comparing our results with costs from other studies or countries is difficult, since mostly reimbursement charges are reported. These reimbursement charges are generally higher than costs and do not reflect real resource use. For that reason we performed a cost price calculation. This approach is also known as micro costing, which has the advantage of allowing others to see how well the analysis matches their own situation where patterns of care may differ ${ }^{30}$. Hence, it becomes possible to compare volumes of use between different countries or settings and to examine whether a large cost difference between erythrocytapheresis and phlebotomy is in fact related to real differences in resource use.

Furthermore it should be noted that the costs in our study are based on a status quo assumption. If erythrocytapheresis is more widely used the costs per single procedure will be even lower due to a more efficient use of equipment. In addition, another potential factor of decreasing erythrocytapheresis costs is the option to use the collected blood for transfusion purposes as has already been done in some parts of the United States, Canada, and more recently in France. In that case 2 units of RBCs can be produced during one erythrocytapheresis procedure.

The cost price for a single treatment procedure might also depend on the location. In our trial, both treatment procedures are performed in Sanquin blood donor centers, which have lower costs for beds, equipment and personnel compared to the hospitals. Although the costs of a single erythrocytapheresis are higher, the total treatment costs are not significantly higher because fewer treatment procedures in the erythrocytapheresis group are needed to reach the recommended target. The costs resulting from the loss of hours absent from work are significantly lower in the erythrocytapheresis group because again fewer procedures are needed to reach a SF level of $50 \mu \mathrm{g} / \mathrm{l}$ or less. This means that patients in erythrocytapheresis group report less hours absent from work compared to the phlebotomy group. Still, further research in a larger group is necessary to confirm these results.

A post hoc analysis of our data (results not shown) on preferable number of treatment procedures showed that heavier patients $(>76 \mathrm{~kg}$ ) had a larger benefit of the erythrocytapheresis treatment. However, this needs further confirmation in future studies with higher number of patients.

In conclusion, erythrocytapheresis significantly reduces the number of treatment procedures as well as treatment duration in weeks compared to phlebotomy and from a societal perspective might also be a cost saving therapy. Studies in a larger population have to be performed to confirm these findings. 


\section{References}

1. Adams PC, Barton JC. How i treat hemochromatosis. Blood 2010;116:317-25.

2. Brissot $P$, Troadec $M B$, Bardou-Jacquet $E$, Le Lan C, Jouanolle AM, Deugnier Y, Loréal O. Current approach to hemochromatosis. Blood Rev 2008;22:195-210.

3. Barton JC, McDonnell SM, Adams PC, Brissot P, Powell LW, Edwards CQ, Cook JD, Kowdley KV. Management of hemochromatosis. Hemochromatosis Management Working Group. Ann Intern Med 1998;129:932-9.

4. Swinkels DW, Jorna AT, Raymakers RA. Synopsis of the Dutch multidisciplinary guideline for the diagnosis and treatment of hereditary haemochromatosis. Neth J Med 2007;65:452-5.

5. Niederau C, Stremmel W, Strohmeyer GW. Clinical spectrum and management of haemochromatosis. Baillieres Clin Haematol 1994; 7:881-901.

6. Niederau C, Fischer R, Purschel A, Stremmel W, Haussinger D, Strohmeyer G. Long-term survival in patients with hereditary hemochromatosis. Gastroenterology 1996;110:1107-19.

7. Mc Donnel S, Preston B, Jewel SA, Barton JC, Edwards CQ, Adams PC, Yip R. . A survey of 2851 patients with hemochromatosis: symptoms and response to treatment. Am J Med 1999;106: 619-25.

8. Mc Donnel S, Grindon A, Preston B, Barton J, Edwards C, Adams PC. A survey op phlebotomy among persons with hemochromatosis. Transfusion 1999;39:651-6.

9. Brissot P, Ball S, Rofail D, Cannon H, Wu Jin V. Hereditary hemochromatosis: patient experience of the disease and phlebotomy treatment. Transfusion 2011;51:1331-8.

10. Wijermans P, van Egmond L, Ypma P, Kerkhoffs JL, Schipperus M, Bohmer L, Agteresch E. Isovolemic erythrocytapheresis technique as an alternative to conventional phlebotomy in patients with polycythemia rubra vera and hemochromatosis. Transfus Apher Sci 2009;40:137.

11. Conte D, Brunelli L, Bozzani A, Tidone L, Quatrini M, Bianchi PA. Erythrocytapheresis in idiopathic haemochromatosis. Br Med J (Clin Res Ed) 1983;286:939.

12. Zoller WG, Kellner H, Spengel FA. Erythrocytapheresis. A method for rapid extracorporeal elimination of erythrocytes. Results in 65 patients. Klin Wochenschr 1988;66:404-9.

13. Rombout-Sestrienkova E, van Noord PA, van Deursen CT, Sybesma BJ, Nillesen-Meertens AE, Koek GH. Therapeutic erythrocytapheresis versus phlebotomy in the initial treatment of hereditary hemochromatosis - A pilot study. Transfus Apher Sci 2007;36:261-7.

14. Rombout-Sestrienkova E, Noord PA, Reuser E, Heeremans J, van Deursen CthBM, Janssen M, Koek GH. Therapeutic Erythrocytapheresis (TE) versus Phlebotomy (P) in the treatment of Hereditary Hemochromatosis $(\mathrm{HH})$ patients: Preliminary results from an ongoing randomized clinical trial (NCT 00202436). Transfus Apher Sci 2009;40:135-6.

15. Muncunill J, Vaquer P, Galmes A, Obrador A, Parera M, Bargay J, Besalduch J. In hereditary hemochromatosis, red cell apheresis removes excess iron twice as fast as manual whole blood phlebotomy. J Clin Apher 2002;17:88-92.

16. Mariani R, Pelucchi S, Perseghin P, Corengia C, Piperno A. Erythrocytapheresis plus erythropoietin: an alternative therapy for selected patients with hemochromatosis and severe organ damage. Haematologica 2005;90:717-8.

17. Kohan A, Niborski R, Daruich J, Rey J, Bastos F, Amerise G, Herrera R, Garcia M, Olivera W, Santarelli MT, Avalos JS, Findor J. Erythrocytapheresis with recombinant human erythropoietin in hereditary hemochromatosis therapy: a new alternative. Vox Sang 2000;79:40-5.

18. Kellner H, Zoller WG. Repeated isovolemic large-volume erythrocytapheresis in the treatment of idiopathic hemochromatosis. Z Gastroenterol 1992;30:779-83.

19. Fernandez-Mosteirin N, Salvador-Osuna C, Garcia-Erce JA, Orna E, Perez-Lungmus G, Giralt M. Comparison between phlebotomy and erythrocytapheresis of iron overload in patients with HFE gene mutations. Med Clin (Barc) 2006;127:409-12.

20. Conte D, Mandelli C, Cesana M, Ferrini R, Marconi M, Bianchi A. Effectiveness of erythrocytapheresis in idiopathic hemochromatosis. Report of 14 cases. Int J Artif Organs 1989;12:59-62.

21. Barton JC. Optimal management strategies for chronic iron overload. Drugs 2007;67:685-700.

22. Rabin R, de Carro F. EQ-5D: a measure of health status from the EuroQol Group. Ann Med 2001, 33:337-43. 
23. Oostenbrink JB, Bouwmans CAM, Koopmanschap MA, Rutten FFH. Handleiding voor kostenonderzoek, methoden en standard kostprijzen voor economische evaluaties in de gezondheidszorg. College voor zorgverzekeringen. Geactualiseerde versie 2004.

24. Koopmanschap MA, Rutten FAA, van Ineveld BM, van Roijen L. The friction cost method for measuring indirect costs of disease. J Health Econ 1999;14,171-89.

25. Efron B, Tibshirani RJ. An introduction to the Bootstrap. London: Chapman \& Hall,1993.

26. Hicken BL, Tucker DC, Barton JC. Patient compliance with phlebotomy therapy for iron overload associated with hemochromatosis. Am J Gastroenterol 2003;98:2072-7.

27. Wiltbank T, Giordano G. The safety profile of automated collections: an analysis of more than 1 million collections. Transfusion 2007;47:1002-5.

28. Popovsky MA. Complications of blood donation: manual and automated blood collection procedures. Transfus Med Hemother 2004;31:49-53.

29. Popovsky MA. Safety of RBC apheresis and whole blood donation in allogenic and autologous blood donors. Transfus Apher Sci 2006;34:205-11.

30. Gold MR, Siegel JE, Russell LB, Weinstein MC. Cost-effectiveness in health and medicine. New York. Oxford University Press. 1996. 


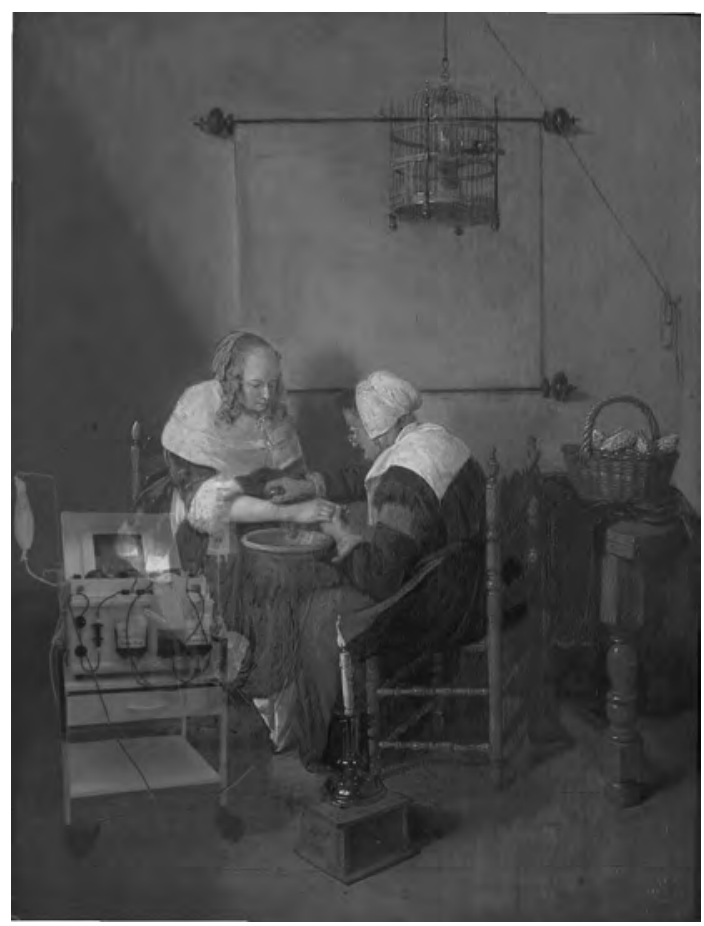

\section{Chapter 4}

Course of iron parameters in HFE-Hemochromatosis patients during initial treatment with erythrocytapheresis compared to phlebotomy

Eva Rombout-Sestrienkova, Ger H. Koek, Rabin Neslo, Marian van Kraaij, Paul P. Menheere, Ad Masclee, Dorine W. Swinkels J Clin Apher 2016 Epub ahead of print 


\section{Summary}

Current treatment for newly diagnosed patients with Hereditary Hemochromatosis $(\mathrm{HH})$ and iron overload consist of weekly phlebotomy or less frequent and more personalized erythrocytapheresis. Previous observations during phlebotomy suggest an increase in intestinal iron uptake caused by lowering of hepcidin as a result of intensive bloodletting. It is not known whether such an effect is present or even more pronounced using erythrocytapheresis since a larger amount of iron is extracted per procedure. In this study we aimed to assess the effect of erythrocytapheresis on the course of iron parameters, with special focus on serum hepcidin. We performed a retrospective proof-of-principle observational study, comparing serum iron parameters in 12 males during the depletion phase using either phlebotomy $(\mathrm{N}=6)$ or erythrocytapheresis $(\mathrm{N}=6)$. Decreases in serum ferritin over time were similar for both treatments but more pronounced using erythrocytapheresis when expressed per treatment procedure. Hemoglobin did not change during erythrocytapheresis, whereas during phlebotomy decreased with $10 \%$. Increase of erythropoietin and soluble transferrin receptor and decrease in transferrin saturation were similar for both treatments. Reduction in serum hepcidin was higher ( $50 \%$ versus $25 \%$ of initial value) and occurred more early using phlebotomy (10 versus 20 weeks after start). In aggregate, compared to phlebotomy, the less frequent and more personalized erythrocytapheresis leads to a more pronounced decrease in serum ferritin per treatment procedure, without a larger decrease in serum hepcidin. This may be clinically relevant and may prevent an increase in intestinal iron uptake and an ensuing vicious circle of more frequent treatment procedures. 


\section{Introduction}

Hereditary Hemochromatosis $(\mathrm{HH})$ is characterised by an increase in iron absorption inappropriate to body iron stores. ${ }^{1}$ Four types of $\mathrm{HH}$ have been reported of which type 1 , associated with mutations in the HFE gene, is most frequent among populations of European origin. About $80 \%$ of all patients with clinically significant iron overload are p.Cys282Tyr homozygote. ${ }^{2}$ The primary cause of iron overload in most forms of $\mathrm{HH}$ is insufficient production of hepcidin by hepatocytes ${ }^{3,4}$ leading to an increased iron uptake in the intestine and iron release by macrophages.

Standard induction treatment in newly diagnosed $\mathrm{HH}$ patients consists of removal of $500 \mathrm{ml}$ whole blood by phlebotomy $(\mathrm{P})$, generally performed on a weekly basis, until the serum ferritin level has decreased below 50 or $100 \mu \mathrm{g} / \mathrm{l}$, depending on the guideline. ${ }^{5-9}$ Hereafter, in the maintenance phase of treatment, the frequency of $P^{\prime} \mathrm{s}$ is reduced to 2-6/year to keep serum ferritin below the target value. Although effective, common side effects of this treatment are fatigue, fainting, pain at the venous access site, hematomas and anemia. ${ }^{10,11}$ Overall, 52\% of patients during the induction phase of treatment and $37 \%$ in the maintenance phase report negative experiences related to treatment and $16 \%$ of patients would even decide not to continue with $\mathrm{P}$ in case alternative options are available. ${ }^{10}$

An alternative option is less frequent and personalized erythrocytapheresis (E), a technique using an apheresis machine that selectively removes erythrocytes and returns leucocytes, platelets and plasma to the patient. This method also offers the possibility for substitution of the removed volume resulting in fewer hemodynamic changes compared with P. Erythrocytapheresis has been evaluated in two randomized trials $^{12,13}$ and several non-randomized studies. ${ }^{14-23}$ From these studies, it was concluded that $E$ is a more effective method for body iron withdrawal compared to $P$, with fewer treatment sessions, less travel and absence from work to reach the same ferritin target values.

Few studies assessed the influence of repeated $\mathrm{P}$ on serum hepcidin and other serum iron parameters over time, ${ }^{24,25}$ showing that serum hepcidin decreased during the depletion phase of $\mathrm{P}$ therapy and remained low during maintenance. ${ }^{24}$ Treatment with $\mathrm{P}$ may thus result in hepcidin deficiency and a greater iron absorption requiring more frequent treatments. It is not known whether such an effect is present in patients undergoing less frequent and more personalized $E$ treatment. The aim of the study was therefore to assess in a "proof of principle" manner the influence of E treatment on the course of iron parameters, with special focus on serum hepcidin. The important question was if $\mathrm{E}$ treatment leads to more pronounced hepcidin deficiency requiring more treatments as a consequence as more iron will be removed per single treatment procedure. 


\section{Methods}

\section{Study design}

This study is a small retrospective proof of principle observational study in which the iron parameters including serum hepcidin, erythropoietin (EPO), soluble transferrin receptor (STfR), serum iron (SI), transferrin saturation (TS), and serum ferritin in 12 newly diagnosed p.Cys282Tyr homozygous males were compared during the iron depletion phase of two different iron withdrawal treatments. Six patients were treated once weekly with $\mathrm{P}$ in the hospital setting of Radboud University Medical Center (Radboudumc), and the other six, referred by Maastricht University Medical Center, were treated with $E$ once every two to four weeks by Sanquin Blood Bank. The choice of $E$ in Maastricht was solely based on the fact that this treatment was only available in Maastricht and not at Radboudumc. Blood samples were all drawn in the context of regular clinical practice and were stored by $-80^{\circ} \mathrm{C}$ until use. The use of samples was with the agreement of patients and was approved by local ethical committee. Depicted samples were drawn shortly before the start of the treatment procedure at 8 different time points from each patient resulting in a total of 96 samples. The first sample was obtained before the first treatment procedure, subsequent samples 2-7 before procedures during the depletion phase and the last $\left(8^{\text {th }}\right)$ sample before a procedure at the end of the depletion phase. In the current study the end of the depletion phase was defined as a serum ferritin concentration below the upper limit of the reference range $(20-250 \mu \mathrm{g} / \mathrm{l})$. From all samples serum ferritin $(\mu \mathrm{g} / \mathrm{l}), \mathrm{SI}(\mu \mathrm{mol} / \mathrm{l})$, transferrin $(\mathrm{g} / \mathrm{l})$, serum hepcidin $(\mathrm{nmol} / \mathrm{l})$, sTfR $(\mathrm{mg} / \mathrm{l})$, EPO $(\mathrm{U} / \mathrm{l})$, hemoglobin $(\mathrm{Hb})(\mathrm{mmol} / \mathrm{l})$ and C-reactive protein (CRP) (mg/l) were measured.

\section{Phlebotomy treatment}

Per single treatment procedure $500 \mathrm{ml}$ whole blood (equals $200-250 \mathrm{ml}$ erythrocytes) was withdrawn conform regular care once weekly. Under the assumption that $1 \mathrm{ml}$ of erythrocytes equals $1 \mathrm{mg}$ iron, ${ }^{6,26}$ the absolute amount of iron removed in this group was estimated by the formula:

$\mathrm{Fe}_{\text {removed }}(\mathrm{mg})=$ blood volume withdrawn $(\mathrm{ml}) \times$ pre-procedure hematocrit $(\mathrm{l} / \mathrm{l})$

\section{Erythrocytapheresis treatment}

Per single treatment procedure 350-800 ml erythrocytes was withdrawn once every two to four weeks (depending on $\mathrm{Hb}$ value of patient). An erythrocytapheresis collection device 944 and $\mathrm{MCS}^{+}$equipment (Haemonetics Corporation, Braintree, Massachusetts, USA) were used. The removed erythrocytes volume was determined by the total estimated blood volume (based on gender, weight and height) and 
hematocrit of each patient and the minimal targeted post-procedure hematocrit set at $32 \%$. The total blood volume was calculated according to formula advised in American Association of Blood Banks (AABB) technical manual ${ }^{27}$ :

Total blood volume male $(\mathrm{ml})=2740 \times \sqrt{\frac{\text { height }(\mathrm{cm}) \times \text { weight }(\mathrm{kg})}{3600}}$

The absolute amount of iron removed in this group was calculated according to:

$\mathrm{Fe}_{\text {removed }}(\mathrm{mg})=$ erythrocytes volume withdrawn $(\mathrm{ml}) \times 0.84$

The correction factor of 0.84 was based on the actual hematocrit of removed erythrocytes.

\section{Laboratory measurements}

CRP and routine hematology characteristics were assessed using routine methods. Exon 4 of the HFE gene was analysed by Sanger Sequencing for the presence of the p.Cys282Tyr mutation in the HFE gene (c.845G>A). EPO was measured by solid-phase, chemiluminescence immunometric assay on an Immulite 2000 Analyzer (Siemens Healthcare Diagnostics), sTfR by immunophelometry on the Behring Nephelometer Analyzer II (Dade Behring / Siemens). TS was calculated from SI concentration and transferrin concentration by the formula ${ }^{28}$ :

TS $(\%)=[(\mathrm{SI}(\mu \mathrm{mol} / \mathrm{l}): 25) /$ transferrin $(\mathrm{g} / \mathrm{l})] \times 100 \%$

Serum ferritin was measured by an immunoassay on the COBAS 6000 (Roche Diagnostics). Serum hepcidin-25 (hepcidin) measurements were performed by a combination of weak cation exchange chromatography and time-of-flight mass spectrometry (WCX-TOF MS). ${ }^{29}$ An internal standard (synthetic hepcidin 24; Peptide International Inc.) was used for quantification. ${ }^{30}$ Peptide spectra were generated on a Microflex LT matrix-enhanced laser desorption/ionisation (MALDI) TOF MS platform (Bruker Daltonics). Serum hepcidin concentrations were expressed as nmol/l (nM)). The lower limit of detection of this method was $0.5 \mathrm{nM}$. Average coefficients of variation were $2.2-3.7 \%$ (intra-run) and $3.9-9.1 \%$ (inter-run) ${ }^{26}$ and the reference range for men is $4.5 \mathrm{nM}^{31,32}$

\section{Statistical analysis}

Small sample sizes precluded extensive statistical evaluation. As an alternative to obtain insights in differences and variations between treatment methods we evaluated both the progression of the iron parameters over time and the mutual dependencies of these parameters within both treatment groups. To this end, we employed an 
exploratory approach by especially graphical judgement for describing the time course of the observations of $\mathrm{Hb}, \mathrm{EPO}, \mathrm{sTfR}$ and TS. Since we don't have a physiological model to base the observed variations of these processes, we describe them by classical first (or second) grade regression lines. These lines must be considered just to be indicators of possible trends of these analytes. For the observations of ferritin and hepcidin, fittings have been made using the modified exponential decay method, using the fitting formula: $y=a^{*} \exp (b /(x+c))$. This model supposes that the concentration of an analyte decreases at a rate proportional to its concentration. The decay of most naturally occurring analytes follows a reversed exponential curve. We used Sigma Plot V13 graphical and statistical software.

To detect the statistical dependencies between pairs of variables among the measured iron parameters we used a Spearman rank correlation.

\section{Results}

\section{Baseline characteristics of study population}

Baseline values of iron parameters were similar for both groups (supplementary tables I and II). Mean values (SD) for E and P, respectively, were: serum ferritin 2482 (2728) and 1698 (996) $\mu \mathrm{g} / \mathrm{l} ; \mathrm{Hb} 9.0$ (0.5) and 9.5 (0.5) mmol/l; EPO 17.9 (12.9) and 9.2 (4.7) U/l; sTfR $0.95(0.27)$ and $0.86(0.18) \mathrm{mg} / \mathrm{l}$; TS 90 (24) and 89 (17)\%, and serum hepcidin $2.8(1.4)$ and $3.9(2.4) \mathrm{nmol} / \mathrm{l}$.

\section{Iron removal characteristics of study population}

In the $E$ group patients needed a mean of $n=15$ (range 8-20) procedures to remove in total a mean of 6940 (range 3760-9120) $\mathrm{mg}$ of iron (Table 4.1). In the P group a mean of $n=28$ (range 14-42) procedures were required to remove in total a mean of 5545 (range 2800-8190) $\mathrm{mg}$ of iron. Per single procedure 2.3 times more iron was removed using E compared to P (466 mg versus $201 \mathrm{mg}$ ). Mean treatment time was 42 weeks (range 21-67) in the E group, versus 36 weeks (range 21-48) in the $P$ group. Mean frequency of treatment procedures over all patients and procedures was 1 procedure in 2.8 weeks (range 2.4-3.4 weeks) in the E group versus 1 procedure in 1.4 weeks (range 1.1-1.9 weeks) in the $P$ group.

There were no adverse events recorded either in $\mathrm{P}$ or $\mathrm{E}$ treatment group. 
Table 4.1 Ferritin concentrations and iron removal characteristics of the study population.

\begin{tabular}{|c|c|c|c|c|c|c|}
\hline Patient No & $\begin{array}{l}\text { Ferritin } \\
\text { initial } \\
(\mu g / \mathrm{I})\end{array}$ & $\begin{array}{l}\text { Ferritin final } \\
\qquad(\mu \mathrm{g} / \mathrm{I})\end{array}$ & $\begin{array}{c}\text { No of } \\
\text { procedures }\end{array}$ & $\begin{array}{c}\text { Treatment } \\
\text { duration } \\
\text { (weeks) }\end{array}$ & $\begin{array}{c}\text { Estimated removal } \\
\text { of iron per } \\
\text { procedure (mg) }\end{array}$ & $\begin{array}{c}\text { Estimated total } \\
\text { removal of iron } \\
(\mathrm{mg})\end{array}$ \\
\hline \multicolumn{7}{|c|}{ Erythrocytapheresis group } \\
\hline 1 & 7925 & 61 & 19 & 49 & 409 & 7760 \\
\hline 2 & 1069 & 74 & 18 & 46 & 445 & 8000 \\
\hline 3 & 3849 & 50 & 20 & 67 & 456 & 9120 \\
\hline 4 & 925 & 53 & 8 & 21 & 470 & 3760 \\
\hline 5 & 1072 & 187 & 17 & 40 & 480 & 8160 \\
\hline 6 & 2213 & 72 & 9 & 29 & 538 & 4840 \\
\hline Mean & 2842 & 83 & 15 & 42 & 466 & 6940 \\
\hline (SD) & 2728 & 52 & 5 & 16 & 43 & 2124 \\
\hline \multicolumn{7}{|c|}{ Phlebotomy group } \\
\hline 7 & 1936 & 44 & 35 & 39 & 200 & 7000 \\
\hline 8 & 612 & 32 & 14 & 24 & 200 & 2800 \\
\hline 9 & 1347 & 70 & 35 & 45 & 205 & 7175 \\
\hline 10 & 1284 & 38 & 21 & 39 & 205 & 4305 \\
\hline 11 & 1474 & 218 & 19 & 21 & 200 & 3800 \\
\hline 12 & 3537 & 220 & 42 & 48 & 195 & 8190 \\
\hline Mean & 1698 & 104 & 28 & 36 & 201 & 5545 \\
\hline (SD) & 996 & 90 & 11 & 11 & 4 & 2186 \\
\hline
\end{tabular}

\section{Influence of treatment method on iron parameters}

Concentrations of iron parameters from blood samples drawn during $E$ and $P$ treatment per individual patient are presented in Supplementary Tables S4.1 and S4.2. The time course of all measured iron parameters per treatment over time is presented in Figure 4.1 as a percentage change from baseline. For serum ferritin change in time was also assessed per treatment procedure and presented in Figure 4.2.

In the $\mathrm{E}$ group $\mathrm{Hb}$ did not change over time, whereas in the $\mathrm{P}$ group it decreased around $10 \%$ (Figure $4.1 \mathrm{~A}$ ). Concentrations of EPO increased during treatment in both groups, but the increase was initially slightly more pronounced in the $\mathrm{P}$ group (Figure 4.1B). The STfR values increased in both treatment groups to a similar extent (Figure 4.1C). The course of TS was also similar for both treatment groups, with a trend towards a more consistent decrease in the $\mathrm{P}$ group (Figure 4.1D). The reduction in serum ferritin values per total treatment time was the same for both groups (Figure 4.1E). However, the decrease in serum ferritin with increased number of treatment procedures was significant more pronounced for E compared to $P$ (Figure 4.2). With respect to serum hepcidin, levels decreased earlier and to a larger extent in the $P$ group and this decrease was most pronounced around 10 weeks after start of treatment and decreased to $25 \%$ of its initial value. In the $\mathrm{E}$ group the decrease in serum hepcidin was less pronounced, to approximately $50 \%$ of its initial value with a maximum reduction around 20 weeks after onset of therapy (Figure 4.1F).

The mutual Spearman rank correlations of the iron parameters in $\mathrm{E}$ and $\mathrm{P}$ are similar with some differences in the magnitude of the correlation between both diagrams, i.e. that $\mathrm{P}$ had higher correlations of i) $\mathrm{Hb}$ with serum hepcidin, STfR, serum ferritin and TS and of ii) EPO with all iron parameters (Figure 4.3). 

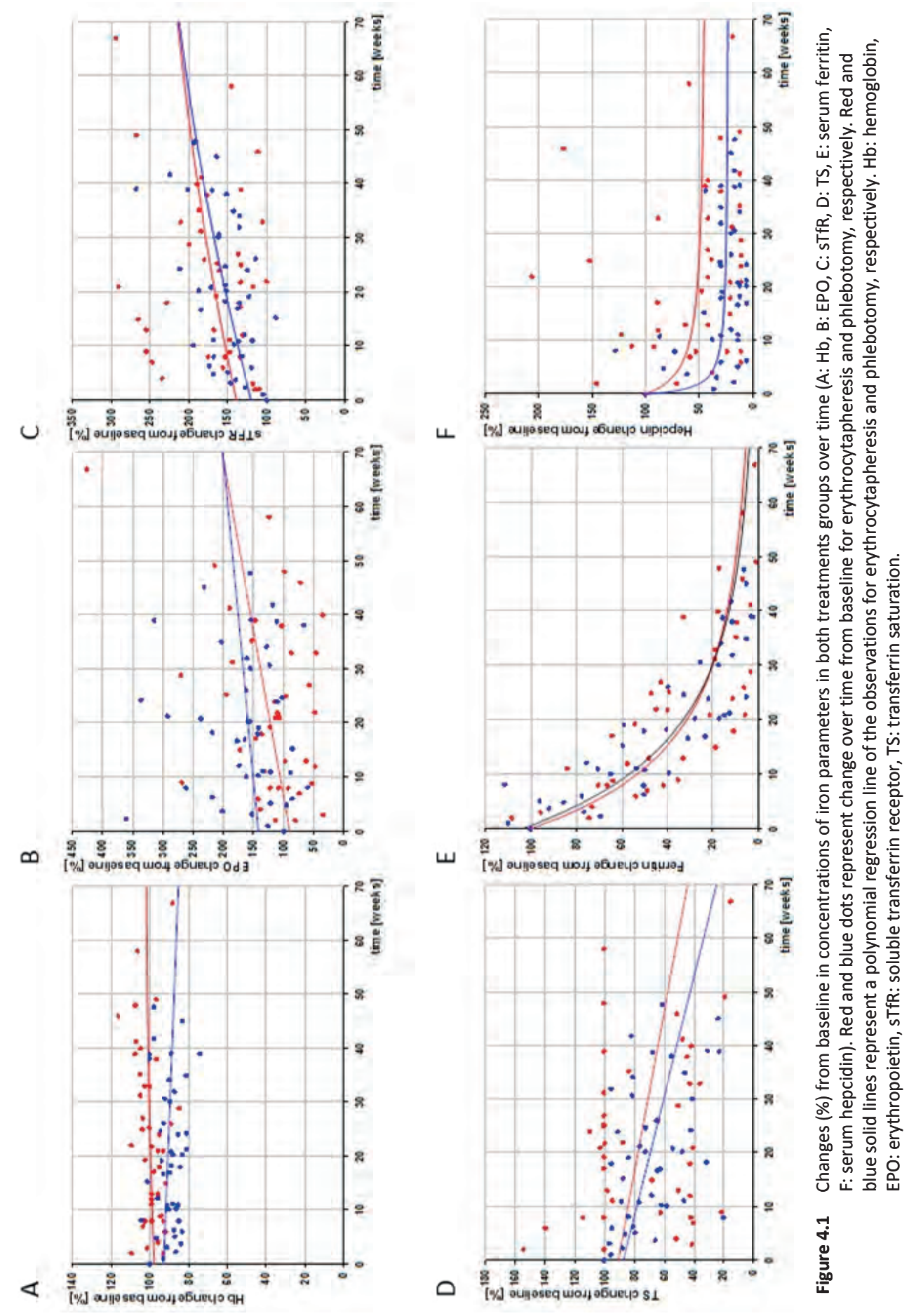


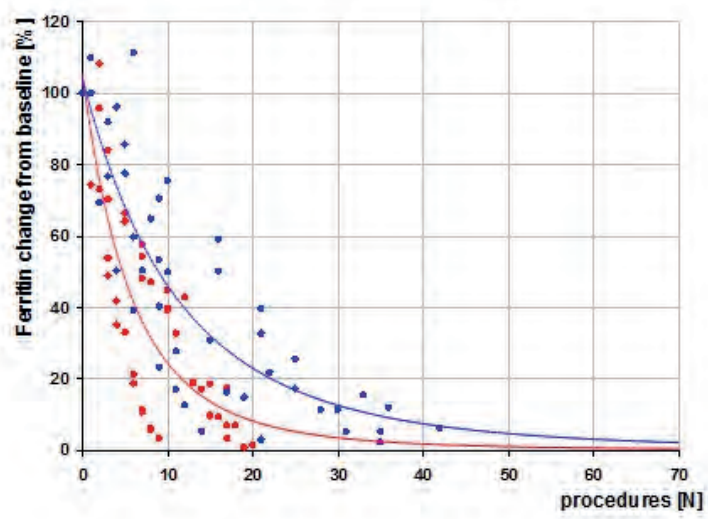

Figure 4.2 Changes (\%) in concentrations of serum ferritin in both treatments groups with increasing number of treatment procedures. Red and blue dots represent observations for erythrocytapheresis and phlebotomy, respectively. Red and blue solid lines represent a polynomial regression line of the observations.
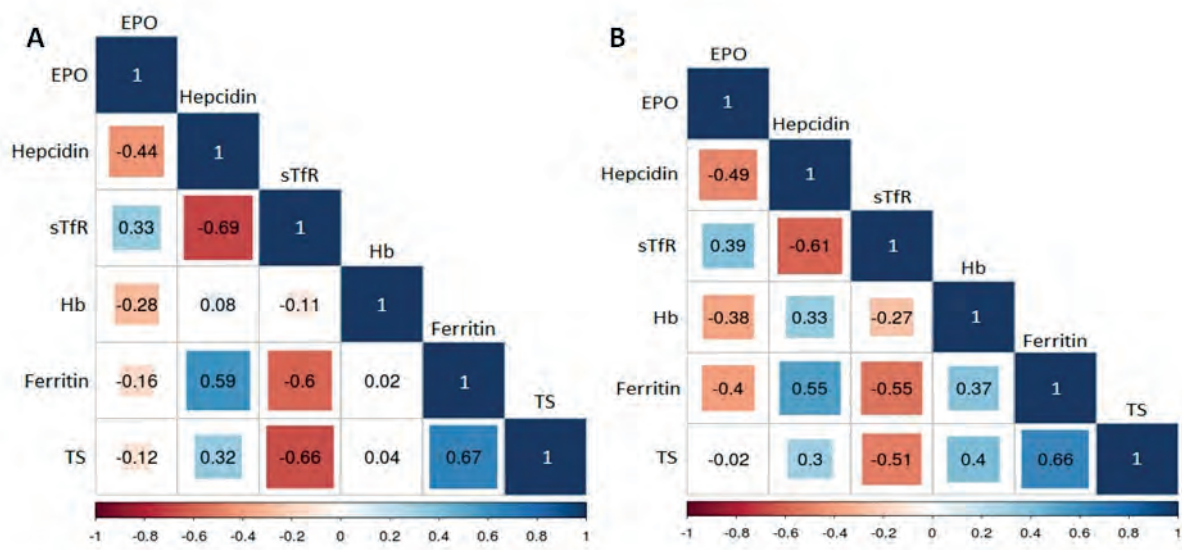

Figure 4.3 Correlation matrices of iron parameters in patients treated by erythrocytapheresis (A) and phlebotomy (B). Spearman rank correlations are given. In red, negative correlation; in blue, positieve correlation. The larger the square the stronger the correlation. Correlations between -0.3 and +0.3 were tested not significant for an $\alpha$ of 0.05 . EPO: erythropoietin, sTfR: soluble transferrin receptor, $\mathrm{Hb}$ : hemoglobin, TS: transferrin saturation. 


\section{Discussion}

In this small retrospective proof of principle observational study we assessed various serum iron parameters during treatment by two different iron withdrawal modalities: $P$ and $E$. Our results point to a similar degree of decrease in serum ferritin and TS over time in both treatment groups with a significant more pronounced decrease in serum ferritin when counted per number of treatment procedures in the E group. During treatment with $\mathrm{P}$ we found a consistent $\pm 10 \%$ decrease in $\mathrm{Hb}$ levels, followed by a decrease in serum hepcidin levels. In patients treated with $\mathrm{E}, \mathrm{Hb}$ levels remained stable over time and the decrease in serum hepcidin concentrations was less pronounced. Analyses to detect dependencies between the different iron parameters showed higher correlations of $\mathrm{Hb}$ with serum hepcidin, STfR, serum ferritin and TS during $P$ therapy.

The above described differences in iron parameters observed during either $\mathrm{P}$ or $\mathrm{E}$ might be due to several factors.

We found a significant more pronounced decrease in serum ferritin when counted per number of treatment procedures in the E group. This might be ascribed to a more personalised approach by use of $E$ with individually determined volume of removed erythrocytes versus standard removed volume of $500 \mathrm{ml}$ of whole blood in the P group.

Our data show that $\mathrm{Hb}$ values in patients treated with $\mathrm{E}$ are stable over time whereas the $\mathrm{Hb}$ levels in the $\mathrm{P}$ group showed a $10 \%$ decrease. First, this difference in response might result from a lower frequency of treatment procedures resulting in an overall prolonged interval between two consecutive $E$ treatments with a longer recovery time and therefore more time allowing for production of new erythrocytes. Secondly, in the E group, the removed volume of erythrocytes was individually determined and dependent on the $\mathrm{Hb}$ values of each individual patient versus a fixed volume of $500 \mathrm{ml}$ whole blood in the $\mathrm{P}$ group. This may indicate that also applying phlebotomy treatments in which blood volumes withdrawn are based on characteristics of individual patients (weight, height and $\mathrm{Hb}$ ) will be worthwhile to investigate. To the best of our knowledge, such approach is not generally used in clinical practice.

Another interesting observation showed that in the $\mathrm{P}$ group when compared with $\mathrm{E}$ increases in EPO levels were initially slightly higher and decreases in serum hepcidin levels were more marked and with earlier response. It is likely that these changes are related to the higher decrease in $\mathrm{Hb}$ in $\mathrm{P}$ when compared with $\mathrm{E}$. These lower $\mathrm{Hb}$ levels and related decreased oxygen delivery will be sensed in the kidneys, inducing EPO production. Recently Kautz et al. ${ }^{33}$ showed an important role for the hormone erythroferrone (ERFE), which is secreted in the circulation after binding of EPO to its receptors on erythroid progenitor cells. ERFE acts directly on hepatocytes to signal for hepcidin suppression in order to increase the iron flow into plasma for new red blood cell synthesis. Indeed hepcidin has been reported to decrease in patients with HFErelated $\mathrm{HH}$ undergoing $\mathrm{P}$ treatment. ${ }^{24,25}$ Apart from the hepcidin suppressive effects of 
(EPO induced) ERFE synthesis, a decrease of hepcidin levels with body iron withdrawal has also been attributed to decrease in circulating iron levels and/or body iron stores. ${ }^{34}$ However, multiple studies support the notion that in case of increased erythropoiesis the erythroid regulator more strongly affects hepcidin synthesis than the iron regulator. ${ }^{35-37}$

Within our study, we observed correlations between $\mathrm{Hb}$ and several iron parameters in the $\mathrm{P}$ group but not in the $\mathrm{E}$ group.

because, measurements after treatment were not performed on a scheduled basis, we cannot fully exclude that due to a difference in frequencies of treatment procedures between both groups and an associated overall more prolonged time interval between the last treatment and blood sampling in E compared with P, increases in EPO and decreases in serum hepcidin in the $E$ group may have been missed.

However, when these results are confirmed in prospective experiments with more frequent sampling, the more gradual and less pronounced decrease of serum hepcidin during $\mathrm{E}$ treatment may be clinically relevant, because significant reduction in serum hepcidin may lead to an exacerbation of the excess release of iron into the circulation, ${ }^{3}$ with an ensuing vicious circle of more frequent treatment procedures of these patients as observed by use of $P$.

Some important limitations of our study have to be acknowledged. First, the sample size is small thereby lacking power for standard statistical analyses with firm conclusion. Second, the interval between the last treatment and blood sampling in E group was more prolonged compared with P. Because, kinetics of changes in iron parameters after red blood cell loss differ, this might have caused observation bias. Third, we cannot exclude that differences between initial and final ferritin values between $E$ and $P$ groups (although not significant) have influenced our results.

Finally, since patients of both $E$ and $P$ group were all male, findings cannot be extrapolated to female patients.

\section{Conclusion}

Our small size retrospective observational study did not confirm our hypothesis that $\mathrm{E}$ treatment may result in a more pronounced decrease of serum hepcidin levels. Therefore, our data are consistent with the notion that compared to $P$, less frequent and more personalized $E$ treatment does not result in excess release of iron in the circulation and the ensuing need for more frequent treatment procedures of these patients. Larger prospective studies in $\mathrm{HH}$ patients with more frequent sampling comparing both treatment modalities are needed to confirm our findings and to gain more insight in the role of serum hepcidin levels in the monitoring of treatment of $\mathrm{HH}$. 


\section{References}

1. Pietrangelo A. Hereditary hemochromatosis: pathogenesis, diagnosis, and treatment. Gastroenterology 2010;139:393-408.

2. Swinkels DW, Janssen MCH, Bergmans J, Marx JJM. Hereditary hemochromatosis: Genetic complexicity and new diagnostic approaches. Clin Chem 2006;52:950-68.

3. Ganz T, Nemeth E. Hepcidin and iron homeostasis. Biochim Biophys Acta 2012;1823:1434-43.

4. Kroot JJC, Tjalsma H, Fleming RE, Swinkels DW. Hepcidin in human iron disorders: diagnostic implications. Clin Chem 2011;57:1650-69.

5. Van Bokhoven MA, van Deursen CThBM, Swinkels DW. Diagnosis and management of hereditary hemochromatosis. BMJ 2011;342:c7251.

6. Adams PC, Barton JC. How I treat hemochromatosis. Blood 2010;116:317-25.

7. Bacon BR, Adams PC, Kowdley KV, Powel LW, Tavill AS. Diagnosis and management of hemochromatosis: 2011 practice guideline by the American association for the study of liver diseases. Hepatology 2011;54:328-43.

8. European Association for the study of the Liver. EASL clinical practice guidelines for HFE hemochromatosis. J Hepatol 2010;53:3-22.

9. Swinkels DW, Jorna AT, Raymakers RA. Synopsis of the Dutch multidisciplinary guideline for the diagnosis and treatment of hereditary haemochromatosis. Neth J Med 2007;65:452-5.

10. Brissot P, Ball S, Rofail D, Cannon H, Wu Jin W. Hereditary hemochromatosis: patient experiences of the disease and phlebotomy treatment: Transfusion 2011;51:1331-8.

11. McDonnel SM, Grindon AJ, Preston BL, Barton JC, Edwards CQ, Adams PC. A survey of phlebotomy among persons with hemochromatosis. Transfusion 1999;39:651-6.

12. Rombout-Sestrienkova $E$, Nieman FHM, Essers $B A B$, van Noord PAH, Janssen $M C H$, van Deursen CThBM, Bos LP, Rombout F, van den Braak R, de Leeuw PW, Koek GH. Erythrocytapheresis versus phlebotomy in the initial treatment of HFE hemochromatosis: results from a randomised trial. Transfusion 2011;52:470-7.

13. Sundic T, Hervig T, Hannisdal S, Assmus J, Ulvik RJ, Olaussen RV, Berentsen S. Erythrocytapheresis compared with whole blood phlebotomy for the treatment of hereditary haemochromatosis. Blood Transfus 2014;12 Suppl 1: s84-9.

14. Conte D, Brunelli L, Bozzani A, Tidone L, Quatrini M, Bianchi PA. Erythrocytapheresis in idiopathic haemochromatosis. Br Med J (Clin Res Ed) 1983;286:939.

15. Zoller WG, Kellner H, Spengel FA. Erythrocytapheresis. A method for rapid extracorporeal elimination of erythrocytes. Results in 65 patients. Klin Wochenschr 1988;66:404-9.

16. Conte D, Mandelli C, Cesana M, Ferrini R, Marconi M, Bianchi A. Effectiveness of erythrocytapheresis in idiopathic hemochromatosis. Report of 14 cases. Int J Artif Organs 1989;12:59-62.

17. Kellner H, Zoller WG. Repeated isovolemic large-volume erythrocytapheresis in the treatment of idiopathic hemochromatosis. Z Gastroenterol 1992;30:779-83.

18. Kohan A, Niborski R, Daruich J, Rey J, Bastos F, Amerise G, Herrera R, Garcia M, Olivera W, Santarelli MT, Avalos JS, Findor J. Erythrocytapheresis with recombinant human erythropoietin in hereditary hemochromatosis therapy: a new alternative. Vox Sang 2000;79:40-5.

19. Muncunill J, Vaquer P, Galmes A, Obrador A, Parera M, Barqay J, Besalduch J. In hereditary hemochromatosis, red cell apheresis removes excess iron twice as fast as manual whole blood phlebotomy. J Clin Apher 2002;17:88-92.

20. Mariani R, Pelucchi S, Perseghin P, Corengia C, Piperno A. Erythrocytapheresis plus erythropoietin: an alternative therapy for selected patients with hemochromatosis and severe organ damage. Haematologica 2005;90:717-8.

21. Fernandez-Mosteirin N, Salvador-Osuna C, Garcia-Erce JA, Orna E, Perez-Lungmus G, Giralt M. Comparison between phlebotomy and erythrocytapheresis of iron overload in patients with HFE gene mutations. Med Clin. (Barc) 2006;127:409-12.

22. Rombout-Sestrienkova E, van Noord PA, van Deursen CT, Sybesma BJ, Nillesen-Meertens AE, Koek GH. Therapeutic erythrocytapheresis versus phlebotomy in the initial treatment of hereditary hemochromatosis - A pilot study. Transfus Apher Sci 2007;36:261-7. 
23. Wijermans $P$, van Egmond L, Ypma P, Kerkhoffs JL, Schipperus M, Bohmer L, Agteresch E. Isovolemic erythrocytapheresis technique as an alternative to conventional phlebotomy in patients with polycythemia rubra vera and hemochromatosis. Transfus Apher Sci 2009;40:137.

24. Van Dijk BA, Laarakkers CM, Klaver SM, Jacobs EM, van Tits L, Janssen MC, Swinkels DW. Serum hepcidin levels are innately low in HFE- related haemochromatosis but differ between C282Yhomozygotes with elevated and normal ferritin levels. Br J Haematol 2008;142:979-85.

25. Girelli D, Trombini P, Bust F, Campostrini N, Sandri M, Pelucchi S, Westerman M, Ganz T, Nemeth E, Piperno A, Camaschella C. A time course of hepcidine response to iron challenge in patients with HFE and TFR2 hemochromatosis. Haematologica 2011;94:500-6.

26. Barton JC. Optimal management strategies for chronic iron overload. Drugs 2007;67:685-700.

27. AABB Technical Manual $10^{\text {th }}$ edtion; $\mathrm{p} 651$.

28. Gambino $\mathrm{R}$, Desvarieux $\mathrm{E}$, Orth $\mathrm{M}$ et al. The relation between chemically measured total iron binding capacity concentrations and immunologically measured transferrin concentrations in human serum. Clin Chem 1997;43:2408-12.

29. Kroot JJC, Laarakkers CMM, Geurts-Moespot AJG, Grebenchtchikov N, Pickkers P, van Ede AE, Peters HPE, van Dongen-Lases E, Wetzels JFM, Sweep FCGJ, Tjalsma H, Swinkels DW. Immunochemical and mass-spectrometry-based serum hepcidine assays for iron metabolism disorders. Clin Chem. 2010;56:10;1570-9.

30. Swinkels DW, Girelli D, Laarakkers C, Kroot J, Campostrini N, Kemna EH, Tjalsma H. Advances in quantitative hepcidin measurements by time-of-flight mass spectrometry. PLoS One 2008;3:e2706.

31. Galesloot TE, Vermeulen SH, Geurts-Moespot AJ, Klaver SM, Kroot JJC, van Tienoven D, Wetzels JFM, Kiemeney LALM, Sweep FC, den Heijer M, Swinkels DW. Serum hepcidin: reference ranges and biochemical correlates in the general population. Blood 2011;117:e218-25.

32. www.hepcidinanalysis.com. Accessed January $29^{\text {th }}, 2015$.

33. Kautz L, Nemeth E. Moleculair liasions between erythropoiesis and iron metabolism. Blood 2014; 124:479-82.

34. Mast AE, Foster TM, Pinder HL, Beczkiewicz CA, Bellisimo DB, Murphy AT, Kovacevic S, Wroblewski VJ, Witcher DR. Behavioral, biochemical and genetic analysis of iron metabolism in high-intensity blood donors. Transfusion 2008;48:2197-204.

35. Mast AE, Schlumpf KS, Wright DJ, Johnson B, Glynn SA, Bush MP, Olbina G, Westerman M, Nemeth E, Ganz T. Hepcidin level predicts haemoglobin concentration in individuals undergoing repeated phlebotomy. Haematologica 2013;98:1324-30.

36. Kemna EH, Kartikasari AE, van Tits L, Pickkers $P$, Tjalsma H, Swinkels DW. Regulation of hepcidin: insights from biochemical analyses on human serum samples. Blood Cells Mol Dis 2008;40:339-46.

37. Huang $\mathrm{H}$, Constante M, Layoun A, Santos MM. Contribution of STAT3 and SMAD4 pathways to the regulation of hepcidin by opposing stimuli. Blood 2009;113:3593-9. 


\section{Supplemental material}

Table S4.1 Descriptives of selected samples during erythrocytapheresis treatment of 6 iron overloaded HFE p.Cys282Tyr homozygous patients.

\begin{tabular}{|c|c|c|c|c|c|c|c|c|c|c|}
\hline ID & $\begin{array}{l}\text { Sample } \\
\text { number }\end{array}$ & $\begin{array}{l}\text { Treatment } \\
\text { phase }^{a}\end{array}$ & $\begin{array}{l}\text { Number of } \\
\text { erythrocytapheresis }\end{array}$ & $\begin{array}{l}\text { Number of weeks } \\
\text { after last } \\
\text { erythrocytapheresis }\end{array}$ & $\begin{array}{c}\mathrm{Hb} \\
(\mathrm{mmol} / \mathrm{I})\end{array}$ & $\begin{array}{l}\text { EPO } \\
(U / I)\end{array}$ & $\begin{array}{l}\text { sTfR } \\
(\mathrm{mg} / \mathrm{l})\end{array}$ & $\begin{array}{l}\text { TS } \\
(\%)\end{array}$ & $\begin{array}{l}\text { Ferritin } \\
(\mu \mathrm{g} /)\end{array}$ & $\begin{array}{l}\text { Hepcidin } \\
\text { (nmol/l) }\end{array}$ \\
\hline 1 & 1 & $\mathrm{~S}$ & n.a. & n.a. & 8.7 & 9.3 & 0.76 & 100 & 7925 & 4.2 \\
\hline 1 & 2 & D & 3 & 3 & 8.9 & 11.3 & 1.16 & 100 & 5565 & 1.0 \\
\hline 1 & 3 & D & 7 & 2 & 8.9 & 11.3 & 1.25 & 100 & 4289 & 2.0 \\
\hline 1 & 4 & $\mathrm{D}$ & 10 & 2 & 8.7 & 18.0 & 1.24 & 100 & 3099 & 1.6 \\
\hline 1 & 5 & D & 13 & 2 & 9.1 & 17.1 & 1.40 & 100 & 1485 & 0.8 \\
\hline 1 & 6 & D & 15 & 2 & 9.1 & 14.0 & 1.42 & 83 & 767 & $<0.5^{c}$ \\
\hline 1 & 7 & D & 17 & 4 & 9.3 & 17.5 & 1.39 & 47 & 257 & $<0.5^{c}$ \\
\hline 1 & 8 & $E$ & 19 & 3 & 8.4 & 19.8 & $2.03^{b}$ & 19 & 61 & $<0.5^{c}$ \\
\hline 2 & 1 & D & 1 & 2 & 8.7 & 16.4 & 1.03 & 100 & 1069 & 1.7 \\
\hline 2 & 2 & D & 2 & 2 & 9.5 & 18.5 & 1.18 & 100 & 1157 & 1.2 \\
\hline 2 & 3 & D & 5 & 2 & 8.6 & 15.1 & 1.38 & 42 & 709 & 0.9 \\
\hline 2 & 4 & $D$ & 7 & 2 & 8.6 & 7.8 & 1.34 & 42 & 614 & 1.5 \\
\hline 2 & 5 & D & 10 & 4 & 9.5 & 7.9 & 1.03 & 87 & 479 & 3.5 \\
\hline 2 & 6 & $D$ & 13 & 2 & 8.9 & 14.2 & 1.08 & 36 & 202 & 1.5 \\
\hline 2 & 7 & D & 16 & 2 & 8.4 & 16.9 & $1.81^{b}$ & 44 & 100 & $<0.5^{c}$ \\
\hline 2 & 8 & $E$ & 18 & 6 & 10.1 & 11.7 & 1.14 & 51 & 74 & 3.0 \\
\hline 3 & 1 & $S$ & n.a. & n.a. & 8.3 & 13.3 & 0.83 & 100 & 3849 & 2.7 \\
\hline 3 & 2 & $D$ & 3 & 2 & 8.2 & 17.5 & 1.22 & 95 & 3232 & 3.3 \\
\hline 3 & 3 & D & 5 & 2 & 8.1 & 19.2 & 1.11 & 100 & 2470 & 2.4 \\
\hline 3 & 4 & D & 8 & 3 & 8.6 & 12.8 & 1.10 & 100 & 1809 & 4.1 \\
\hline 3 & 5 & D & 11 & 4 & 8.9 & 19.4 & 1.10 & 100 & 1260 & 1.2 \\
\hline 3 & 6 & D & 14 & 3 & 8.9 & 13.1 & 1.59 & 100 & 656 & 0.8 \\
\hline 3 & 7 & D & 17 & 4 & 8.8 & 16.4 & 1.20 & 100 & 268 & 1.6 \\
\hline 3 & 8 & $E$ & 20 & 4 & 7.3 & 56.5 & $2.44^{\mathrm{b}}$ & 15 & 50 & $<0.5^{c}$ \\
\hline 4 & 1 & $S$ & n.a. & n.a. & 9.3 & 8.3 & $0.68^{b}$ & 100 & 925 & 2.4 \\
\hline 4 & 2 & D & 2 & 2 & 8.9 & 11.4 & 1.59 & 51 & 675 & 0.9 \\
\hline 4 & 3 & $D$ & 3 & 3 & 9.6 & 6.1 & 1.68 & 40 & 451 & 1.4 \\
\hline 4 & 4 & D & 4 & 2 & 8.7 & 22.2 & 1.73 & 21 & 324 & 2.7 \\
\hline 4 & 5 & D & 5 & 4 & 9.2 & 8.1 & 1.73 & 50 & 304 & 1.5 \\
\hline 4 & 6 & D & 6 & 2 & 8.5 & 14.2 & $1.80^{b}$ & 68 & 172 & $<0.5^{c}$ \\
\hline 4 & 7 & D & 7 & 3 & 8.8 & 11.2 & 1.55 & 42 & 99 & $<0.5^{c}$ \\
\hline 4 & 8 & $E$ & 8 & 3 & 8.9 & 8.8 & $1.97^{b}$ & 41 & 53 & $<0.5^{c}$ \\
\hline 5 & 1 & D & 1 & 2 & 9.0 & 43.2 & 1.00 & 100 & 1072 & 1.2 \\
\hline 5 & 2 & D & 2 & 3 & 9.1 & 15.0 & 1.17 & 41 & 1025 & 13.3 \\
\hline 5 & 3 & D & 5 & 2 & 8.5 & 22.8 & 1.47 & 62 & 685 & 1.1 \\
\hline 5 & 4 & D & 7 & 2 & 8.6 & 26.9 & 1.67 & 98 & 515 & $<0.5^{c}$ \\
\hline 5 & 5 & $D$ & 10 & 2 & 8.9 & 47.3 & 1.33 & 99 & 426 & $<0.5^{c}$ \\
\hline 5 & 6 & D & 12 & 3 & 9.3 & 24.9 & 1.36 & 100 & 459 & $<0.5^{c}$ \\
\hline 5 & 7 & D & 15 & 2 & 9.0 & 19.9 & $2.10^{b}$ & 43 & 198 & $<0.5^{c}$ \\
\hline 5 & 8 & $E$ & 17 & 1 & 9.4 & 15.0 & $1.89^{b}$ & 42 & 187 & $<0.5^{c}$ \\
\hline 6 & 1 & $S$ & n.a. & n.a. & 9.7 & 16.7 & 1.42 & 41 & 2213 & 4.6 \\
\hline 6 & 2 & $D$ & 1 & 2 & 9.0 & 13.4 & 1.55 & 63 & 1642 & 6.7 \\
\hline 6 & 3 & D & 3 & 2 & 8.9 & 23.5 & $2.21^{b}$ & 57 & 1190 & $<0.5^{c}$ \\
\hline 6 & 4 & D & 4 & 2 & 9.0 & 18.0 & $2.48^{b}$ & 47 & 922 & $<0.5^{c}$ \\
\hline 6 & 5 & D & 6 & 3 & 9.0 & 18.8 & 1.66 & 42 & 470 & $<0.5^{c}$ \\
\hline 6 & 6 & D & 7 & 3 & 9.2 & 19.0 & $2.27^{b}$ & 45 & 248 & $<0.5^{c}$ \\
\hline 6 & 7 & D & 8 & 2 & 8.6 & 26.8 & $2.55^{b}$ & 26 & 136 & $<0.5^{c}$ \\
\hline 6 & 8 & $\mathrm{E}$ & 9 & 2 & 8.2 & 44.9 & $2.83^{b}$ & 21 & 72 & $<0.5^{c}$ \\
\hline
\end{tabular}

During erythrocytapheresis $400-800 \mathrm{ml}$ of erythrocytes was withdrawn. $\mathrm{Hb}$ : hemoglobin ( $1 \mathrm{mmol} / \mathrm{l}=1.61 \mathrm{~g} / \mathrm{dl})$, EPO: erythropoietin, sTfR: soluble transferrin receptor, TS: transferrin saturation, ${ }^{a} \mathrm{~S}$ : before start treatment, D: depletion phase, E: last treatment of depletion phase, ${ }^{\mathrm{b}}$ value below or above reference range, sTfR reference range: $0.76-1.76 \mathrm{mg} / \mathrm{l}$, ${ }^{\mathrm{C}}$ below lower limit of detection of $0.5 \mathrm{nM}$ of the hepcidin assay used, $\mathrm{n} . \mathrm{a} . \mathrm{n}$ not applicable 
Table S4.2 Descriptives of selected samples during phlebotomy treatment of 6 iron overloaded HFE p.Cys282Tyr homozygous patients.

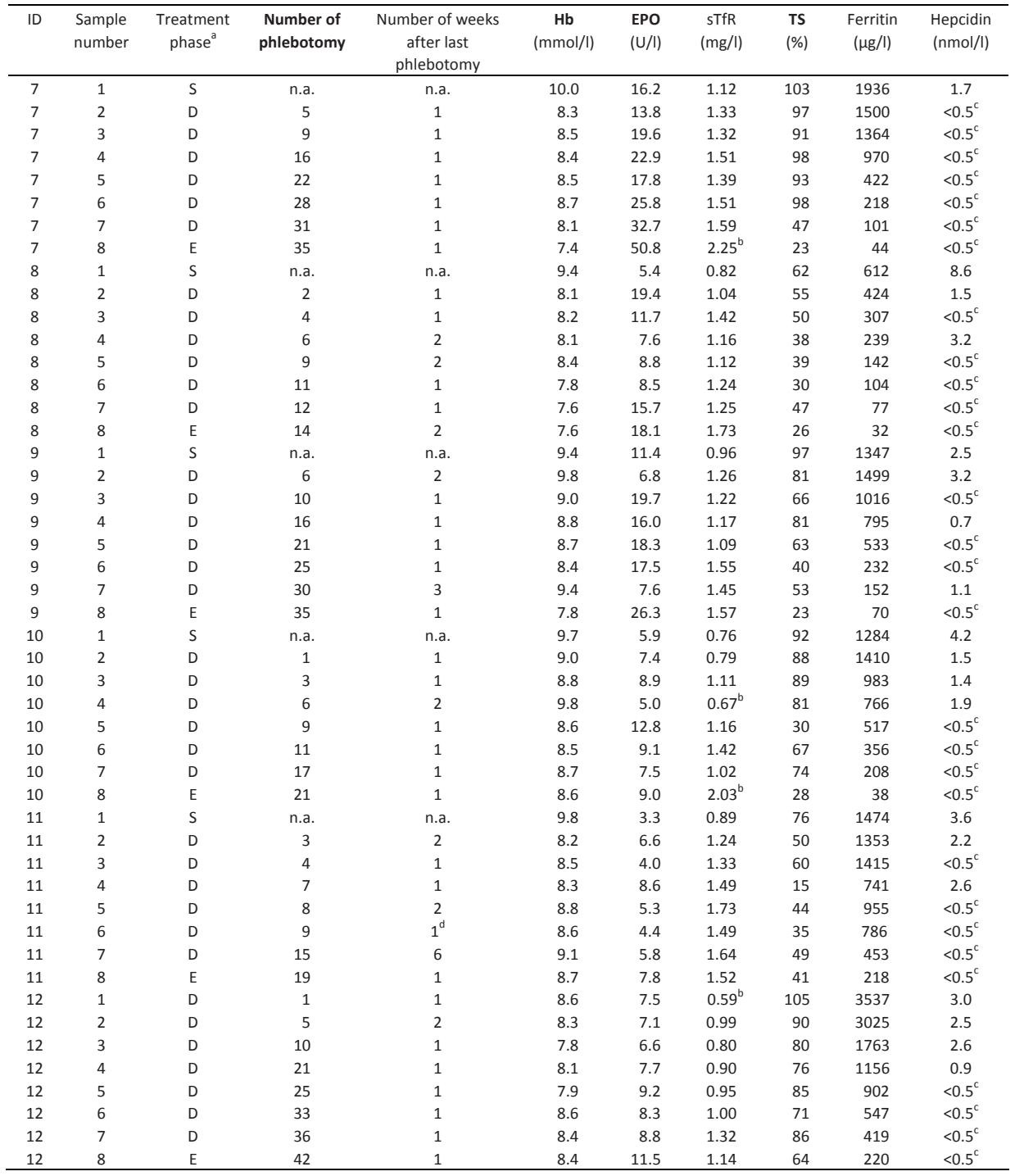

During a standard phlebotomy $500 \mathrm{ml}$ of whole blood was withdrawn. $\mathrm{Hb}$ : hemoglobin (1 $\mathrm{mmol} / \mathrm{l}=1.61 \mathrm{~g} / \mathrm{dl})$, EPO: erythropoietin, sTfR: soluble transferrin receptor, TS: transferrin saturation, ${ }^{a} \mathrm{~S}$ : before start of depletion phase, D: depletion phase, E: last treatment of depletion phase, ${ }^{b}$ value below or above reference range, sTfR reference range: $0.76-1.76 \mathrm{mg} / \mathrm{l}$, ${ }^{\mathrm{c}}$ below lower limit of detection limit of $0.5 \mathrm{nM}$ of the hepcidin assay used, ${ }^{d}$ previous phlebotomy only $250 \mathrm{ml}$, n.a.: not applicable 



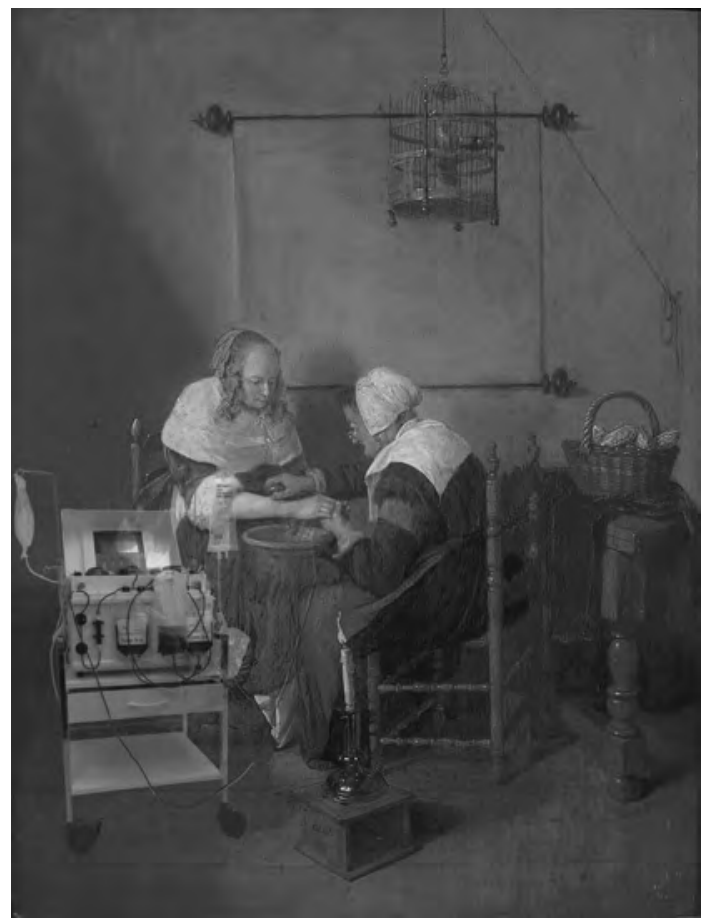

Chapter 5

Predicting the number of treatments in naïve hereditary hemochromatosis patients treated by phlebotomy or erythrocytapheresis

Eva Rombout-Sestrienkova, Bjorn Winkens, Marian van Kraaij, Cees Th.B.M van Deursen, Mirian C.H. Janssen, Alexander M.J. Rennings, Dorothea Evers, Jean-Louis Kerkhoffs, Ad Masclee, Ger H Koek 


\section{Abstract}

\section{Background and aims}

Standard treatment for newly diagnosed patients with hereditary hemochromatosis $(\mathrm{HH})$ and iron overload consists of phlebotomy or more personalized erythrocytapheresis. Erythrocytapheresis is more efficient, but infrequently used because of costs and specialized collection equipment. The main aim of our study was to develop a mathematical model that predicts the number of treatment procedures needed for the initial treatment, by either using phlebotomy or erythrocytapheresis and helps physicians to select the most effective treatment modality for the individual patient.

\section{Methods}

A retrospective data analysis of 97 newly diagnosed $\mathrm{HH}$ patients (C282Y homozygous), treated between 2002 and 2013 either with phlebotomy $(N=54)$ or erythrocytapheresis $(N=43)$ until serum ferritin (SF) reached levels $\leq 100 \mu \mathrm{g} / \mathrm{l}$. To check which predictors were significantly related to the number of treatment procedures, multiple linear regression analysis was used for each treatment method separately.

\section{Results}

Regarding erythrocytapheresis, initial SF, initial hemoglobin $(\mathrm{Hb})$, and body weight were the best practical predictors, while for phlebotomy these were initial SF and body weight. The established formulas for the number of treatment procedures were:

$X=28.6+(0.004 \times$ initial SF $)-(1.82 \times$ initial $\mathrm{Hb})-(0.08 \times$ body weight $)$ with $R^{2}$ of 0.70 and VMSPE of 3.7 for erythrocytapheresis and

$X=21.4+\left(0.011 \times\right.$ initial SF) $-(0.17 \times$ body weight $)$ with $R^{2}$ of 0.69 and VMSPE of 7.9 for phlebotomy.

\section{Conclusions}

The developed formulas provide an estimation of the number of treatment procedures, helping physicians and patients in choosing the most effective treatment method. Prospective studies are needed to confirm the validity of these formulas. 


\section{Introduction}

Hereditary hemochromatosis $(\mathrm{HH})$ is the most prevalent inherited metabolic disorder. It is characterized by an increased iron absorption that is inappropriate to body iron stores resulting in progressive accumulation of tissue iron, especially in the liver, heart, pancreas, joints, skin and gonads. ${ }^{1}$

Therapy is based on the removal of excesses of body iron. Serum ferritin (SF) levels are used not only as a marker for the total amount of iron overload, but also serve to monitor the effectiveness of treatment. To date, standard treatment involves phlebotomy, which, in the initial phase, is generally performed on a weekly basis, with removal of 450-500 $\mathrm{ml}$ whole blood per procedure until SF levels are reduced to target level. Up till 2011, this target level was $<50 \mu \mathrm{g} / \mathrm{I}^{2-4}$ Updated guidelines, now advise to aim for SF levels between 50 and $100 \mu \mathrm{g} / \mathrm{l} .{ }^{5,6}$ Hereafter, during the maintenance treatment phase, the frequency of phlebotomies will decrease to around 2 to 6 procedures per year. Although phlebotomy appears to be very effective, side effects are common and include fatigue, fainting, pain at the venous access site, hematomas, and anemia. Negative experiences related to treatment have been reported by $52 \%$ of $\mathrm{HH}$ patients during the initial phase of treatment and $37 \%$ during the maintenance phase, while $16 \%$ of patients considered discontinuing phlebotomy in case alternative options would be available. ${ }^{7-8}$

Erythrocytapheresis, a technique in which an apheresis machine selectively removes erythrocytes while returning leucocytes, platelets and plasma to the patient, forms a good alternative for phlebotomy. With erythrocytapheresis, up to $1000 \mathrm{ml}$ of red blood cells (RBCs) per single procedure can be removed compared to 200 to $250 \mathrm{ml}$ RBCs per phlebotomy procedure. The volume of RBCs removed is determined individually and based on total blood volume (TBV) and actual hematocrit (Hct) values of each patient. The American Association for Apheresis (ASFA) guidelines recommend the use of erythrocytapheresis as a first-line therapy for $\mathrm{HH}^{9}{ }^{9}$ Results from two randomized ${ }^{10-11}$ and several non-randomized studies ${ }^{12-24}$ indicate that, compared to phlebotomy, erythrocytapheresis is a more effective method, removing at least twice as much iron per single procedure. Additional benefits are the possibility for substitution of the removed volume resulting in fewer hemodynamic changes compared to phlebotomy, as well as the preservation of valuable blood components such as plasma proteins, platelets, and white blood cells. This approach is particularly well suited for cardiovascular compromised patients and patients with liver cirrhosis, hypoproteinemia and/or thrombocytopenia. Especially for patients with higher body weight (>75 kg), and a larger TBV, as well as high initial Hct values and thus a high achievable $\Delta$ Hct, erythrocytapheresis appears to be much more efficient compared to phlebotomy. ${ }^{10,23}$

One of the most frequently mentioned obstacles for the use of erythrocytapheresis in daily practice, are the costs per single procedure. Concerning the Dutch situation, the costs per single erythrocytapheresis procedure are 3.5 higher compared to a single 
phlebotomy procedure. ${ }^{10}$ However, due to a considerable reduction in the total number of needed treatment procedures, travelling costs, and costs related to absence of work, erythrocytapheresis was demonstrated to be cost-effective. ${ }^{10}$ It should be taken into account however that procedure costs may vary considerably among countries.

Being able to reliably predict the needed numbers of procedures prior to start of treatment, would be of great benefit in selecting either phlebotomy or erythrocytapheresis as the treatment modality that best fits the individual patient. Moreover, this will on forehand provide insights in expected treatment-related costs, which will be of great value for insurance companies.

The aim of this study therefore was to develop a clinically relevant prediction model that estimates the needed number of procedures when using either phlebotomy or erythrocytapheresis for the initial treatment of newly diagnosed $\mathrm{HH}$ patients thereby aiming to decrease SF value to target levels $\leq 100 \mu \mathrm{g} / \mathrm{l}$.

\section{Materials and methods}

\section{Study participants}

We retrospectively analysed data of 97 newly diagnosed patients with $\mathrm{HH}$ and increased SF levels, who all were homozygous for C282Y and were treated by either phlebotomy $(\mathrm{N}=54)$ or erythrocytapheresis $(\mathrm{N}=43)$ between 2002 and 2013, until SF became $\leq 100 \mu \mathrm{g} / \mathrm{l} .38$ of these patients (19 treated with phlebotomy and 19 with erythrocytapheresis) were participants of the earlier published randomized controlled trial (RCT, ClinicalTrials.gov. Identifier NCT00202436) ${ }^{10}$ and another 59 patients (35 treated with phlebotomy and 24 treated with erythrocytapheresis) were treated in four other medical centers (Zuyderland Medical Center Heerlen, HAGA Teaching Hospital The Hague, Radboud University Medical Center Nijmegen, Leiden University Medical Center Leiden, and Sanquin Blood Bank Maastricht) in the period shortly before (2002-2004) and after (2009-2014) the execution of our RCT. All patients were treated conform Dutch guidelines. ${ }^{6}$

\section{Treatments methods}

For phlebotomy, initial treatment procedures were applied once weekly. During each procedure $500 \mathrm{ml}$ whole blood was removed.

Erythrocytapheresis procedures were applied once every two to four weeks, during every procedure $350-800 \mathrm{ml}$ of erythrocytes were withdrawn, depending on the estimated TBV (which is based on sex, body weight, and height), and Hct of the patient. Minimal targeted post-procedure Hct was set at $30 \%$. Erythrocytapheresis procedures were carried out using an erythrocytapheresis collection device 944 and 
$\mathrm{MCS}^{+}$equipment (Haemonetics Corporation, Braintree, Massachusetts, USA) or flow automatic centrifugal cell separator Cobe Spectra (Caridian BCT, Lakewood, Co).

\section{Monitoring of treatment}

Prior to each treatment procedure, $\mathrm{Hb}$, Hct, mean corpuscular volume (MCV), SF, serum iron, and transferrin saturation (TS), were measured.

\section{Laboratory measurements}

Hematologic characteristics were assessed using routine methods. SF was measured by a luminescent immunoassay with a reference range of $15-400 \mu \mathrm{g} / \mathrm{l}$ for males and of $10-200 \mu \mathrm{g} / \mathrm{l}$ for females.

All authors had access to the study data and reviewed and approved the final manuscript.

\section{Statistical analysis}

\section{Data analysis}

Numerical variables were presented by mean $( \pm S D)$ or median (interquartile range $(\mathrm{IQR})$ ), i.e. $25^{\text {th }}(\mathrm{P} 25)-75^{\text {th }}$ percentile (P75)), and categorical variables by numbers (\%). Differences between treatment methods (erythrocytapheresis/phlebotomy) were assessed using an independent-samples t-test for numerical variables, and a chi-square test or Fisher's exact test, (whenever appropriate) for categorical variables. To assess which predictors (such as: initial SF, initial $\mathrm{Hb}$ count, and TBV) were significantly related to the outcome, i.e. number of treatment procedures, multiple linear regression analysis was used for each treatment method separately. As sensitivity analysis, we also checked whether body mass index (BMI) instead of TBV (both based on body weight and height), or only body weight instead of TBV were predictors for number of treatment procedures.

A $p$-value $\leq 0.05$ was considered statistically significant. All analyses were performed using computer software (IBM SPSS Statistics for Windows, Version 22.0, IBM Corp, Armonk, NY).

\section{Prediction models}

The main outcome of the study was to develop a reliable model that predicts the needed numbers of procedures during the initial treatment of $\mathrm{HH}$ thereby aiming to reach target SF levels $\leq 100 \mu \mathrm{g} / \mathrm{l}$. The erythrocytapheresis model was applicable to procedures performed once in two-four weeks and the phlebotomy model to standard depletion of $500 \mathrm{ml}$ whole blood once weekly. Overall prediction quality of the model 
was expressed in R-square (closer to 1 is higher quality) as well as in square root of the mean squared prediction error (VMSPE; closer to 0 is higher quality).

\section{Results}

\section{Patient characteristics}

Baseline patient characteristics are summarized in Table 5.1. No significant differences between the two treatment groups were observed except for lower initial mean $\mathrm{Hb}$ count in the erythrocytapheresis group.

Table 5.1 Baseline and end of treatment characteristics of both treatment groups.

\begin{tabular}{lccc}
\hline Parameter/Method & $\begin{array}{c}\text { Erythrocytapheresis } \\
(\mathrm{N}=43)\end{array}$ & $\begin{array}{c}\text { Phlebotomy } \\
(\mathrm{N}=54)\end{array}$ & P value \\
\hline Age (years) & $54(11)$ & $53(12)$ & 0.53 \\
Male (N (\%)) & $32(74.4)$ & $44(81.5)$ & 0.40 \\
Height (cm) & $176(10)$ & $177(9)^{\mathrm{a}}$ & 0.48 \\
Weight (kg) & $81(15)$ & $84(15)^{\mathrm{a}}$ & 0.32 \\
BMI & $26.2(3.1)$ & $26.9(4.7)^{\mathrm{a}}$ & 0.38 \\
Estimated TBV (ml) $^{\text {Initial Serum Ferritin }}{ }^{\mathrm{b}}$ & $5107(855)$ & $5301(762)^{\mathrm{a}}$ & 0.24 \\
Final Serum Ferritin $^{\mathrm{b}}$ & $1207(800-1956)$ & $1174(727-1766)$ & $0.87^{\mathrm{c}}$ \\
Initial Hemoglobin $^{\mathrm{a}}$ & $48(41-62)$ & $49(43-80)$ & $0.21^{\mathrm{c}}$ \\
Final Hemoglobin $_{\text {Number of treatment procedures }}$ & $9.2(0.8)$ & $9.6(0.8)^{\mathrm{d}}$ & 0.02 \\
\hline
\end{tabular}

Presented data are means (SD), unless otherwise stated. ${ }^{a} 1$ missing value; ${ }^{b}$ Median (IQR); ${ }^{c}$ Mann-Whitney test; ${ }^{d} 2$ missing values; ${ }^{2} 3$ missing values. Reference ranges: serum ferritin: $30-400 \mu \mathrm{g} / \mathrm{l}$ (males) and 10-200 $\mu \mathrm{g} / \mathrm{l}$ (females); hemoglobin: 8.2-11.0 mmol/l (males) and 7.3-9.7 mmol/l (females), $1 \mathrm{mmol} / \mathrm{l}=$ $1.61 \mathrm{~g} / \mathrm{dl}, 1 \mathrm{~g} / \mathrm{dl}=0.6206 \mathrm{mmol} / \mathrm{l}, \mathrm{IQR}=$ interquartile range

\section{Treatment results and predictors}

The mean number of treatment procedures needed to reach a targeted SF value $\leq 100 \mu \mathrm{g} / \mathrm{l}$ was significantly lower in patients treated with erythrocytapheresis $(12 \pm 6)$

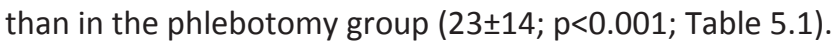

In Table 5.2 three different linear regression models are presented separately for each treatment method. The most significant predictor for the total number of treatment procedures for both treatment methods was the initial SF value $(p<0.001)$.

For erythrocytapheresis, initial $\mathrm{Hb}$ count was significantly related to the number of treatment procedures, irrespective of whether TBV, BMI, or body weight was included in the model ( $p=0.004,0.009,0.028$ respectively). For phlebotomy, initial $\mathrm{Hb}$ count did not contribute significantly to the presented models $(p=0.687,0.705,0.767$ respectively), and also did not influence the prediction quality of the model. Therefore, the initial $\mathrm{Hb}$ count was removed from the phlebotomy models. 


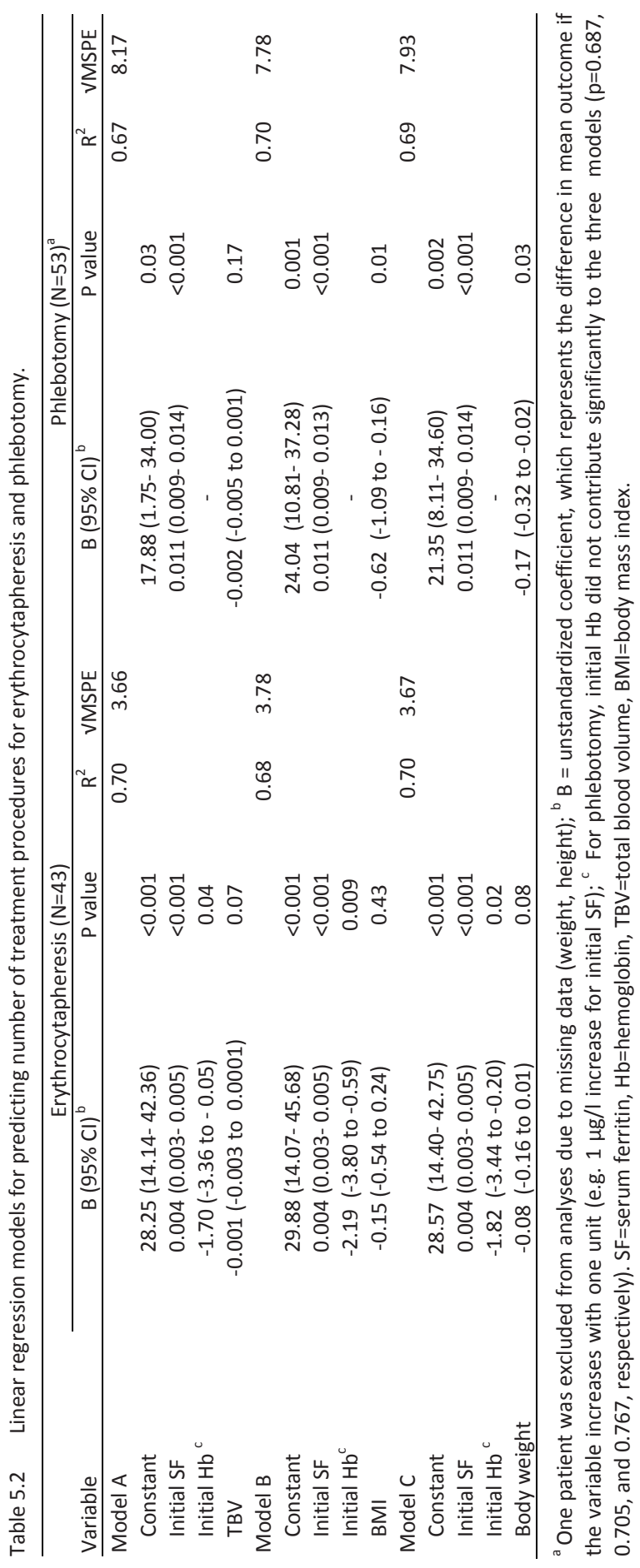


For erythrocytapheresis, neither TBV, nor BMI, nor body weight were significantly associated to total number of procedures, with similar prediction qualities of the various models $\left(R^{2}=0.70,0.68,0.70 ; \mathrm{VMSPE}=3.7,3.8,3.7\right.$, respectively). For phlebotomy, BMI and body weight, but not TBV, were significantly associated to the number of treatment procedures $(p=0.010,0.028$, and 0.171 , respectively). However, the prediction quality did not differ much between the three models $\left(R^{2}=0.70,0.69\right.$, 0.67; VMSPE=7.8, 7.9, 8.2, respectively).

Since the prediction quality was similar for the three models and body weight is the most often and easily available parameter in daily clinical practice, the final prediction formulas (presented in Table 5.3) use values of initial SF and body weight for both treatment methods, with the addition of initial $\mathrm{Hb}$ count for erythrocytapheresis method.

Table 5.3 Prediction rule for estimated number of treatment procedures for erythrocytapheresis method $\left(R^{2}=0.70 ; \mathrm{VMSPE}=3.7\right)$ and phlebotomy method $\left(R^{2}=0.69\right.$, VMSPE $\left.=7.9\right)$.

Erythrocytapheresis

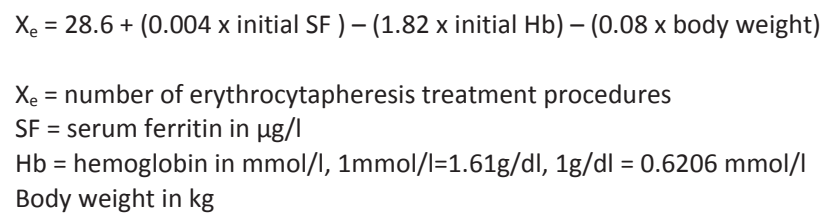

Presented formulas showed better accuracy for the erythrocytapheresis prediction model compared to phlebotomy $\left(R^{2}=0.70\right.$, VMSPE 3.7 for erythrocytapheresis versus $R^{2}=0.69$, VMSPE 7.9 for phlebotomy, respectively). This higher accuracy of the erythrocytapheresis prediction model was also reflected by plotting the predicted number of treatment procedures (based on model C) against the observed number of treatment procedures for erythrocytapheresis (Figure 5.1) and phlebotomy (Figure 5.2).

Estimated numbers of treatment procedures calculated according to the established models are presented in Table 5.4. In line with our expectations and earlier published data, erythrocytapheresis appears to be much more efficient for all patients, but especially for patients with higher body weight, as well as high initial Hb values ${ }^{10,23}$. 


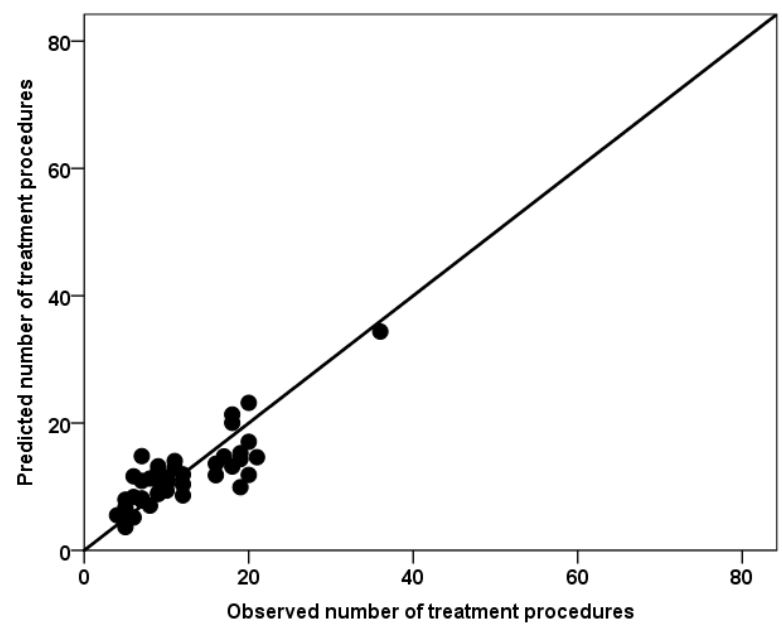

Figure 5.1 Observed versus predicted number of treatment procedures using erythrocytapheresis as treatment modality. Predicted numbers are based on model C, using initial SF, body weight, and initial $\mathrm{Hb}$ count as predictors $\left(\mathrm{R}^{2}=0.70 ; \mathrm{VMSPE}=3.7\right)$.

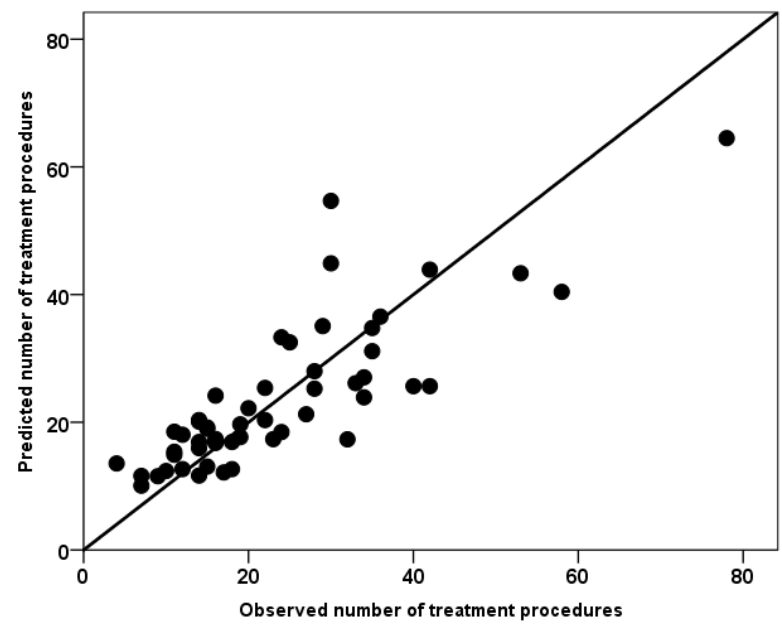

Figure 5.2 Observed versus predicted number of treatment procedures using phlebotomy as treatment modality. Predicted numbers are based on model $\mathrm{C}$, using initial SF, and body weight as predictors $\left(\mathrm{R}^{2}=0.69\right.$; VMSPE$\left.=7.9\right)$. 
Table 5.4 Estimated number of treatment procedures for erythrocytapheresis (E) and phlebotomy (P) using the formulas in Tables 5.3, where realistic values for initial SF $(=1000,2000,3000 \mu \mathrm{g} / \mathrm{l})$, body weight $(=50,80,110 \mathrm{~kg})$ and $\mathrm{Hb}(=8.0,10.0,12.0 \mathrm{mmol} / \mathrm{l})$ were chosen.

\begin{tabular}{llrrrrrr}
\hline & \multicolumn{9}{c}{ Body Weight $(\mathrm{kg})$} \\
\cline { 3 - 8 } $\mathrm{Hb}(\mathrm{mmol} / \mathrm{l})$ & $\mathrm{SF}(\mu \mathrm{g} / \mathrm{l})$ & $\mathrm{E}$ & $\mathrm{P}$ & $\mathrm{E}$ & $\mathrm{P}$ & $\mathrm{E}$ & $\mathrm{P}$ \\
\hline $8.0(13 \mathrm{~g} / \mathrm{dl})$ & 1000 & 14 & 24 & 12 & 19 & 9 & 14 \\
& 2000 & 18 & 35 & 16 & 30 & 13 & 25 \\
& 3000 & 22 & 46 & 20 & 41 & 17 & 36 \\
$9.0(14.5 \mathrm{~g} / \mathrm{dl})$ & 1000 & 12 & 24 & 10 & 19 & 7 & 14 \\
& 2000 & 16 & 35 & 14 & 30 & 11 & 25 \\
$10.0(16 \mathrm{~g} / \mathrm{dl})$ & 3000 & 20 & 46 & 18 & 41 & 15 & 36 \\
& 1000 & 10 & 24 & 8 & 19 & 6 & 14 \\
& 2000 & 14 & 35 & 12 & 30 & 10 & 25 \\
\hline
\end{tabular}

\section{Discussion}

For many decades phlebotomy has been widely accepted as the standard treatment for patients with $\mathrm{HH}$. However, more recent publications report favourable data with respect to the use of erythrocytapheresis as a more individualized treatment modality. These recent publications ${ }^{10-24}$ point to a higher efficacy of erythrocytapheresis which was demonstrated by a significant decrease in numbers of treatment procedures during the initial treatment phase with moreover a decrease in initial treatment duration.

Nevertheless, the costs, the specialized equipment, and availability of collection centers for erythrocytapheresis, all play a major role in deciding which therapy will be of benefit for the individual patient. For these reasons we aimed to establish a model that reliably predicts the number of treatment procedures necessary to reduce SF levels $\leq 100 \mu \mathrm{g} / \mathrm{l}$, using either phlebotomy or erythrocytapheresis.

Initial SF was the best predictor for the number of required treatment procedures for both treatment methods. This biochemical parameter, used to monitor the effectiveness of treatment, is directly related to total body iron. In earlier publications, a mean decrease of about $30 \mu \mathrm{g} / \mathrm{l}$ per single phlebotomy procedure is found to occur ${ }^{25}$. In our $\mathrm{RCT}^{10}$ a mean decrease of $70 \mu \mathrm{g} / \mathrm{l}$ per single phlebotomy treatment versus $140 \mu \mathrm{g} / \mathrm{l}$ per single erythrocytapheresis treatment was reached. Panch et al ${ }^{26}$ also observed that initial SF was the best predictor for the total number of phlebotomy treatments in patients with secondary iron overload. However, it should be taken into account that measurements of SF suffer from low specificity as elevated SF values may also result from a range of other factors such as inflammatory, metabolic, and neoplastic conditions. 
The second best predictor for erythrocytapheresis method was in line with our expectations, initial $\mathrm{Hb}$ count. In normal conditions, there is a linear relationship between concentration of $\mathrm{Hb}$ and $\mathrm{Hct}$ count. By personalized erythrocytapheresis, the volume of RBCs removed is based on initial Hct values of each patient. Evers and colleagues $^{23}$ also showed that for patients with a high initial Hct count and thus a high achievable $\Delta$ Hct target, erythrocytapheresis is more efficient in initial iron depletion as well as during the maintenance phase. These authors presented a mathematical tool for predicting the efficiency rate of a single erythrocytapheresis procedure compared to a single phlebotomy procedure. Results of that study showed that in $\mathrm{HH}$ patients erythrocytapheresis was on average 1.9 times more efficient than standard phlebotomy. For phlebotomy, in line with our expectations, initial $\mathrm{Hb}$ value did not significantly contribute to the presented models.

Surprisingly, for erythrocytapheresis neither TBV, nor BMI, nor body weight were significantly associated to total number of procedures, while for phlebotomy body weight as well as BMI were significantly associated to the number of treatment procedures. For practical reasons we choose to use body weight in both prediction models.

The accuracy of the here presented models appeared to be better for erythrocytapheresis $\left(R^{2} 0.70\right.$, VMSPE 3.7) compared to phlebotomy $\left(R^{2} 0.69\right.$, VMSPE 7.9), which most likely is reflection of the more personalized approach associated with erythrocytapheresis.

Slightly higher prediction quality $\left(R^{2} 0.80\right)$ presented by group of Panch et al. ${ }^{26}$ might result from differences in the pathophysiology of iron overload between both groups of patients. In our HH patients, several additional factors will have influenced the rate of iron mobilisation ${ }^{27}$ making predictions more difficult. Manet et al. recently pointed to an important role for the iron reabsorption index (IRI), a reliable indicator of body iron accumulation and thus of the potential severity of the individual $\mathrm{HH}$ phenotype in patients with hereditary hemochromatosis. ${ }^{28}$ These authors showed that IRI is more closely correlated with body weight than with BMI, is higher in patients with advanced liver disease (in agreement with previous studies), and is significantly lower in women. All these factors add to a substantial derivation of accuracies of our prediction formulas.

Some important limitations of our study have to be acknowledged. First, due to small sample sizes we could only establish these models without further validating or implementing them in clinical practice. It would be of great interest to establish a validation cohort wherein the here presented model could be confirmed and improved. Second, several additional factors, such as individual clinical patient conditions, and IRI, will have influenced the rate of individual iron mobilization, and thus the accuracy of both models. Finally, for future studies a cost-efficiency analysis is needed, taking into account patient preferences. 
In conclusion, we have developed a practical and feasible clinical prediction rule that can help clinicians and patients in selecting the proper treatment modality by calculating the expected number of treatment procedures needed to achieve targeted SF levels $\leq 100 \mu \mathrm{g} / \mathrm{I}$ in newly diagnosed $\mathrm{HH}$ patients. These models might give insight into what most likely represents the most convenient, effective, and cost-efficient therapy for the individual patient.

Further prospective studies validating and optimizing our predicton model may lead to a calculation tool with a higher predictive quality that will be implemented in the personalized care of $\mathrm{HH}$ patients. 


\section{References}

1. Pietrangelo A. Hereditary hemochromatosis: pathogenesis, diagnosis, and treatment. Gastroenterology 2010; 139:393-408.

2. Van Bokhoven MA, van Deursen CThBM, Swinkels DW. Diagnosis and management of hereditary hemochromatosis. BMJ 2011; 342:c7251.

3. Adams PC, Barton JC. How I treat hemochromatosis. Blood 2010; 116:317-25.

4. European Association for the study of the Liver. EASL clinical practice guidelines for HFE hemochromatosis. J Hepatol 2010; 53:3-22.

5. Bacon BR, Adams PC, Kowdley KV, et el. Diagnosis and management of hemochromatosis: 2011 practice guideline by the American association for the study of liver diseases. Hepatology 2011; 54:328-43.

6. Swinkels DW, Jorna AT, Raymakers RA. Synopsis of the Dutch multidisciplinary guideline for the diagnosis and treatment of hereditary haemochromatosis. Neth J Med 2007; 65:452-5.

7. Brissot P, Ball S, Rofail D, et al. Hereditary hemochromatosis: patient experiences of the disease and phlebotomy treatment: Transfusion 2011; 51:1331-8.

8. McDonnel SM, Grindon AJ, Preston BL, et al. A survey of phlebotomy among persons with hemochromatosis. Transfusion 1999; 39: 651-6.

9. Schwartz J, Winters JL, Padmanabhan A, et al. Guidelines on the use of therapeutic apheresis in clinical practice-evidence-based approach from the writing committee of the American society for apheresis: the sixth special issue. J Clin Apher. 2013; 28:145-284.

10. Rombout-Sestrienkova E, Nieman FHM, Essers BAB, et al. Erythrocytapheresis versus phlebotomy in the initial treatment of HFE hemochromatosis: results from a randomised trial. Transfusion 2011; 52:470-7.

11. Sundic T, Hervig T, Hannisdal S, et al. Erythrocytapheresis compared with whole blood phlebotomy for the treatment of hereditary haemochromatosis. Blood Transfus. 2014; 12 Suppl 1: s84-9.

12. Conte D, Brunelli L, Bozzani A, et al. Erythrocytapheresis in idiopathic haemochromatosis. Br Med J. (Clin Res Ed) 1983; 286:939.

13. Zoller WG, Kellner H, Spengel FA. Erythrocytapheresis. A method for rapid extracorporeal elimination of erythrocytes. Results in 65 patients. Klin Wochenschr. 1988; 66:404-9.

14. Conte D, Mandelli C, Cesana M, et al. Effectiveness of erythrocytapheresis in idiopathic hemochromatosis. Report of 14 cases. Int J Artif Organs. 1989; 12:59-62.

15. Kellner H, Zoller WG. Repeated isovolemic large-volume erythrocytapheresis in the treatment of idiopathic hemochromatosis. Z Gastroenterol. 1992; 30:779-83.

16. Kohan A, Niborski R, Daruich J, et al. Erythrocytapheresis with recombinant human erythropoietin in hereditary hemochromatosis therapy: a new alternative. Vox Sang. 2000; 79:40-5.

17. Muncunill J, Vaquer $\mathrm{P}$, Galmes A, et al. In hereditary hemochromatosis, red cell apheresis removes excess iron twice as fast as manual whole blood phlebotomy. J Clin Apher. 2002; 17:88-92.

18. Mariani R, Pelucchi S, Perseghin P, et al. Erythrocytapheresis plus erythropoietin: an alternative therapy for selected patients with hemochromatosis and severe organ damage. Haematologica. 2005; 90:717-8.

19. Fernandez-Mosteirin N, Salvador-Osuna C, Garcia-Erce JA, et al. Comparison between phlebotomy and erythrocytapheresis of iron overload in patients with HFE gene mutations. Med Clin. (Barc) 2006; 127:409-12.

20. Rombout-Sestrienkova E, van Noord PA, van Deursen CT, et al. Therapeutic erythrocytapheresis versus phlebotomy in the initial treatment of hereditary hemochromatosis- A pilot study. Transfus Apher Sci. 2007; 36:261-7.

21. Wijermans $P$, van Egmond L, Ypma $P$, et al. Isovolemic erythrocytapheresis technique as an alternative to conventional phlebotomy in patients with polycythemia rubra vera and hemochromatosis. Transfus Apher Sci. 2009; 40:137.

22. Poullin P, Lefevre PA. Effectiveness of therapeutic erythrocytapheresis to achieve iron depletion in hereditary type 1 hemochromatosis: Report of 30 cases. Transfus Clin Biol. 2011;18:553-8. 
23. Evers D, Kerkhoffs JL, van Egmond L, et al. The efficiency of therapeutic erythrocytapheresis compared to phlebotomy: A mathematical tool for predicting respons in hereditary hemochromatosis, polycythemia vera, and secondary erythrocytosis. J Clin Apher. 2014; 29:133-8.

24. Rombout-Sestrienkova E, Winkens B, Essers BAB, et al. Erythrocytapheresis versus phlebotomy in the maintenance treatment of HFE hemochromatosis patients: results from a randomized crossover trial. Transfusion 2015; 00;00-00.

25. Harrison SA, Bacon BR. Hereditary hemochromatosis, update for 2003. J Hepatol 2003:38;14-23.

26. Panch SR, Yau YY, West K, et al. Initial serum ferritin predicts number of therapeutic phlebotomies to iron depletion in secondary iron overload. Transfusion. 2015;55:611-22.

27. Adams PC. Factors affecting the rate of iron mobilization during venesection therapy for genetic hemochromatosis. Am J Hematol. 1988;58:16-9.

28. Manet $G$, Bardou-Jacquet $E$, Perrin $M$, et al. The iron reabsorption index: a new phenotypic and pathophysiological descriptor in HFE hemochromatosis. Eur J Gastroenterol Hepatol. 2013;25:1321-9. 


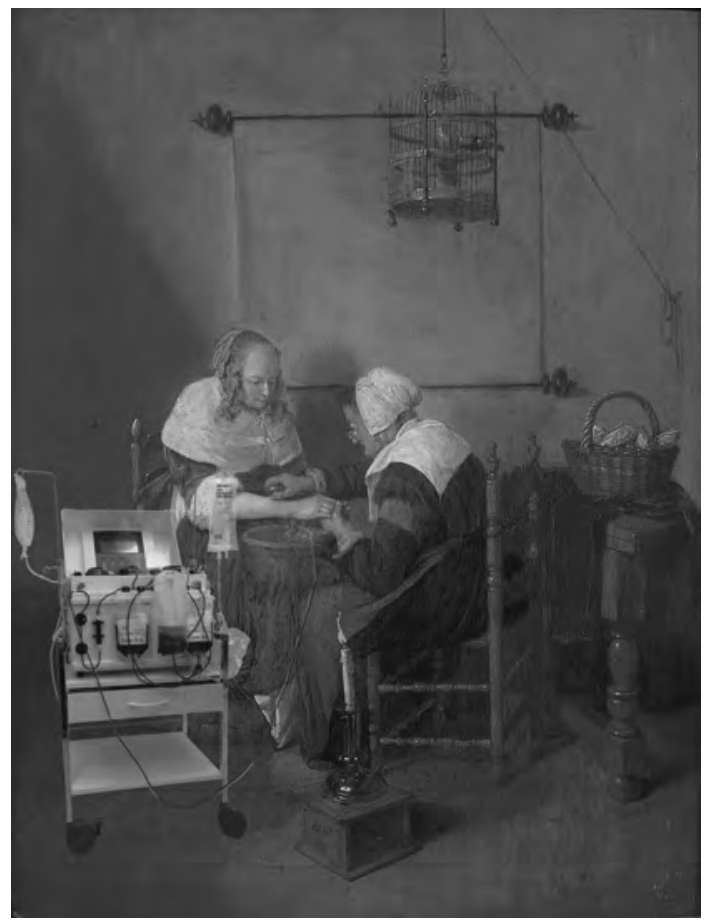

Chapter 6

Erythrocytapheresis versus phlebotomy in the maintenance treatment of HFE hemochromatosis patients; results from a randomized cross-over trial

Eva Rombout-Sestrienkova, Bjorn Winkens, Brigitte AB Essers, Fred HM Nieman, Paulus AH Noord, Mirian CH Janssen, Cees ThBM van Deursen, Annelies Boonen, Ellen PJM Reuser-Kaasenbrood, Judith Heeremans, Marian van Kraaij, Ad Masclee, Ger H Koek 


\section{Abstract}

\section{Background}

Phlebotomy is standard maintenance treatment of patients with hereditary hemochromatosis $(\mathrm{HH})$. Erythrocytapheresis, which selectively removes red blood cells, provides a new, potentially more effective treatment option. Our aim was to evaluate the effectiveness of erythrocytapheresis over phlebotomy for maintenance therapy in patients with $\mathrm{HH}$.

\section{Study design and methods}

We conducted a two-treatment-arms, randomized, cross-over clinical trial, involving 46 patients, treated for 1 year with either erythrocytapheresis or phlebotomy to keep the ferritin level at not more than $50 \mu \mathrm{g} / \mathrm{l}$. After 1 year, patients were switched to the other treatment modality. Primary endpoint was the number of treatment procedures per treatment year. Secondary endpoints were inter-treatment intervals, several aspects of health-related quality of life, costs, and patient discomfort as well as preference for one of both treatments.

\section{Results}

The mean number of required treatment procedures per treatment year was significantly higher using phlebotomy versus erythrocytapheresis (3.3 versus 1.9 ; mean difference $1.4,95 \% \mathrm{Cl} 1.1$, 1.7). The median inter-treatment time was 2.3 times longer for erythrocytapheresis. There was no significant difference in overall health assessed by SF-36 and EQ-5D respectively, between both treatments arms. The number of self-reported swollen joints was significantly higher during phlebotomy treatment. The mean treatment costs of one treatment year were $235 €$ for phlebotomy versus $511 €$ for erythrocytapheresis. Eighty percent of patients preferred erythrocytapheresis as treatment method.

\section{Conclusion}

Erythrocytapheresis significantly reduced the number of treatment procedures per treatment year, although the mean treatment costs per year are higher in our health care system. It is the preferred treatment for the majority of patients. 


\section{Introduction}

Hereditary Hemochromatosis $(\mathrm{HH})$ is a common genetic disorder, characterized by increased iron absorption that is inappropriate to body iron stores and resulting in a progressive accumulation of iron in tissues, especially in the liver, heart, pancreas, joints, skin and gonads. Clinical manifestations are diverse and not specific. The most common initial symptoms are extreme fatigue (46\%), arthralgia (44\%) and loss of libido (26\%). ${ }^{1}$ In an advanced stage of the disease, the clinical manifestations include hepatomegaly, cirrhosis, congestive heart failure, arrhythmias, diabetes mellitus, destructive arthropathy, hypogonadotropic hypogonadism and skin pigmentation.

Once $\mathrm{HH}$ is diagnosed, the therapy is straightforward and effective since it is based on the removal of the excess of body iron. Serum ferritin (SF) level is used not only as a marker for the amount of iron overload but also to monitor the effectiveness of treatment. Life expectancy of $\mathrm{HH}$ patients on therapy is equal to that of the general population if the disorder is diagnosed before the onset of cirrhosis.

The widely applied standard treatment is phlebotomy, which is, in the initial phase, generally performed on a weekly basis. During each procedure $500 \mathrm{ml}$ whole blood is removed, until the SF level is reduced to $50 \mu \mathrm{g} / \mathrm{I}^{2-6}$ Hereafter, in what is called the maintenance phase of treatment, the frequency of phlebotomies' is decreased to two to six per year.

The treatment with phlebotomy may be accompanied by side effects, such as fatigue, fainting, pain at the venous access site, hematomas and anemia. ${ }^{7-8}$ Negative experiences such as travel, loss of time and discomfort by the procedure itself have been reported by $52 \%$ of patients during the induction phase and by $37 \%$ of patients in the maintenance phase. Sixteen percent of patients would decide not to continue with phlebotomy therapy if better alternative options were available. ${ }^{7}$

One such alternative is the use of erythrocytapheresis, whereby red blood cells (RBCs) are selectively removed using an apheresis machine. This method has been evaluated in two randomized ${ }^{9-10}$ and several non-randomized trials. ${ }^{11-20}$ Most studies indicate that when compared to phlebotomy, erythrocytapheresis is a more effective method removing at least double the amount of iron per single procedure, ${ }^{9,15,16,18-20}$ since with this method up to $1000 \mathrm{ml}$ RBCs per single procedure can be removed compared to 200 to $250 \mathrm{ml}$ RBCs per phlebotomy. The volume of RBCs removed is determined and individually based on sex, weight, total blood volume and actual hematocrit (Hct). Thus, with erythrocytapheresis fewer treatment sessions will be needed, fewer hospital visits, travel expenses, and absence of work. Another potential advantage of erythrocytapheresis is the possibility for substitution of the removed volume resulting in fewer hemodynamic changes when compared to phlebotomy as well as the preservation of valuable blood components such as plasma proteins, platelets and white blood cells. This approach is particularly suited for patients with cardiac disease or liver cirrhosis or suffering from hypoproteinemia and/or thrombocytopenia. 
Recently we have shown in a randomized trial ${ }^{9}$ on initial therapy in $\mathrm{HH}$ patients that significantly fewer treatment procedures were required using erythrocytapheresis compared to phlebotomy (9 versus 27 respectively, ratio $0.33 ; 95 \%$ confidence interval $[\mathrm{Cl}], 0.25-0.45)$ to reach the target ferritin value. However, the question has not been answered yet whether erythrocytapheresis is also more effective in the maintenance phase of therapy. Therefore, the primary aim of this study was to evaluate the effectiveness of erythrocytapheresis compared with phlebotomy in keeping SF at a level of not more than $50 \mathrm{\mu g} / \mathrm{l}$, defined as number of treatment procedures per year.

\section{Materials and methods}

\section{Study design}

We conducted a two-treatment-arms, randomized, cross-over clinical trial, involving 46 patients with $\mathrm{HH}$, who in the past for at least 6 months had received phlebotomy as maintenance therapy in three collaborating hospitals. Participants were randomly assigned in a 1:1 ratio to either start with erythrocytapheresis or continue with phlebotomy as a maintenance treatment to keep SF of not more than $50 \mu \mathrm{g} / \mathrm{l}$. After 1 year of treatment, when SF levels reached more than $50 \mu \mathrm{g} / \mathrm{l}$, patients were switched to the other treatment modality. The decision when to schedule the next treatment procedure was made by an independent person, based on SF measurements, which were taken every other month (six times per year). When SF level reached more than $50 \mu \mathrm{g} / \mathrm{l}$, the independent person made the decision to schedule the patient for the next treatment procedure. This person was blinded for other patient data and for treatment procedures.

The primary outcome measure of the study was the number of procedures per treatment year. Secondary outcome measures were the inter-treatment interval necessary to keep the measured SF levels of not more than $50 \mu \mathrm{g} / \mathrm{l}$, disease activity, health-related quality of life, costs, discomfort, and patient preference.

\section{Participants}

Between May 2008 and May 2011, HH patients receiving phlebotomy as maintenance treatment, were referred from three hospitals (Maastricht University Medical Centre, Radboud University Medical Centre Nijmegen, Zuyderland Medical Center, Heerlen/Brunssum/Sittard). Inclusion criteria were as follows: homozygous for C282Y mutation, age 18 years and older, weight $50 \mathrm{~kg}$ or more, currently treated in hospital setting with maintenance phlebotomy therapy for at least 6 months, signed informed consent, and willingness to fill out additional questionnaires at three points in time. Exclusion criteria were as follows: excessive overweight $\left(\mathrm{BMl}>35 \mathrm{~kg} / \mathrm{m}^{2}\right)$, chelating therapy, forced dietary regime, aged below 18 years, pregnancy, and malignancy. All 
participants gave written informed consent and were randomized by an independent person by a permutated block randomization scheme. The ethical committee of each participating hospital approved the study.

\section{Interventions}

\section{Phlebotomy}

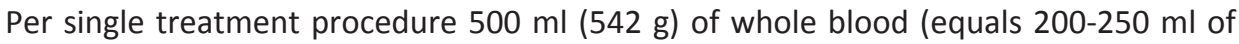
RBCs) was withdrawn. Under the assumption that one $\mathrm{ml}$ of RBCs equals $1 \mathrm{mg}$ of iron, the absolute amount of iron removed in this group was estimated by the formula

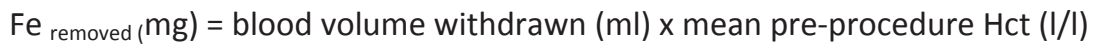

\section{Erythrocytapheresis}

Per single treatment procedure, 350 to $800 \mathrm{ml} \mathrm{RBCs}$ was withdrawn. The removed RBCs volume was determined by the total estimated blood volume (based on weight and height) and Hct of each individual patient. The minimal targeted post-procedure Hct was set at $32 \%$. The absolute amount of iron removed in this group was calculated according to the equation

$$
\mathrm{Fe}_{\text {removed }}(\mathrm{mg})=\mathrm{RBCs} \text { volume withdrawn }(\mathrm{ml}) \times 0.84
$$

The correction factor 0.84 was based on the actual Hct of removed RBCs.

Sanquin Blood Bank performed all phlebotomy and erythrocytapheresis treatment procedures.

\section{Monitoring of treatment}

In both study arms, every-other-month levels of SF, transferrin, transferrin saturation (TS), iron, hemoglobin ( $\mathrm{Hb}), \mathrm{Hct}$, mean corpuscular volume, and C-reactive protein were measured. Liver enzymes (aspartate aminotransferase [AST], alanine aminotransrerase $[\mathrm{ALT}]$ ), total protein, and albumin were measured at three time points, that is, after inclusion, and after the first and second years of treatment. All blood samples were analyzed by one laboratory (Maastricht University Medical Centre).

In addition to the laboratory assessments, patients were asked to complete a set of questionnaires. Since no specific disease score is available for $\mathrm{HH}$, specific aspects of health that are known to be affected by $\mathrm{HH}$ were measured on a visual analogue scale (VAS) ranging from 0 to 10 in which 10 refers to worse outcome, and addressing 
fatigue, level of pain, and/or swelling in the peripheral joints, and level and duration of morning stiffness (averaged for further analyses). In addition the number of swollen joints had to be indicated on a mannequin on which 38 joints could be crossed. Selfreport generic health-related quality of life was measured with the SF- 36 and the EQ-5D. ${ }^{21-22}$ The scores of the EQ - 5D were converted to a utility score by using the Dolan algorithm, ${ }^{23}$ while based on the scores of the SF-36 items, a SF-6D health state valuation score was calculated. ${ }^{24}$ All self-reported questionnaires were assessed at baseline, after the first, and second years of treatment.

Discomfort during treatment and the preference of the patients for one of the treatment methods was assessed by a simple questionnaire in which patients, at the end of the study, were asked to rate how the treatment methods have been experienced during the study period. Three domains were measured: 1) experience with respect to impairment in daily life (nine items), 2) patient comparison between both methods (five items), and 3) patient preference for one of the methods and location (two items). Within the nine items measuring the impairment with respect to daily life, four clusters were separated. Cluster 1 consists of three items: complaints/symptoms experienced by patients in the period shortly after treatment procedure, reflecting the after-effects of treatment procedure on energy status, intensity of joint pain and appetite. Cluster 2 consists of two items: complaints or symptoms experienced by patients during the treatment procedure, reflecting dizziness and fainting or syncope. Cluster 3 consists of two items, fitting the treatment procedure in everyday life given the number of needed treatment procedures and the duration of a visit for each procedure. Cluster 4 consists of two items described as side effects during the treatment procedure itself concerning pain at insertion and incidence of hematomas. The answers to the items were given as 5-point Likert scales, varying from "very much agree", "agree", "not agree-nor disagree", or "disagree", to "very much disagree ". In addition, in open questions, patients could indicate how they felt about each method as well as the location where the procedures were performed (blood bank during the study or hospital before the begin of study).

\section{Statistical analysis}

\section{Sample size calculation}

Based on paired-samples t test, at least 44 patients should be included to detect a medium standardized effect size, that is Cohen's $d$ of $0.5,{ }^{25}$ in number of treatment procedures per year with a power of $90 \%$, assuming a two-sided significance level $\alpha$ of 0.05 . To compensate for a possible $20 \%$ dropout or nonadherence rate, 11 additional patients should be included. 


\section{Data analysis}

\section{Number of treatment procedures}

For the primary endpoint, the number of treatment procedures the patient underwent in a 1-year period, a linear mixed model was used with method erythrocytapheresis versus method phlebotomy, Period 1 or 2 (first and second treatment year), and the interaction between method and period as fixed factors. A random intercept was included to account for the correlation between the two measurements within a patient. In case of a non-significant interaction between method and period, this interaction term was removed from the model. If the interaction between period and method was significant, which means that the treatment effect was significantly different in Period 1 as compared to Period 2, then combining these treatment effects was not preferred. Therefore, in this case, we reported the treatment effect for each period separately. The same is done for the other outcome variables mentioned below.

\section{Inter-treatment interval}

The inter-treatment intervals, as secondary endpoint, were analyzed using KaplanMeier curves and compared between the methods by using log-rank tests for each period separately, since these methods account for a censored inter-treatment interval, which was the case for patients with only one treatment procedure in 1 year.

\section{Costs analysis}

Costs analysis was limited to the direct treatment costs per year. We used for both treatment procedures a cost price calculation performed by Sanquin Blood Supply's financial department, as was described previously. ${ }^{9}$ This analysis was based on the actual personal costs for blood bank personnel, material costs (such as collecting bag or apheresis collection device), equipment costs (collecting equipment and collecting bed), tests costs, and indirect costs (building, information technology, overhead). Uncertainty intervals $\left(2.5^{\text {th }}\right.$ and $97.5^{\text {th }}$ percentiles) for the mean differential costs were calculated by the bootstrap method. ${ }^{26}$ All costs are presented in Euros.

\section{Aspects of health and generic health-related quality of life}

The between-methods difference in these variables, which were assessed by means of the VAS scores (fatigue, joint pain, joint stiffness), number of swollen joints and total score for SF-36 and EQ- 5D, were analyzed using the same linear mixed model as for the primary endpoint, where the baseline score was added as fixed variable. Analyses of joint pain and stiffness were repeated in the subgroup that indicated to have swollen joints in the mannequin. 


\section{Patient discomfort and preference questions}

Means and standard deviations (SD; minimum and maximum) were calculated for items in the questionnaire. A principal component analysis was performed on the items measuring the disadvantages with the respect to impairment in daily life. Components were found that cluster items with a common content. Cronbach's alpha was calculated to measure the internal consistency of each component. Means and SDs were presented for the VAS version of these components which may range from 0 (worst possible score) to 100 (best possible score). Paired-samples t tests or Wilcoxon signed-rank tests, where appropriate, were performed for the components measuring both clinical procedures and also for the items concerning the comparison between the procedures. Preference for one of the treatment methods (Domain 3) has been presented as a frequency and percentage.

A p-value of less than or equal to 0.05 is considered to be statistically significant. All data analysis was performed with computer software (SPSS Statistics for Windows, Version 22.0, IBM, Armonk, NY).

\section{Results}

A total of $53 \mathrm{HH}$ patients ( 40 men, 13 women) were randomly assigned to one of the two treatments arms (Figure 6.1). Twenty-eight patients started with phlebotomy (phlebotomy/erythrocytapheresis group) and 25 with erythrocytapheresis treatment (erythrocytapheresis/phlebotomy group). There were seven (13\%) dropouts in the first year of treatment, two patients who were randomly assigned to start with phlebotomy, and five patients assigned to erythrocytapheresis, and there was one dropout in the second year of the study (patient randomly assigned to phlebotomy/ erythrocytapheresis group). In total, 46 patients, 38 men (83\%) and eight women (17\%), were analyzed (26 randomly assigned to phlebotomy/erythrocytapheresis and 20 randomly assigned to erythrocytapheresis/phlebotomy group). One of these patients finished only the first treatment year (randomly assigned to phlebotomy/erythrocytapheresis group) and two patients did not need any treatment during the whole 2-year trial period (randomly assigned to phlebotomy/ erythrocytapheresis group) because the SF level remained less than $50 \mu \mathrm{g} / \mathrm{l}$. Therefore, these two patients were not included in the finally analysis.

Baseline patient characteristics are shown in Table 6.1. No significant differences were found in any of the characteristics between patients starting with phlebotomy versus those starting with erythrocytapheresis. In five patients (11\%) liver enzymes (AST, ALT) were slightly elevated and 25 patients (54\% evenly divided between groups) had swollen joints. 


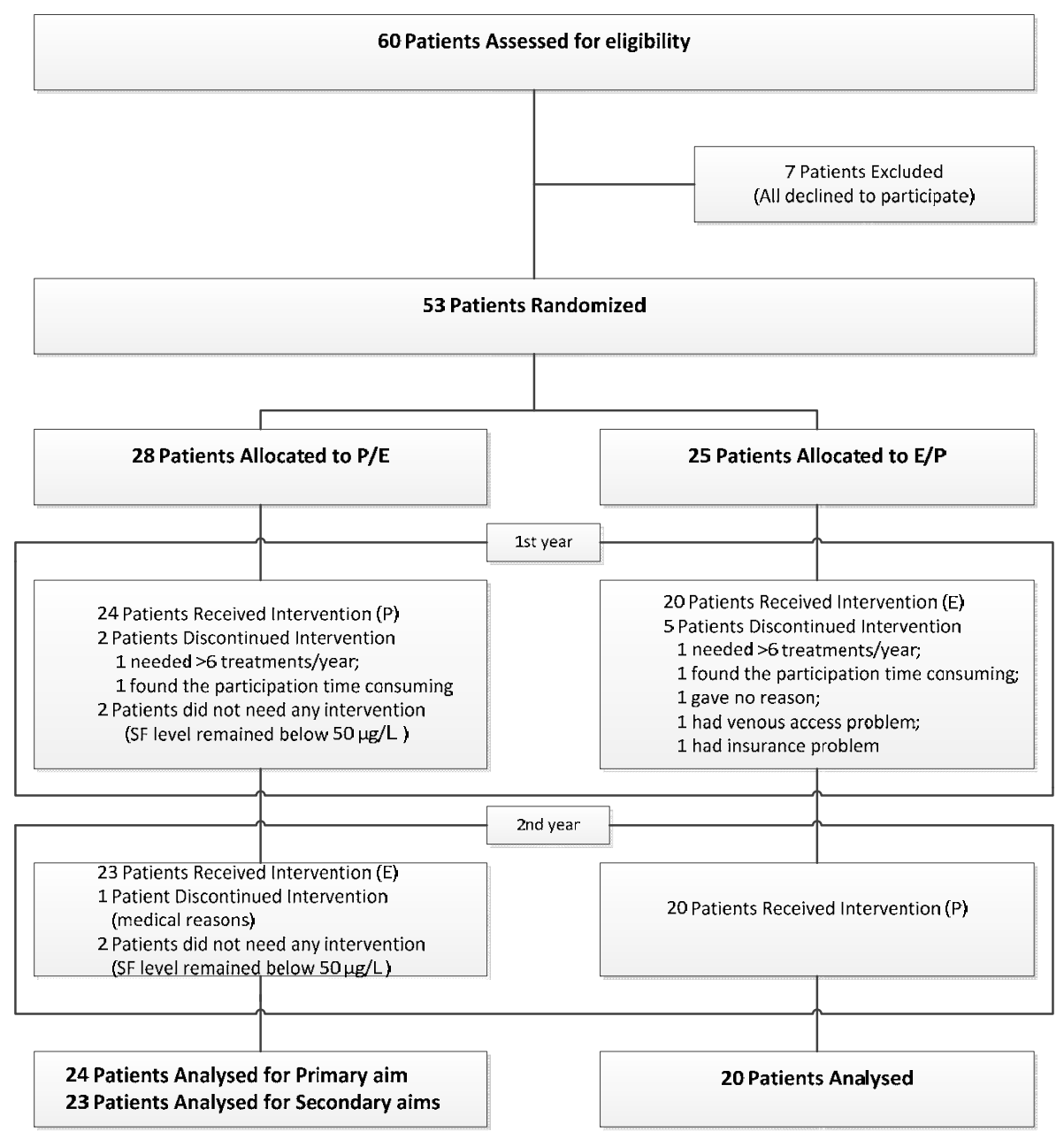

Figure 6.1 Study flow chart.

\section{Number of treatment procedures}

Linear mixed- model analysis showed that there was no significant interaction between treatment periods and treatment methods $(p=0.459)$, which means that the treatment effect was not significantly different in Period 1 (first treatment year) compared to Period 2 (second treatment year). The mean number of required treatment procedures was significantly higher for phlebotomy (mean, 3.3) compared to erythrocytapheresis (mean, 1.9; mean difference 1.4, 95\% Cl 1.1, 1.7; $\mathrm{p}<0.001$ ). 
Table 6.1 Baseline characteristics of the patients.*

\begin{tabular}{lccc}
\hline Characteristics and variables (reference) & Overall $(\mathrm{N}=46)$ & $\mathrm{P} / \mathrm{E}(\mathrm{N}=26) \dagger$ & $\mathrm{E} / \mathrm{P}(\mathrm{N}=20) \ddagger$ \\
\hline Age (year) & $55(9.0)$ & $57(9.2)$ & $53(8.4)$ \\
Weight $(\mathrm{kg})$ & $83(13.4)$ & $84(15.1)$ & $82(11.1)$ \\
Length $(\mathrm{cm})$ & $178(8.6)$ & $179(10.2)$ & $176(5.9)$ \\
SF $(16-250 \mathrm{ug} / \mathrm{l})$ & $38(32)$ & $40(37)$ & $36(25)$ \\
TS $(20-45 \%)$ & $58(26)$ & $57(25)$ & $60(27)$ \\
Hb (mmol/I) & $9.1(0.68)$ & $9.1(0.68)$ & $9.1(0.68)$ \\
Hct (\%) & $42(2.7)$ & $42(2.8)$ & $42(2.7)$ \\
MCV & $92(5.1)$ & $93(5.3)$ & $92(4.8)$ \\
Total protein (60-80 g/I) § & $71(3.6)$ & $71(4.1)$ & $71(3.0)$ \\
Albumin (32-47 g/l) § & $40(2.3)$ & $40(2.3)$ & $40(2.3)$ \\
AST (0-35 U/I) § & $21(10.1)$ & $23(12.1)$ & $19(6.7)$ \\
ALT (0-45 U/I) & $26(12.1)$ & $27(12.9)$ & $25(11.2)$ \\
CRP (0-10 mg/l) & $2(1.6)$ & $2(1.6)$ & $2(1.7)$ \\
Level of fatigue & $4.0(2.9)$ & $3.7(3.3)$ & $4.4(2.5)$ \\
Number swollen joints (38 joints-count) & $6.4(9.8)$ & $6.2(10.0)$ & $6.6(9.8)$ \\
Level of pain in the peripheral joints & $3.2(3.1)$ & $3.4(3.2)$ & $3.0(3.0)$ \\
Level and duration of morning stiffness & $2.9(2.7)$ & $2.8(2.6)$ & $2.9(2.8)$ \\
Patients with swollen joints (\%) & 54 & 54 & 55 \\
SF 36 & $0.74(0.12)$ & $0.75(0.13)$ & $0.74(0.11)$ \\
EQ 5D & $0.76(0.23)$ & $0.75(0.27)$ & $0.78(0.18)$ \\
\hline
\end{tabular}

* Data are reported as mean $(\mathrm{SD})$; † First year $\mathrm{P}$ treatment, second year $\mathrm{E}$ treatment; $¥$ First year E treatment, second year P treatment; § One patient in P/E group had a missing value; " Two patients (one patient in each group) had a missing value; $C R P=C$ reactive protein; $E=$ erythrocytapheresis; $P=$ phlebotomy; $\mathrm{MCV}=$ mean corpuscular volume; $\mathrm{TS}=$ transferrin saturation.

\section{Inter-treatment interval}

As for the inter-treatment time, there was a significant difference between the treatment methods for each period. Therefore, the difference in treatment methods will be discussed for each period separately. For Period 1 (first treatment year), the median inter-treatment time, that is, the time at which $50 \%$ of patients received the second treatment, was significantly less for phlebotomy treatment (median, 113 days; $95 \% \mathrm{Cl}, 107-119$ days) compared to erythrocytapheresis treatment (median, 273 days; $95 \% \mathrm{Cl}, 92-454$ days, log-rank test $\mathrm{p}=0.001$ ). Similar results were obtained for Period 2 (second treatment year), that is, a median of 118 days $(95 \% \mathrm{Cl}, 104-132$ days) for phlebotomy treatment versus a median of 275 days $(95 \% \mathrm{Cl}, 188-362$ days, log-rank test $p=0.002$ ) for erythrocytapheresis treatment (Figure. 6.2 and 6.3 showing the Kaplan-Meier curves of each treatment method for Periods 1 and 2, respectively).

\section{Iron removed}

During phlebotomy, each time $500 \mathrm{ml}$ of whole blood was withdrawn per treatment procedure per patient. During erythrocytapheresis the mean amount of removed RBCs was $627 \mathrm{ml}$. This corresponds to an iron removal per procedure of $217 \mathrm{mg}$ by phlebotomy treatment versus $527 \mathrm{mg}$ by erythrocytapheresis treatment. Thus, 
2.4 times more iron was withdrawn during a single erythrocytapheresis compared to a single phlebotomy procedure.

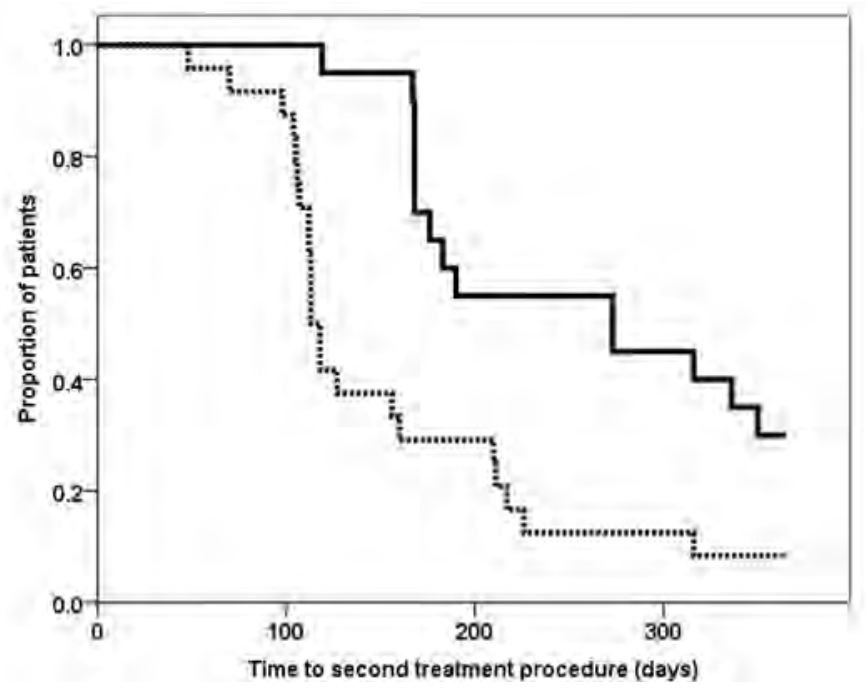

Figure 6.2 Kaplan-Meier curves for Period 1 (first treatment year): bold line represents erythrocytapheresis and dashed line phlebotomy.

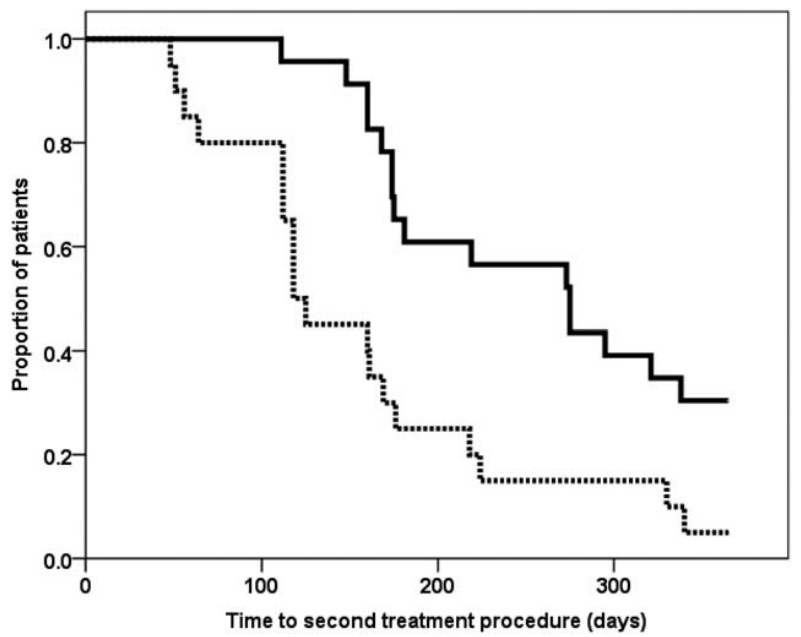

Figure 6.3 Kaplan-Meier curves for Period 2 (second treatment year): bold line represents erythrocytapheresis and dashed line phlebotomy. 
The mean total amount of blood withdrawn per patient per year was $1670 \mathrm{ml}$ of whole blood by phlebotomy versus $1252 \mathrm{ml}$ of RBCs by erythrocytapheresis. This corresponds to a mean of $726 \mathrm{mg}$ iron versus $1054 \mathrm{mg}$ iron per year for phlebotomy and erythrocytapheresis respectively. Thus, the total mean quantity of iron withdrawn per year was 1.5 times higher with erythrocytapheresis compared to phlebotomy.

\section{Specific aspects of health related quality of life}

Stratified analysis for fatigue showed that in Period 1 the estimated mean score was significantly higher using erythrocytapheresis; for Period 2, the difference in estimated mean scores was not significant (Table 6.2). The estimated mean number of swollen joints was significant lower with erythrocytapheresis (initially mean of 6.4 vs. 5.0 during the erythrocytapheresis treatment and 7.1 during the phlebotomy treatment). No significant differences between treatment methods were seen for the level of joint pain as well as for the joint stiffness. When limiting the analysis to those with swollen joints no significant difference were found between treatment methods.

Table 6.2 Specific aspects of health related quality of life (measured on a VAS) ranging from 0 to 10 (in which 10 refers to worse outcome).

\begin{tabular}{|c|c|c|c|c|c|c|c|}
\hline \multicolumn{8}{|c|}{ Mean } \\
\hline Aspect & & $\begin{array}{c}\text { Interaction* } \\
\text { p value }\end{array}$ & $\begin{array}{c}\text { Erythro- } \\
\text { cytapheresis }\end{array}$ & Phlebotomy & $\begin{array}{c}\text { Mean } \\
\text { difference }\end{array}$ & $95 \% \mathrm{Cl}$ & $p$ value \\
\hline \multirow[t]{3}{*}{ Fatigue } & & $0.047+$ & & & & & \\
\hline & Period 1 & & 5.3 & 3.7 & 1.6 & $0.3,2.9$ & $0.017 \dagger$ \\
\hline & Period 2 & & 4.0 & 4.9 & -0.8 & $-2.2,0.5$ & 0.233 \\
\hline $\begin{array}{l}\text { Number of } \\
\text { swollen joints }\end{array}$ & & 0.344 & 5.0 & 7.1 & -2.1 & $-3.8,-0.3$ & $0.023+$ \\
\hline \multirow{2}{*}{$\begin{array}{l}\text { Level of joint } \\
\text { pain }\end{array}$} & All & 0.509 & 3.4 & 3.1 & 0.3 & $-0.5,1.2$ & 0.416 \\
\hline & $\begin{array}{l}\text { Those with } \\
\text { swollen joints } \\
(\mathrm{N}=22)\end{array}$ & 0.238 & 4.6 & 4.7 & -0.1 & $-1.5,1.3$ & 0.899 \\
\hline \multirow[t]{2}{*}{ Joint stiffness } & All & 0.640 & 3.3 & 3.6 & -0.4 & $-1.0,0.2$ & 0.193 \\
\hline & $\begin{array}{l}\text { Those with } \\
\text { swollen joints } \\
(\mathrm{N}=22)\end{array}$ & 0.721 & 4.8 & 5.5 & -0.7 & $-1.7,0.3$ & 0.147 \\
\hline
\end{tabular}

\footnotetext{
* Interaction between period and method. If the interaction between period and method was statistically significant, which means that the treatment effect was significantly different in period 1 as in period 2 , then combining these treatment effects was not preferred. Therefore, in this case, we reported the treatment effect for each period separately; + Significant.
}

\section{Health-related quality of life and societal health utility}

There was no significant interaction between treatment periods and treatment methods ( $p=0.284$ for SF-36, $p=0.419$ for EQ- 5D). Differences in estimated mean SF-36 
and EQ- 5D scores were not significant. For SF-36, a mean of 0.72 for phlebotomy versus a mean of 0.70 for erythrocytapheresis was seen with $95 \% \mathrm{Cl}$ for the difference in means -0.02 to $0.04(p=0.479)$. Analysis of EQ- 5D showed a mean of 0.75 for phlebotomy versus a mean of 0.71 for erythrocytapheresis; with $95 \% \mathrm{Cl}$ of -0.01 to 0.09 $(p=0.089)$.

\section{Costs}

The costs calculated for one phlebotomy treatment procedure were $72.80 €$ versus $270.20 €$ for one erythrocytapheresis treatment procedure. The mean costs for an average maintenance treatment per year were $234.68 €$ (range $72.80 €-436.80 €$ ) for phlebotomy versus $510.53 €$ (range $270.20 €$ - $810.60 €$ ) for erythrocytapheresis, making a significant difference of $276 €$ (95\% Cl $232 €-317 €)$.

\section{Patient discomfort and preference}

Out of 46 patients, 42 filled out the questionnaires presented at the end of the study and were included in this analysis. In the first part of the questionnaire, which included nine items measuring the disadvantages (separated in four clusters), no significant differences were observed between the two treatment methods in any of the four clusters (Table 6.3).

Table 6.3 The disadvantages during both treatment methods.

\begin{tabular}{lcccccc}
\hline & $\begin{array}{c}\text { Phlebotomy treatment } \\
(\mathrm{N}=42)\end{array}$ & $\begin{array}{c}\text { Erythrocytapheresis treatment } \\
(\mathrm{N}=42)\end{array}$ & & p value \\
\hline Clusters of items & $\begin{array}{c}\text { Cronbach's } \\
\text { alpha }\end{array}$ & VAS* & $\begin{array}{c}\text { Cronbach's } \\
\text { alpha }\end{array}$ & VAS * & Paired- & $\begin{array}{c}\text { Wilcoxon } \\
\text { samples } \\
\text { signed rank } \\
\text { test }\end{array}$ \\
\hline Cluster 1† & 0.76 & 61.2 & 0.64 & 64.1 & 0.49 & 0.56 \\
Cluster 2 $\ddagger$ & 0.67 & 72.6 & 0.60 & 70.3 & 0.65 & 0.26 \\
Cluster 3 § & 0.81 & 82.7 & 0.68 & 76.8 & 0.27 & 0.17 \\
Cluster 4\| & 0.85 & 73.8 & 0.82 & 73.3 & 0.62 & 0.30 \\
\hline
\end{tabular}

* VAS 0-100; 100 indicating less impact (better); + Complaints reflecting the after-effects of treatment procedure on energy status, intensity of joint pain and appetite; $¥$ Complaints during the treatment procedure, reflecting dizziness and fainting/syncope; $\S$ Fitting treatment procedures in everyday life; \| Complaints during the treatment procedure, concerning pain at insertion and incidence of hematomas.

In the second part of the questionnaire (data not shown), patients were asked to provide reasoning for preferring one treatment method over the other on the basis of five questions per treatment method. For phlebotomy the reliability was 0.87 and the mean VAS was 33.2 versus a reliability of 0.96 and the mean VAS of 47.7 for erythrocytapheresis. Differences were not significant $(p=0.10$ in the paired- samples $t$ test and $p=0.16$ in the Wilcoxon signed rank test). 
In the third part of the questionnaire (open questions), patients were able to choose their preferred treatment method and also the location where the treatment should be performed. One (2.4\%) patient did not answer these questions and was not included in the results.

With respect to method preference, $33(80,5 \%)$ patients chose erythrocytapheresis, and two $(4.9 \%)$ chose phlebotomy, while six (14.6\%) had no preference. Reasons for preference of erythrocytapheresis were as follows: lower frequency of treatments (48\%), withdrawal of only RBCs and return of other blood components (24\%), effectiveness of the method (9\%), less burden to body and veins (9\%), and feeling better after erythrocytapheresis when compared to phlebotomy (6\%).

With respect to location preference, 32 patients (78\%) preferred the blood bank, one patient $(2.4 \%)$ the hospital, while eight (19.5\%) had no preference. Major reasons for blood bank preference were as follows: personal attention (25\%), professional and friendly staff (22\%), and quiet environment without patient contacts $(9 \%)$.

\section{Discussion}

This study is the first to systematically compare, in a randomized cross-over trial, effectiveness of erythrocytapheresis with phlebotomy in the maintenance treatment of $\mathrm{HH}$ patients who are homozygous for the $\mathrm{C} 282 \mathrm{Y}$ mutation. A significantly lower number of treatment procedures per year were needed using erythrocytapheresis compared to phlebotomy. Furthermore, a significantly longer inter-treatment time was observed with erythrocytapheresis compared to phlebotomy. No significant difference between both treatments methods was found in relation to health issues including joint pain and joint stiffness, although the mean number of swollen joints measured by the 38 joints-count was significantly lower during erythrocytapheresis. The generic quality of life assessed by SF- 36 and in societal value for health status assessed by EQ5D were not significantly different between both treatment methods. Notwithstanding, the majority of patients choose erythrocytapheresis as the preferable treatment with a blood bank as the preferable setting.

With respect to the number of treatment procedures, erythrocytapheresis is a more effective treatment with an observed reduction in treatment procedures per year of $42 \%$. This is due to the fact that 2.4 times more iron is removed per procedure.

The evaluation of inter-treatment interval showed 2.3 times longer interval by use of erythrocytapheresis. This is in line with the efficacy of erythrocytapheresis in the depletion phase of treatment shown in our previous randomized study. ${ }^{9}$ The aspect of the inter-treatment interval might be clinically relevant because the compliance of patients who adhere to maintenance therapy may decline over time due to the inconvenience of frequent clinic visits and the discomfort associated with the procedure. $^{27}$ 
Of the $\mathrm{HH}$ patients, up to $81 \%$ manifest with chronic active, progressive, inflammatory arthropathy with a predilection for the MCP finger joints, which may progress despite therapy. ${ }^{28-38}$ In our study, 25 patients (54\%) had swollen joints. Although the number of swollen joints became significantly lower during erythrocytapheresis, the level of joint pain and stiffness in those with swollen joints, was not significantly different. As yet, classic phlebotomy treatment failed to show a reduction in swollen joints and joints symptoms; this could not be explained, however with regard to the number of patients included in this study and the problem of multiple testing this outcome may be a result of a Type I error and should be explored in future studies.

Another important issue nowadays is treatment costs. The mean direct costs in our health care system per treatment year were significantly higher using erythrocytapheresis compared to phlebotomy (510.53€ versus $234.68 €$ ). This is in contrast to our study in the initial therapy where cost analysis showed no significant difference in total treatment costs between both methods, and the costs resulting from productivity loss were significantly lower for erythrocytapheresis treatment. ${ }^{9}$ Explanations for the difference are probably the fact that more treatments were needed in a shorter time period to reach the preferred ferritin level, as for patient in the maintenance phase fewer treatments per year are needed. It could be suspected that the cost benefit will be reached after a longer time period. Another fact is that in this study costs resulting from the loss of hours absent from work were not taken into account, since many participants were already retired. Furthermore the costs for a single treatment might also depend on the location. In our trial both treatments were performed at Sanquins' donation locations, which have lower costs for beds, equipment and personnel compared to the hospitals. Currently, in the Netherlands, collected blood of hemochromatosis patients cannot be used for transfusion. If readyto-use RBCs were allowed to be used for transfusion, this would have impact on the costs. For patients in the Netherlands however the costs of both procedures are paid by insurance companies.

While no differences were seen in generic health related quality of life as measured by the SF-36 and EQ-5D questionnaires and no differences were shown by scores from questionnaires measuring disadvantages during both treatment methods, patients had a clear preference $(80 \%)$ for erythrocytapheresis. The reduction in time expenditure and the return of other blood components are the two most important reasons for patient's preferring erythrocytapheresis. Especially the reduction in time might improve patient compliance, which is highly relevant in a condition of chronic disease such as $\mathrm{HH}$.

As a preferred location for treatment, $78 \%$ of patients choose the blood bank, because of personal attention, friendly staff and quiet environment, although we need to realize that this result might be partly affected by trial- related attention through questionnaires and extra monitoring, but also because of the fact that many patients do not like to be in a hospital environment often sitting in a daycare ward where chemotherapy is given as is the case in our hospital setting. 
In conclusion, erythrocytapheresis, in $\mathrm{HH}$ maintenance therapy, significantly reduced the number of treatment procedures per treatment year, significantly increased intertreatment interval between two consecutive treatment procedures, and was the method of preference for the majority patients, although the cost were higher in our health care system. Future therapy strategies should be individualized depending on the number of treatments needed to maintain the ferritin level in the therapeutic range. 


\section{References}

1. McDonnell SM, Preston BL, Jewell SA, et al. survey of 2,851 patients with hemochromatosis: symptoms and response to treatment. Am J Med. 1999;106:619-24.

2. European Association for the study of the lever. EASL clinical practice guidelines for HFE hemochromatosis. Journal of Hepatology 2010;53:3-22.

3. Bacon BR, Adams PC, Kowdley KV, et al. Diagnosis and management of hemochromatosis: 2011 Practice Guideline by the American Association for the Study of Liver Diseases. Hepatology 2011;54:328-43.

4. Adams PC, Barton JC. How I treat hemochromatosis. Blood 2010;116:317-25.

5. Brissot P, Troadec MB, Bardou-Jacquet E, et al. Current approach to hemochromatosis. Blood Rev 2008;22:195-210.

6. Swinkels DW, Jorna AT, Raymakers RA. Synopsis of the Dutch multidisciplinary guideline for the diagnosis and treatment of hereditary hemochromatosis. Neth J Med 2007;65:452-5.

7. Brissot $P$, Ball S, Rofail D, et al. Hereditary hemochromatosis: patient expieriences of the disease and phlebotomy treatment: Transfusion. 2011;51:1331-8.

8. McDonnel SM, Grindon AJ, Preston BL, et al. A survey of phlebotomy among persons with hemochromatosis. Transfussion 1999;39: 651-6.

9. Rombout-Sestrienkova E, Nieman FHM, Essers BAB, et al. Erythrocytapheresis versus phlebotomy in the initial treatment of HFE hemochromatosis: results from a randomized trial. Transfusion 2011; 52:470-7.

10. Sundic T, Hervig T, Hannisdal S, et al. Erythrocytapheresis compared with whole blood phlebotomy for the treatment of hereditary hemochromatosis. Blood Transfus 2014;12 Suppl 1:s.84-9.

11. Conte D, Brunelli L, Bozzani A, et al. Erythrocytapheresis in idiopathic haemochromatosis. Br Med J. (Clin Res Ed) 1983;286:939.

12. Zoller WG, Kellner H, Spengel FA. Erythrocytapheresis. A method for rapid extracorporeal elimination of erythrocytes. Results in 65 patients. Klin Wochenschr. 1988;66:404-9.

13. Conte D, Mandelli C, Cesana M, et al. Effectiveness of erythrocytapheresis in idiopathic hemochromatosis. Report of 14 cases. Int J Artif Organs. 1989;12:59-62

14. Kellner H, Zoller WG. Repeated isovolemic large-volume erythrocytapheresis in the treatment of idiopathic hemochromatosis. Z Gastroenterol. 1992;30:779-83.

15. Kohan A, Niborski R, Daruich J, et al. Erythrocytapheresis with recombinant human erythropoietin in hereditary hemochromatosis therapy: a new alternative. Vox Sang. 2000;79:40-5.

16. Muncunill J, Vaquer P, Galmes A, et al. In hereditary hemochromatosis, red cell apheresis removes excess iron twice as fast as manual whole blood phlebotomy. J Clin Apher. 2002;17:88-92.

17. Mariani R, Pelucchi S, Perseghin P, et al. Erythrocytapheresis plus erythropoietin: an alternative therapy for selected patients with hemochromatosis and severe organ damage. Haematologica. 2005; 90:717-8.

18. Fernandez-Mosteirin N, Salvador-Osuna C, Garcia-Erce JA, et al. Comparison between phlebotomy and erythrocytapheresis of iron overload in patients with HFE gene mutations. Med Clin. (Barc) 2006; 127:409-12.

19. Rombout-Sestrienkova E, van Noord PA, van Deursen CT, et al. Therapeutic erythrocytapheresis versus phlebotomy in the initial treatment of hereditary hemochromatosis - A pilot study. Transfus Apher Sci. 2007;36:261-7.

20. Wijermans $P$, van Egmond L, Ypma $P$, et al. Isovolemic erythrocytapheresis technique as an alternative to conventional phlebotomy in patients with polycythemia rubra vera and hemochromatosis. Transfus Apher Sci. 2009;40:137.

21. Aaronson NK, Muller M, Cohen PD, et al. Translation, validation, and norming of the Dutch language version of the SF-36 Health Survey in community and chronic disease populations. J Clin. Epidemiol. 1998;51:1055-68.

22. EuroQol Group. EuroQol - a new facility for the measurement of health related quality of life. Health Policy. 1990;16:199-208.

23. Dolan P. Modeling valuations for Euroqol health states. Medical Care 1997;35:1095-108. 
24. Brazier J, Roberts J, Deverill M. The estimation of a preference-based single index measure for health from the SF-36. J Health Econ 2002;21:271-92.

25. Cohen J. Statistical Power Analysis for the Behavioral Sciences (2nd ed.), New Jersey: Lawrence Erlbaum Associates, ISBN 0-8058-0283-5.

26. Efron B, Tibshirani RJ. An introduction to the bootstrap. London: Chapman \& Hall;1993.

27. Hicken BL, Tucker DC, Barton JC. Patient compliance with phlebotomy therapy for iron overload associated with hemochromatosis. Am J Gastroenterol 2003;98:2072-7.

28. Carroll GJ, Breidahl WH, Bulsara MK, et al. Hereditary hemochromatosis is characterized by a clinically definable arthropathy that correlates with iron load. Arthritis Rheum 2011;63:286-94.

29. Dymock IW, Hamilton EB, Laws JW, et al. Arthropathy of haemochromatosis. Ann Rheum Dis 1970;29:469-76.

30. Edwards $\mathrm{CQ}$, Cartwright $\mathrm{GE}$, Skolnick $\mathrm{MH}$, et al. Homozygosity for hemochromatosis: clinical manifestations. Ann Intern Med 1980;93:519-25.

31. Huaux JP, Geubel A, Koch MC, et al. The arthritis of hemochromatosis. Clin Rheumatol 1986;5:317-24.

32. Schumacher HR, Straka PC, Krikker MA, et al. The arthropathy of hemochromatosis. Ann N Y Acad Sci 1988;526:522-33.

33. Faraawi R, Harth M, Kertesz A, et al. Arthritis in haemochromatosis. J Rheumatol 1993;20:448-52.

34. Sinigaglia L, Fargion S, Fracanzani AL, et al. Bone and joint involment in genetic hemochromatosis: role of cirrhosis and iron overload. J Rheumatol 1997;9:1809-13.

35. Valenti L, Fracanzani AL, Rossi V, et al. The hand arthropathy of hereditary hemochromatosis is strongly associated with iron overload. J Rheumatol 2008;35:153-8.

36. Richette $\mathrm{P}$, Ottaviani S, Vicaut E, et al. Musculoskeletal complications of hereditary hemochromatosis: a case-control study. J Rheumatol 2010;37:2145-50.

37. Askari AD, Muir WA, Rosner IA, et al. Arthritis of hemochromatosis: clinical spectrum, relation of histocompatibility antigens and effectiveness of early phlebotomy. Am J Med 1983;75:957-65. 


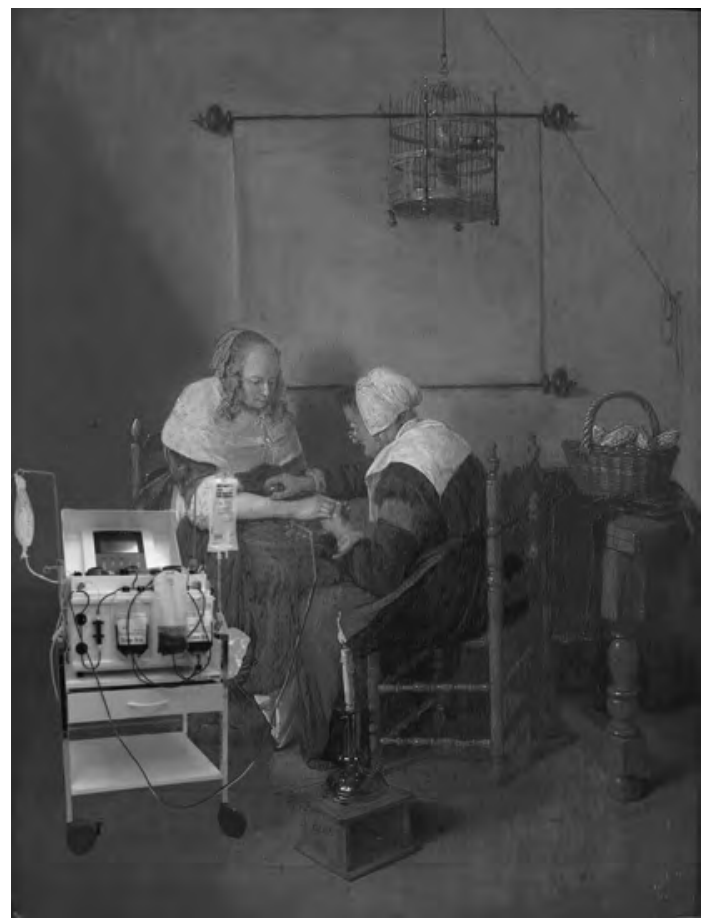

Chapter 7

End-stage cardiomyopathy because of hereditary hemochromatosis successfully treated with erythrocytapheresis in combination with left ventricular assist device support

Eva Rombout-Sestrienkova, Nicolaas De Jonge, Kateřina Martinakova, Corinne Klöpping, Karin PM van Galen, Aryan Vink, Elly MCJ Wajon, Wim M Smit, Cor van Bree, Ger H Koek 


\section{Introduction}

$\mathrm{HH}$ is a common heritable disease, characterized by an increase in iron absorption from the gut inappropriate to body iron stores, resulting in a progressive accumulation of iron in tissues, especially in liver, pancreas, joints, skin en gonads. Cardiac involvement is less frequent (15\%), nevertheless can also occur, causing arrhythmias and in rare cases restrictive or non-ischemic dilated cardiomyopathy (DCM).

Iron overload cardiomyopathy has been defined as the presence of systolic or diastolic cardiac dysfunction secondary to increased deposition of iron in the heart and contribute to mortality and morbidity of $\mathrm{HH}$ patients. ${ }^{1}$ Non-transferrin bound iron enters cardiac myocytes in the ferrous $2+$ form through L-type calcium channels. Iron is then bound to ferritin and transported to lysosome for degradation and long term storage in myocytes. Once the antioxidant capacity of the cell is exceeded, iron is catalyzed by the rapid Fenton reaction producing hydroxyl ions, responsible for membrane permeability alterations. These modifications create a leak of hydrolytic enzymes that initiate cell damage and subsequent cardiac myocyte death. ${ }^{2}$ Pathologic iron depositions begins within the epicardium, extends to the myocardium and finally to the endocardium, which helps explains that early in the disease process patients may be totally asymptomatic, whereas severely overloaded patients can have terminal irreversible heart failure symptoms. Thus, early identification of the disease is very important. Initial clinical presentation is often shortness of breath as a result of left ventricular diastolic dysfunction secondary to a restrictive pathophysiology, with later progress to a dilated cardiomyopathy with left ventricular systolic dysfunction and irreversible heart failure symptoms. ${ }^{2}$

We report a case of heart failure, caused by DCM, in the setting of unrecognized hereditary hemochromatosis, successfully treated with erythrocytapheresis in combination with left ventricular assist device support.

\section{Patient casus}

A 51 year-old man with a two years history of type II diabetes mellitus, erectile dysfunction and 3-month history of fatigue was referred in March 2011 to the cardiology department of a local hospital because of 1 week of progressive dyspnea, orthopnea, leg oedema and increasing abdominal girth. His only medication was tolbutamide and metformin. He drank alcohol sporadically with maximum of $1 \mathrm{drink} / \mathrm{d}$ and had a history of shoulder arthralgia's. On physical examination, the patient had brownish-gray skin pigmentation. He was tachypneic with blood pressure of 105/80 $\mathrm{mmHg}$ and regular heart rate of 118 beats per minute. He had jugular venous distension, bilateral pulmonary crackles, II/VI systolic murmur heard at the apex, ascites and pitting oedema in both lower legs. The ECG showed sinus tachycardia with left atrial and ventricular hypertrophy and repolarization abnormalities. A chest 
radiograph (Figure 7.1) revealed cardiomegaly and bilateral pleural effusion. The echocardiogram showed a dilated left and right ventricle with severely compromised systolic function (left ventricular ejection fraction, 20\%), and no ventricular hypertrophy. There was moderate mitral and tricuspid insufficiency with elevated right sided pressures $(40-45 \mathrm{mmHg})$. Coronary angiography was notable for no significant coronary artery disease, and the diagnosis of a non-ischemic DCM was made. Laboratory findings included increased levels of urea $9.3(2.5-6.4) \mathrm{mmol} / \mathrm{l}$, total bilirubin $21(<17) \mu \mathrm{mol} / \mathrm{l}$, aspartate aminotransferase $51 \quad(<40) \mathrm{U} / \mathrm{l}$, alanine aminotranferase $52(<45) \mathrm{U} / \mathrm{I}$, gamma glutamyltransferase $58(<50) \mathrm{U} / \mathrm{I}, \mathrm{N}$-terminal of the prohormone brain natriuretic peptide $350(<12) \mathrm{pmol} / \mathrm{l}$, and glucose 9.6 (3.6-5.6) $\mathrm{mmol} / \mathrm{l}$. Treatment with diuretics and inotropic agents was begun with initial improvements in his hemodynamics. However, a few days later the patient deteriorated and was transferred to a tertiary center. At that time he was in cardiogenic shock with low blood pressure despite inotropic support and subsequently required an intra-aortic balloon pump. Hemodynamic measurements showed a pulmonary artery pressure of $38 / 24 \mathrm{mmHg}$, mean 29 , with a pulmonary capillary wedge pressure of 24 and a right atrial pressure of $15 \mathrm{mmHg}$ and a cardiac output of $3.8 \mathrm{l} / \mathrm{min}$ (cardiac index, $1.9 \mathrm{l} / \mathrm{min} /$ per meter squared). His clinical condition did not improve so a left ventricle assist device (LVAD) was implanted as a bridge to heart transplantation.

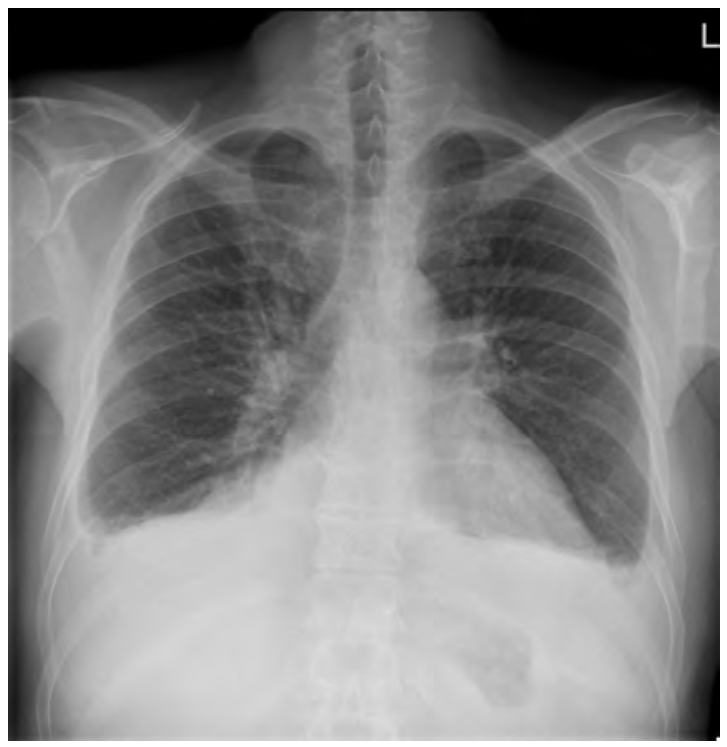

Figure 7.1 Chest radiographs at first admission showing cardiac enlargement, pulmonary congestion and bilateral pleural effusion. 
The myocardium tissue of the left ventricular apex, removed during LVAD implantation, showed widespread iron depositions in the cardiomyocytes (Figure 7.2).
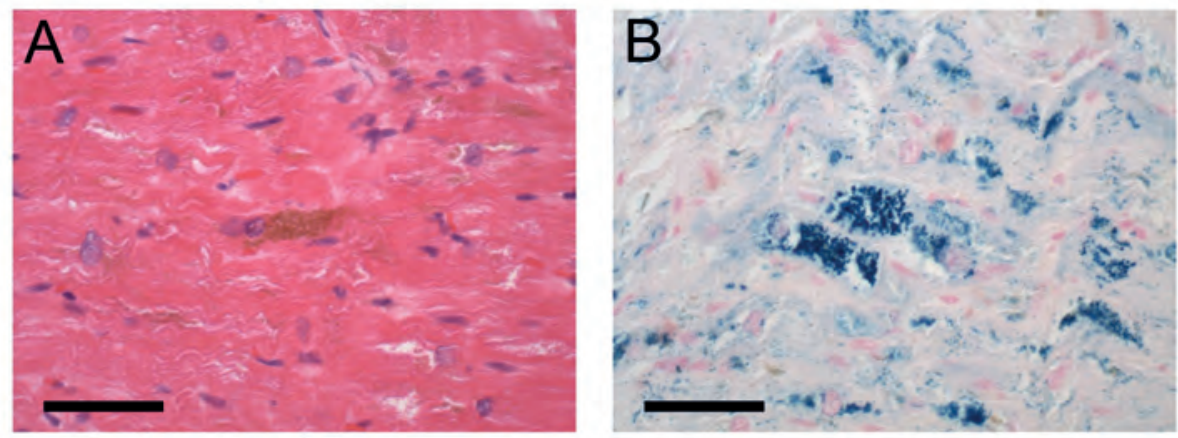

Figure 7.2 Cardiac tissue removed during LVAD implantation.

A. Myocardium of the apex of the left ventricle with brown pigment in the cardiomyocytes. Hematoxylin \& eosin staining, Bar=100 $\mu \mathrm{m}$. B. Prussian blue iron staining showing the iron in blue. Bar $=100 \mu \mathrm{m}$.

These findings were compatible with cardiac hemochromatosis explaining the cause of the DCM. Iron parameters showed elevated serum ferritin (SF) of 3711 (25-250) $\mu \mathrm{g} / \mathrm{I}$ and transferrin saturation of $88 \%$. DNA testing confirmed a homozygous substitution of tyrosine for cysteine at position 282 (C282Y) in the hereditary hemochromatosis (HH) HFE protein. After LVAD implantation, the patient recovered rapidly and was discharged from the hospital. Treatment of iron overload was started with phlebotomy, performed once weekly with a removal of 300 to $500 \mathrm{ml}$ whole blood per procedure (Table 7.1), decreasing the SF level from $3011 \mu \mathrm{g} / \mathrm{l}$ to $1796 \mu \mathrm{g} / \mathrm{l}$. Because of slow SF decrease and side effects such as frequent palpitations, syncope and dizziness during phlebotomy, treatment was switched to erythrocytapheresis with a frequency of one procedure every 2 to 3 weeks. About $500 \mathrm{ml}$ erythrocytes, fully compensated with the same volume of saline per procedure, were removed. In total 20 uneventful erythrocytapheresis procedures were performed over a period of 51 weeks. The total removed erythrocytes volume was $9700 \mathrm{ml}$ with an estimated total iron removal of $7760 \mathrm{mg}$ (Table 7.1). Treatment was stopped at a SF level of $41 \mu \mathrm{g} / \mathrm{l}$. The patients' liver enzymes normalized with no signs of cirrhosis. After the normalization of SF, while on the LVAD, his heart function gradually recovered. Because of the potential option of explantation of the assist device, heart failure medication such as angiotensinconverting enzyme inhibitors and $\beta$-blockers were optimized and repeated echocardiograms and exercise tests were performed while turning off the pump. When these tests all demonstrated sufficient recovery of cardiac function, it was decided to explant the device. This operation, performed 23 month after initial implantation, went uneventful and the patient was discharged from the hospital 8 days after 
explantation. Echocardiographic measurements post- LVAD removal were as follows: left ventricular end-diastolic diameter of 47 (versus 64 pre - LVAD implantation), left ventricular end-systolic diameter of $32 \mathrm{~mm}$ (versus $53 \mathrm{~mm}$ pre-LVAD implantation), and mitral deceleration time 170 ms (versus 100 ms pre- LVAD implantation; Figure 7.3A and 7.3B). Currently, 12 month after the explantation of the LVAD he remains in good clinical condition, New York Heart Association I, without signs of heart failure and near normal left ventricular function.

Table 7.1 Parameters of treatment with phlebotomy and erythrocytapheresis.

\begin{tabular}{lcc}
\hline & Phlebotomy & Erythrocytapheresis \\
\hline Serum Ferritin at the start of treatment $(\mu \mathrm{g} / \mathrm{l})$ & 3011 & 1796 \\
Serum Ferritin at the end of treatment $(\mu \mathrm{g} / \mathrm{l})$ & 1796 & 41 \\
No procedures & 21 & 20 \\
Treatment duration (weeks) & 28 & 51 \\
Treatment interval (days) & 10 & 18,5 \\
Total volume removed $(\mathrm{ml})$ & 8800 (whole blood) & 9700 (erythrocytes) \\
Estimated removal of iron per procedure $(\mathrm{mg})$ & 168 & 388 \\
Estimated total removal of iron $(\mathrm{mg})$ & 3520 & 7760 \\
\hline
\end{tabular}
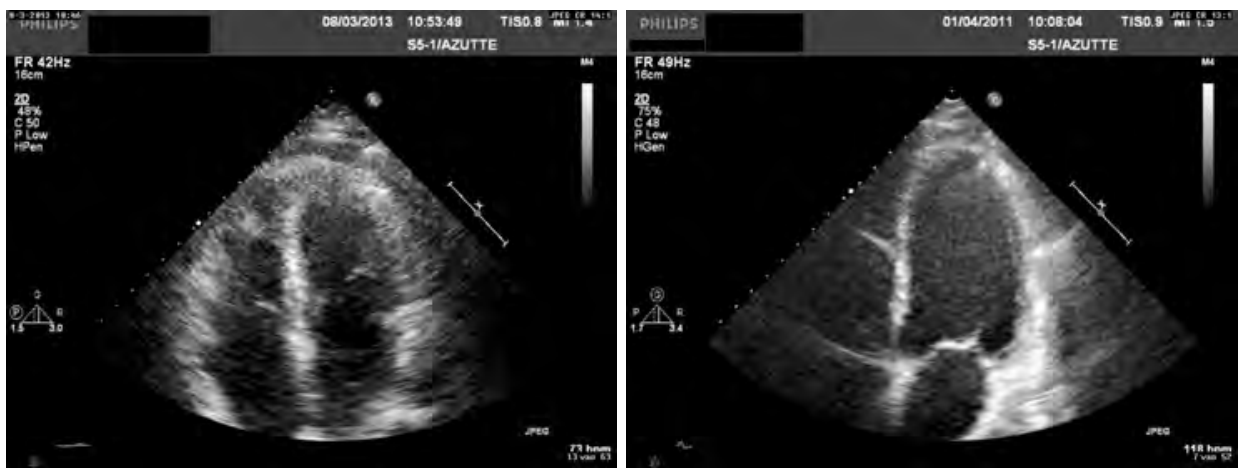

Figure 7.3 Apical 4-chamber view echo pre and post LVAD. A: post LVAD removal. B: pre LVAD implantation.

\section{Discussion}

Standard therapy for patients with primary iron accumulation is phlebotomy.

In this case we described the use of an alternative treatment option, which is erythrocytapheresis. During this procedure erythrocytes are selectively removed from whole blood by aphaeresis, followed by reinfusion of leukocytes, platelets and plasma to the patient. This method has been evaluated in 1 randomized $^{3}$ and a few nonrandomized studies. ${ }^{4,5}$ Results from all shows that erythrocytapheresis is a much 
more effective and faster method and removes at least twice as much iron per single procedure compared with phlebotomy. This is especially advantageous in situations of life- threatening organ complications because of iron overload as in this case. The other important benefit of this method is individualized fluid management during the procedure which makes it more suitable for hemodynamically compromised patients. Prognosis of patients with iron overload cardiomyopathy depends on establisghing the diagnosis early and beginning therapy early. ${ }^{6}$ However, in the presented case, the endstage DCM with severe systolic dysfunction, requiring support from an LVAD, did fully recover after the treatment with erythrocytapheresis. In addition to showing successful treatment of $\mathrm{HH}$ with erythrocytapheresis, this case has 2 other main points: 1) $\mathrm{HH}$ may cause a DCM and 2) therapy for $\mathrm{HH}$ is still worthwhile even when patients present with cardiogenic shock since the patient improved and was able to be explanted without decompensation $\approx 1$ year after LVAD explant. 


\section{References}

1. Liu P, Oliveri N. Iron overload cardiomyopathies: new insight into an old disease. Cardiovasc Drugs Ther 1994;8:101-10.

2. Guijja P, Rosing DR, Tripodi DJ, Shizukuda Y. Iron overload cardiomyopathy. Better understanding of an increasing disorder. J Am Coll Cardiol 2010;56:1001-12.

3. Rombout-Sestrienkova $E$, Nieman FHM, Essers BAB, van Noord PAH, Janssen MCH, van Deursen CThBM, Bos LP, Rombout F, van den Braak R, de Leeuw PW, Koek GH. Erythrocytapheresis versus phlebotomy in the initial treatment of HFE hemochromatosis: results from a randomized trial. Transfusion 2011;52:470-7.

4. Muncunill J, Vaquer P, Galmes A, Galmes A, Obrador A, Parera M, Bargay J, Besalduch J. In hereditary hemochromatosis, red cell apheresis removes excess iron twice as fast as manual whole blood phlebotomy. J Clin Apher 2002;17:88-92.

5. Fernandez-Mosteirin N, Salvador-Osuna C, Garcia-Erce JA, Orna E, Perez-Lungmus G, Giralt M. Comparison between phlebotomy and erythrocytapheresis of iron overload in patients with HFE gene mutations. Med Clin. (Barc) 2006;127:409-12.

6. Murphy CJ, Oudut GY. Iron-overload cardiomyopathy: pathophysiology, diagnosis and treatment. J Card Fail. 2010;16:888-900. 



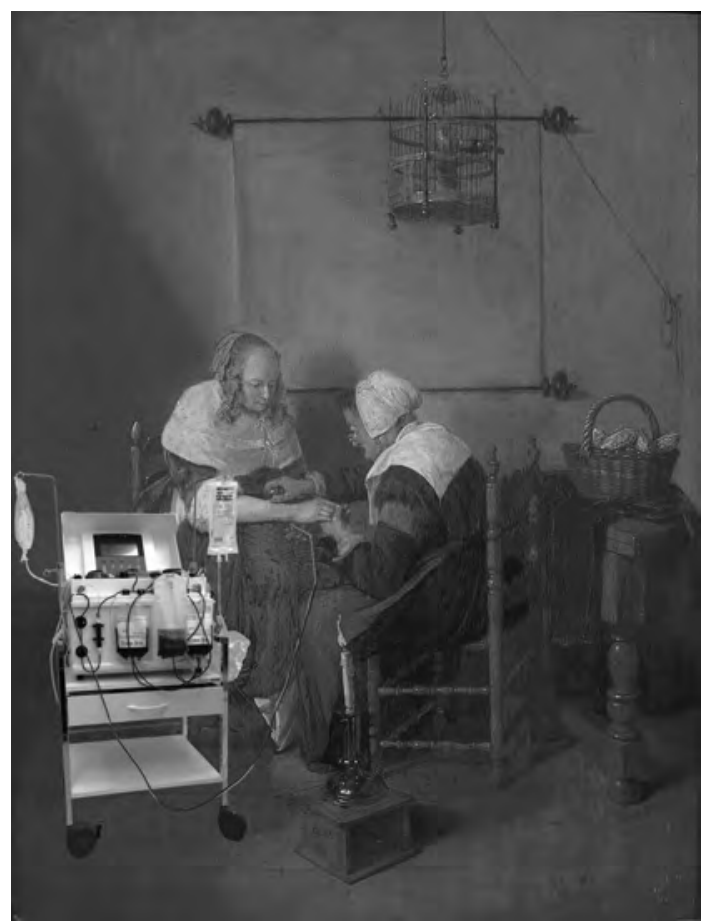

Chapter 8

General discussion 

Hereditary hemochromatosis $(\mathrm{HH})$ is a common genetic disorder, characterized by increased iron absorption that is inappropriate to body iron stores and resulting in progressive accumulation of iron in tissues and organs with impairment of their function, especially in the liver, heart, pancreas, joints, skin and gonads. The treatment is based on the removal of body iron excess and consists of two phases: the depletion phase with the goal of lowering serum ferritin (SF) to target values, and the maintenance phase with the goal to keep the target SF values lifelong stable. Although guidelines advise to target SF below $50 \mu \mathrm{g} / \mathrm{l}$, the majority of experts in the field state that SF levels close to $50 \mu \mathrm{g} / \mathrm{L}$ are the optimal target levels. ${ }^{1,2}$ There are three different types of iron depletion treatments used in $\mathrm{HH}$ patients: phlebotomy, erythrocytapheresis and oral or parenteral chelators. Chelators are only used in selected patients i.e. without appropriate access to peripheral veins and in case of severe anemia.

Phlebotomy has been widely accepted as the standard treatment of $\mathrm{HH}$ for many decades. A more recent alternative for $\mathrm{HH}$ treatment is erythrocytapheresis, a technique using an apheresis machine that selectively removes red blood cells (RBC's) and returns valuable blood components such as plasma proteins, clotting factors, platelets, etc. to the patient. In the last 20 years an increasing number of reports about the use of erythrocytapheresis has been published. Many of these studies showed higher efficacy of erythrocytapheresis compared to phlebotomy, with a significant reduction in the number of needed treatment procedures. Some reports even showed a significant reduction in treatment duration. ${ }^{3-16}$

In the current thesis our aim was to study in a evidence based way the role of erythrocytapheresis in the depletion and maintenance phase of treatment by patients with type $1 \mathrm{HH}$ and we hypothesized that this treatment method would decrease the number of needed treatment procedures with at least $50 \%$, leading to less adverse events, better quality of life, less costs, and better compliance of patients when compared to treatment with phlebotomy (chapter 1).

\section{The depletion phase of treatment}

In chapter 2 we presented a pilot study, performed between 2002 and 2005. Results from newly diagnosed type $1 \mathrm{HH}$ patients $(\mathrm{N}=6)$, treated in the depletion phase with personalized erythrocytapheresis were compared with a historical group of type $1 \mathrm{HH}$ patients $(\mathrm{N}=6)$ treated with standard phlebotomy. We found a reduction of almost $70 \%$ in both, the total number of treatment procedures as well as the total duration of treatment, by use of erythrocytapheresis compared to phlebotomy. However a historical comparison of two small groups has its limitations in concluding that erythrocytapheresis was superior to phlebotomy. It was stated that a prospective study, preferably of a randomized type, was needed to evaluate the differences between these two therapeutic modalities in more detail. 
Therefore we conducted between December 2005 and November 2008 a twotreatment-arms, randomized, clinical trial (RCT), involving 38 newly diagnosed patients with type $1 \mathrm{HH}$, homozygous for $\mathrm{p} . \mathrm{C} 282 \mathrm{Y}$ mutation. The primary outcome measure was the number of treatment procedures to reach the SF target level of $50 \mu \mathrm{g} / \mathrm{l}$ or less. Secondary outcomes were the total duration of treatment, the occurrence of side effects, change in iron status and liver function, health related quality of life and costs. Results from this RCT, comparing erythrocytapheresis with phlebotomy in depletion phase of treatment are presented in chapter 3. It was shown that erythrocytapheresis compared to phlebotomy reduced the number of treatment procedures by $67 \%$ ( $57 \%$ after adjustment for initial SF and body weight) as well as treatment duration by $42 \%$ (30\% after adjustment). The observed reduction ratio of 0.33 (for adjustment) is in agreement with the results of our pilot study. Despite an imbalance in initial SF between both treatment arms after randomization, multivariate analysis with correction for confounders like patient weight and initial SF confirmed the conclusions from the univariate analysis. For number of treatment procedures the reduction ratio of 0.43 as found in the multiple regression analysis was still below the ratio of 0.50 which was set in the protocol as endpoint, but just exceeds the estimated upper $95 \%$ confidence limit of 0.50 . In hindsight, we assume that a somewhat higher power and/or a by baseline SF stratified randomization design might have led to an upper confidence level within the 0.50 or less range.

A post hoc analysis of the data showed that patients with a body weight above $76 \mathrm{~kg}$ had the largest benefit from erythrocytapheresis. Based on the results from this RCT we made recommendations on the treatment with erythrocytapheresis in $\mathrm{HH}$ patients.

\section{Advised treatment regime for the depletion phase}

The recommended procedure frequency is once every 2-3 weeks, depending on hemoglobin recovery. The removed RBC's volume must be individually determined and is dependent on total blood volume (based on sex, body weight and height) and actual hematocrit (Hct) of each individual patient. Usually the removed volume is between $350-800 \mathrm{ml}$ RBC's. The minimal targeted post procedure Hct must be set at $30 \%$, preferably at $32-34 \%$. In patients without co-morbidities and estimated removed RBC's volume $\leq 500 \mathrm{ml}$, substitution is not needed. In case of higher removed RBC's volume, it is recommended to replace $30 \%$ of the removed RBC's volume with isotonic saline, during the first treatment procedure. Depending on how well the patient tolerates the first procedure, $0 \%-50 \%$ of the estimated removed RBC's volume can be replaced in all subsequent treatment procedures. In patients with cardiac disease standard replacement of $50-100 \%$ of removed RBC's volume is recommended.

Monitoring of erythrocytapheresis treatment in depletion phase is identical to phlebotomy treatment with the exception of more frequent SF measurements, which should be measured after every $3^{\text {rd }}$ erythrocytapheresis procedure in the early phase 
of treatment and after every procedure when SF approaches the targeted range of 50-100 $\mu \mathrm{g} / \mathrm{l}$.

\section{The maintenance phase of treatment}

The use of erythrocytapheresis in the maintenance therapy was studied in a cross-over RCT, performed in the period between May 2008 and May 2011, and is described in chapter 6. The primary endpoint was the number of treatment procedures per treatment year. Secondary endpoints were inter-treatment intervals, several aspects of health-related quality of life, costs, and patient discomfort as well as preference for one of both treatments.

Results showed that erythrocytapheresis reduced the number of treatment procedures per treatment year with $42 \%$ and increased inter-treatment interval between two consecutive treatment procedures compared to phlebotomy with 2.3 times. Based on the results of this study we made recommendations on treatment of $\mathrm{HH}$ in the maintenance phase.

\section{Advised treatment regime for the maintenance phase}

In the maintenance phase of $\mathrm{HH}$ treatment the erythrocytapheresis frequency can be reduced and varies between 1-3 procedures per year, sometimes even lower: just one procedure in 1.5-2 years. The policy of monitoring is identical to the phlebotomy treatment: SF measurements every six months.

\section{Adverse events}

The use of apheresis equipment generally leads to a reduction in moderate and severe adverse events compared to phlebotomy. ${ }^{17}$ This is also related to the saline compensation and the longer collection time during apheresis procedures, facilitating trans-capillary refilling of the intravascular compartment. ${ }^{18}$

The most frequent, but still seldom described adverse reactions during therapeutic apheresis procedures include citrate reactions such as muscle cramps, paraesthesia's, nausea, attributable to infusion of citrate, which is used to anti-coagulate the patient's blood entering the apheresis equipment. However, compared to other therapeutic apheresis procedures, patients undergoing erythrocytapheresis, only rarely experience citrate reactions, because of the restricted volume of infused citrate ions, attributed to the restricted procedure time (15-45 minutes for erythrocytapheresis versus 3-5 hours for other therapeutic procedures).

In both studies that are described in chapters $\mathbf{3}$ and $\mathbf{6}$, we have actively screened and monitored for adverse events. 
During the depletion phase of treatment (chapter 3) all adverse events appeared to be mild or very mild in both treatments groups. In the erythrocytapheresis group, three out of 19 patients (15.8\%) reported eight events (one case of very mild citrate reaction, one vasovagal collapse and six cases of mild dizziness) at a total of 171 (4.7\%) procedures. In the phlebotomy group, five of 19 patients (26.3\%) reported 10 events (one short-lasting collapse and nine cases of mild dizziness) at a total of 513 (1.9\%) procedures. This difference was not significant when expressed by number of patients nor when expressed as adverse events per number of required procedures.

During maintenance treatment, as described in chapter 6 , no significant differences were observed between the two treatment methods concerning patient discomfort during and after the treatment procedure.

The both studies showed no difference in adverse events between either phlebotomy or erythrocytapheresis, although the number of patients in these studies was limited and studies were not powered to show a difference in adverse events.

\section{Quality of life}

There was no significant different in quality of life between both treatment methods during the depletion as well during the maintenance phase of treatment. However both studies (chapter $\mathbf{3}$ and chapter $\mathbf{6}$ ) were not powered to show the difference between both methods.

\section{Costs}

One of the most prominent obstacles for the use of erythrocytapheresis in daily practice are the costs of a single procedure.

In the RCT described in chapter $\mathbf{3}$ we indicated that in the Dutch situation the costs were 3.5 higher compared to those of a single phlebotomy. Despite this, total treatment costs during depletion phase of treatment were in the same range or even lower for erythrocytapheresis because of a considerable reduction in the number of total treatment procedures, travel costs and costs resulting from work-absenteeism. It should be taken into account that procedure costs may vary considerably among countries. However, when erythrocytapheresis is more widely used, the costs per single procedure will be reduced due to a more efficient use of equipment and staff. In addition, the collected RBC's may be used for transfusion purposes, which will also reduce the costs. Recent data based on a web-questionnaire completed by 35 blood services from 33 countries indicate that in $69 \%$ of blood services allow blood donation from individuals with genetic hemochromatosis. ${ }^{19}$ 
In the randomized cross-over study described in chapter 6 , the mean costs for an average maintenance treatment per year were $234.68 €$ (range 72.80-436.80 €) for phlebotomy versus $510.53 €$ (range $270.20-810.60 €$ ) for erythrocytapheresis, making a significant difference of $276 €(95 \% \mathrm{Cl} 232-317)$ in favor of phlebotomy. This is in contrast to the cost analysis from our RCT concerning the depletion phase of therapy. This may probably be explained to the fact that for the maintenance phase of therapy fewer treatments per year are needed. It could be assumed that an equal cost/benefit ratio for both treatments can also be reached but after a longer follow up period. Another factor is that in the present study costs resulting from the work-absenteeism were not taken into account, since many participants in this study were already retired.

\section{Preference of patients}

Although, there was no significant difference between quality of life between both methods, the trial performed in the maintenance phase (chapter 6) showed, that erythrocytapheresis is the method of preference for the majority of patients (81\%).

Reasons for preference of erythrocytapheresis were as follows: lower frequency of treatments (48\%), withdrawal of only RBC's and return of other blood components (24\%), effectiveness of the method (9\%), less burden to body and veins (9\%), and better feeling after erythrocytapheresis when compared to phlebotomy (6\%).

\section{Iron parameters}

In chapter 4 we presented results from a retrospective observational study, comparing serum iron parameters in 12 males with type $1 \mathrm{HH}$ during the depletion phase using either phlebotomy $(n=6)$ or erythrocytapheresis $(n=6)$. These results showed, that the more personalized erythrocytapheresis leads to a less pronounced decrease in serum hepcidin. This may be clinically relevant and may prevent a rebound increase in intestinal iron uptake due to a decrease in serum hepcidin, leading to a more or less vicious circle of more frequent treatment procedures as has been observed by treatment with phlebotomy. ${ }^{20,21}$ Furthermore, this study showed that both methods lead to an acute drop of $\mathrm{Hb}$ value, but erythrocytapheresis leads to more stable $\mathrm{Hb}$ value over the whole treatment period by using a more individualized approach and extension of the recovery time period between two consecutive procedures. Although the results of this small retrospective observational study are very tempting, this certainly needs to be confirmed in prospectively conducted studies. 


\section{Predicting the number of treatments}

It would be of great benefit for the patient and his physician when already at start of initial treatment the total number of procedures could be predicted. This may guide them in shared decision making on the best individual therapy, either phlebotomy or erythrocytapheresis and will provide insight in cost effectiveness for instance for the insurance companies. In chapter $\mathbf{5}$ we present a prediction rule that estimates the number of treatment procedures needed for the initial treatment of $\mathrm{HH}$, by either using phlebotomy or erythrocytapheresis. The rule is based on a retrospective data analysis, carried out in 97 newly diagnosed $\mathrm{HH}$ patients (C282Y homozygous), treated with either phlebotomy $(\mathrm{N}=54)$ or erythrocytapheresis $(\mathrm{N}=43)$ until SF reached levels $\leq 100 \mu \mathrm{g} / \mathrm{l}$. Regarding erythrocytapheresis, initial SF, initial hemoglobin ( $\mathrm{Hb})$, and body weight were the best practical predictors, while for phlebotomy these were initial SF and body weight. This model could help physicians to select the most effective treatment modality for the individual patient. It should be kept in mind that this analysis was based partly on retrospective data and that further prospective studies validating and optimizing our predicton model may lead to a calculation tool with a higher predictive quality.

\section{Advantages of erythrocytapheresis}

Erythrocytapheresis appears to be a better tolerated type of treatment applicable to a wider range of patients, including more complicated and older patients. This better tolerance may be the consequence of the possibility for substitution of the removed RBC's volume with saline, albumin or other colloid solutions resulting in fewer hemodynamic changes compared to phlebotomy, making this treatment particularly well suited for patients with cardiac diseases, as described in chapter 7. We described here a case history of a patient with end-stage cardiomyopathy due to $\mathrm{HH}$. This patient was successfully treated with erythrocytapheresis in combination with left ventricular assisted device support. Although this patient was first a candidate for heart transplantation, after de-ironing the cardiac condition of the patient was improved in a way that there was no longer any need for a heart transplantation.

\section{Comparing erythrocytapheresis and phlebotomy}

In the comparison between erythrocytapheresis and phlebotomy it is obvious that phlebotomy is a simple procedure and can be performed in various situations. In contrast, for erythrocytapheresis one needs adequate equipment and trained staff. 
The latter procedure, therefore, is restricted to specially equipped health care centers, or alternatively, to blood donation centers.

The studies presented in this thesis have focused on erythrocytapheresis as alternative therapy for phlebotomy in the depletion and maintenance phase of $\mathrm{HH}$ treatment.

Based on the results of these studies we conclude (Table 8.1) :

- Higher efficacy and efficiency of personalized erythrocytapheresis in both phases of $\mathrm{HH}$ treatment, especially in patients with higher TBV or body weight and in patients with higher $\mathrm{Hb}$ or achievable $\Delta \mathrm{Hct}$

- Cost effectiveness of erythrocytapheresis in the depletion phase of treatment

- Better tolerability of erythrocytapheresis by patients with cardiac disease

- Preference of patients for erythrocytapheresis treatment

- Possibly a positive effect of erythrocytapheresis on the compliance with both the depletion and maintenance treatment through decreasing the number of treatment procedures

- No significant differences in number of adverse events between phlebotomy and erythrocytapheresis

In concordance with these results the current guidelines of the American Association for Apheresis (ASFA) recommend the use of erythrocytapheresis as a first-line therapy for all $\mathrm{HH}$ patients. ${ }^{22}$

\section{Conclusion}

Phlebotomy is still the most widely accepted treatment of $\mathrm{HH}$. However personalized erythrocytapheresis appears to be a more effective treatment modality with an optimal balance between effectiveness, tolerability and costs and is an excellent alternative for phlebotomy. It is especially relevant to take patient preferences into account in the process of shared decision making between patient and physician when discussing alternatives for $\mathrm{HH}$ treatment.

In the future prospectively conducted studies are needed, to assess the effect of erythrocytapheresis on the course of iron parameters with special focus on serum hepcidin, as well as prospective studies validating and optimizing our predicton model. 


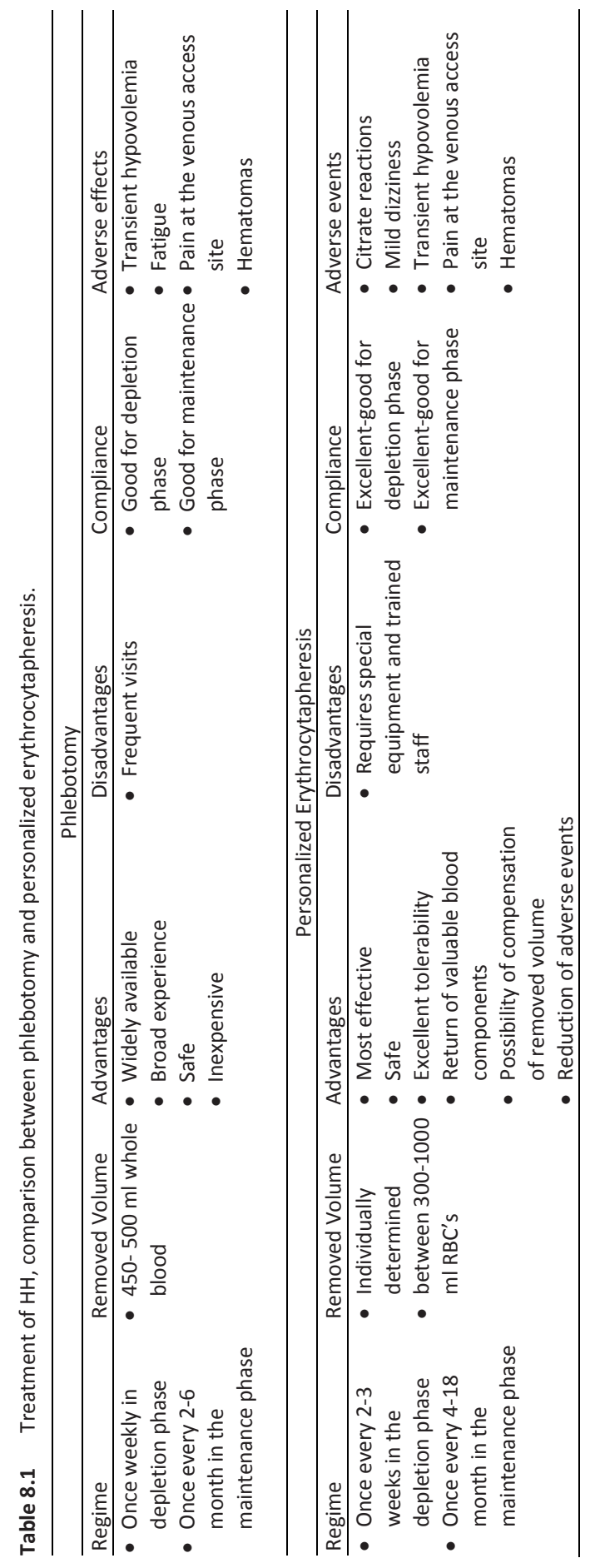




\section{References}

1. Kanwar P, Kowdley KW. Diagnosis and treatment of hereditary hemochromatosis: an update. Expert Rev Gastroenterol Hepatol. 2013;7:517-30.

2. Brissot P. Optimizing the diagnosis and the treatment of iron overload deseases. Expert Rev Gastroenterol Hepatol. 2016;10:359-70.

3. Conte D, Brunelli L, Bozzani A, et al. Erythrocytapheresis in idiopathic haemochromatosis. Br Med J. (Clin Res Ed) 1983; 286:939.

4. Zoller WG, Kellner H, Spengel FA. Erythrocytapheresis. A method for rapid extracorporeal elimination of erythrocytes. Results in 65 patients. Klin Wochenschr. 1988; 66:404-9.

5. Conte D, Mandelli C, Cesana M, et al. Effectiveness of erythrocytapheresis in idiopathic hemochromatosis. Report of 14 cases. Int J Artif Organs. 1989; 12:59-62.

6. Kellner H, Zoller WG. Repeated isovolemic large-volume erythrocytapheresis in the treatment of idiopathic hemochromatosis. Z Gastroenterol. 1992; 30:779-83.

7. Kohan A, Niborski R, Daruich J, et al. Erythrocytapheresis with recombinant human erythropoietin in hereditary hemochromatosis therapy: a new alternative. Vox Sang. 2000; 79:40-5.

8. Muncunill J, Vaquer P, Galmes A, et al. In hereditary hemochromatosis, red cell apheresis removes excess iron twice as fast as manual whole blood phlebotomy. J Clin Apher. 2002; 17:88-92.

9. Mariani R, Pelucchi S, Perseghin P, et al. Erythrocytapheresis plus erythropoietin: an alternative therapy for selected patients with hemochromatosis and severe organ damage. Haematologica. 2005; 90:717-8.

10. Fernandez-Mosteirin N, Salvador-Osuna C, Garcia-Erce JA, et al. Comparison between phlebotomy and erythrocytapheresis of iron overload in patients with HFE gene mutations. Med Clin. (Barc) 2006; 127:409-12.

11. Wijermans $P$, van Egmond $L$, Ypma $P$, et al. Isovolemic erythrocytapheresis technique as an alternative to conventional phlebotomy in patients with polycythemia rubra vera and hemochromatosis. Transfus Apher Sci. 2009; 40:137.

12. Poullin P, Lefevre PA. Effectiveness of therapeutic erythrocytapheresis to achieve iron depletion in hereditary type 1 hemochromatosis: Report of 30 cases. Transfusion Clinique et Biologique. 2011;18: 553-8.

13. Řeháček V, Bláha $M$, Jirušová $H$, Černohorská J, Papoušek P. Therapeutic erythrocytapheresis in the initial treatment of hereditary hemochromatosis. Acta Medica. 2012;55(4):180-5.

14. Stefashyna O, Stern M, Infanti L, Holbro A, Tichelli A, Buser A, O'Meara A. Pattern of care of blood donors with early-uncomplicated hereditary haemochromatosis in a Swiss blood donation centre. Vox Sang. 2014;106:111-7.

15. Evers D, Kerkhoffs JL, Van Egmond L, Schipperus MR, Wijermans PW. The efficiency of therapeutic erythrocytapheresis compared to phlebotomy: A mathematical tool for predicting respons in hereditary hemochromatosis, polycythemia vera, and secondary erythrocytosis. J Clin Apher. 2014; 29:133-8.

16. Sundic T, Hervig T, Hannisdal S, et al. Erythrocytapheresis compared with whole blood phlebotomy for the treatment of hereditary hemochromatosis. Blood Transfus. 2014; 12 Suppl 1:s.84-9.

17. Wiltbank T. Donor reaction rates: a preliminary comparison of automated vs. whole blood procedures. Transfusion. 2002; 42(Suppl): 675.

18. Popovsky MA. Complications of blood donation: manual and automated blood collection procedures. Transf Med and Hemotherapy. 2004; 31: 49-53.

19. Pauwels NS, De Buck E, Compernolle V, Vandekerckhove P. Worldwide policies on haemochromatosis and blood donation: a survey among blood services. Vox Sang. 2013;105,121-8.

20. Van Dijk BA, Laarakkers CM, Klaver SM, Jacobs EM, van Tits L, Janssen MC, Swinkels DW. Serum hepcidin levels are innately low in HFE- related haemochromatosis but differ between C282Yhomozygotes with elevated and normal ferritin levels. Br J Haematol. 2008; 142(6):979-85.

21. Girelli D, Trombini P, Bust F, Campostrini N, Sandri M, Pelucchi S, Westerman M, Ganz T, Nemeth E, Piperno A, Camaschella C. A time course of hepcidine response to iron challenge in patients with HFE and TFR2 hemochromatosis. Haematologica 2011; 94(4):500-6. 
22. Schwartz J, Winters J.L, Padmanabhan A, Balogun RA, Delaney M, Linenberger ML, Szczepiorkowski ZM, Williams ME, Wu Y, Shaz BH. Guidelines on the use of therapeutic apheresis in clinical practiceevidence-based approach from the writing committee of the American society for apheresis: the sixth special issue. J Clin Apher. 2013;28:145-284. 


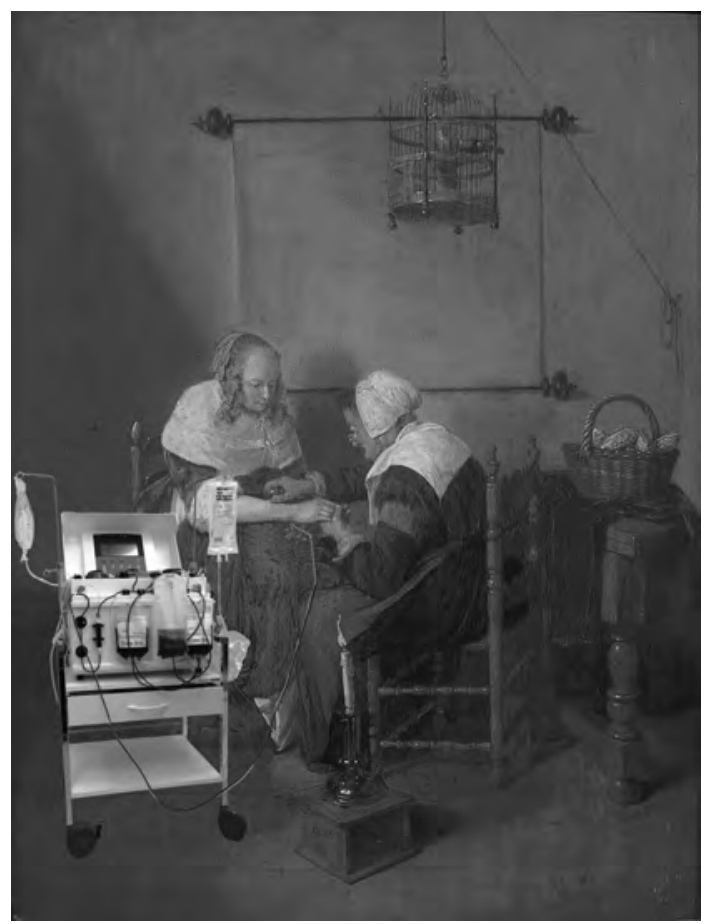

Samenvatting 



\section{Samenvatting}

Hereditaire Hemochromatose $(\mathrm{HH})$ is de meest voorkomende autosomaal recessieve aandoening onder de Noord-Europese bevolking, met een prevalentie van $0,4 \% .{ }^{1} \mathrm{HH}$ wordt gekenmerkt door een toegenomen ijzerabsorptie, die kan leiden tot een overmatige ijzerstapeling in de weefsels en organen met functieverlies als resultaat. De meest frequent aangedane organen zijn lever, hart, alvleesklier, gewrichten, huid en gonaden.

De aandoening is de eerste keer beschreven als "bronze diabetes" door Trousseau in $1865 .^{2}$ De naam hemochromatose is geïntroduceerd door von Recklinghausen in 1889. ${ }^{3}$ Sheldon heeft als eerste in 1953 gewezen op een aangeboren afwijking in het ijzer metabolisme als oorzaak van deze aandoening. ${ }^{4}$ In 1996 werd door Feder de mutatie in het zogenaamde HFE gen, die verantwoordelijk is voor het klinische beeld bij de meerderheid van de patiënten, ontdekt. ${ }^{5}$

Op dit moment zijn 4 typen van $\mathrm{HH}$ bekend, waarbij type 1, de zogenaamd HFE gerelateerde $\mathrm{HH}$, het meest voorkomende is. De meest voorkomende mutatie, gelokaliseerd op de korte arm van chromozoom 6, is G-A transitie op de nucleotide 845 van het HFE gen, resulterend in substitutie van cysteïne door tyrosine in aminozuur 282, aangegeven als p.C282Y (subtype 1a). In de bevolking van Noord-Europa komt homozygotie voor deze mutatie bij 1 op 200-300 inwoners voor. Echter slechts 1-33\% van alle homozygote dragers ontwikkelt ook het klinische beeld van ijzerstapeling. De penetrantie van de aandoening is veel lager bij de vrouwen dan bij mannen $(1,2 \%$ versus $28,4 \%) .^{8}$ Dit komt door het fysiologische bloedverlies tijdens menstruaties, ijzerverbruik in de zwangerschap en het anti-oxidante effect van oestrogenen. Daarnaast spelen hogere hepcidine levels een rol. Dit is waargenomen in muizen ${ }^{8}$ en bij p.C282Y homozygote vrouwen met een $\mathrm{BMI} \geq 28 \mathrm{~kg} / \mathrm{m}^{2}{ }^{2}$. Een ander bekend subtype (subtype 1 b) is de p.H63D mutatie. Deze mutatie veroorzaakt geen klinisch relevante ijzerstapeling, maar kan als cofactor in combinatie met een p.C282Y mutatie een bijdrage leveren aan het ontwikkelen van het klinische beeld van ijzerstapeling. De andere, niet HFE gerelateerde, $\mathrm{HH}$ genotypen hebben een zeer lage prevalentie. Type $2 \mathrm{HH}$ is geassocieerd met mutaties in het hemojuvelin (subtype 2a) of het hepcidine (subtype $2 \mathrm{~b}$ ) gen. Type $3 \mathrm{HH}$ wordt veroorzaakt door mutaties in het transferinne receptor gen en type 4 ( $A$ en $\mathrm{B}$ ) $\mathrm{HH}$ door mutaties in het ferroportin gen. Een andere vorm van ernstige ijzerstapeling is aceruloplasminemia, veroorzaakt door afwezigheid van het feroxidase enzym ceruloplasmine. Deze ziekte wordt gekarakteriseerd door ijzerstapeling in verschillende organen inclusief het centrale zenuwstelsel.

De types 1, 2, en 3 zijn gekarakteriseerd door onvoldoende aanmaak van hepcidine, een peptide dat een sleutelrol speelt in de homeostase van het ijzer metabolisme. ${ }^{10-11}$ Alleen bij type 4 is de productie van hepcidine normaal, maar is de export functie van ferroporin verloren gegaan $(4 A)$ of is de receptor functie van ferroportine veranderd (4B). 
De manifestatie van $\mathrm{HH}$ is zeer divers en varieert van alleen genetische afwijkingen (genotype), biochemische afwijkingen (biochemische fenotype) tot ernstige orgaan beschadiging (klinische fenotype). Ongeveer een derde van alle patiënten ontwikkelt het klinische ziektebeeld. De meest voorkomende afwijking bij klinische onderzoek is hepatomegalie. ${ }^{6}$ De meest voorkomende symptomen zijn chronische vermoeidheid, gewrichtsklachten, buikklachten en verhoogde levertransanminasen. ${ }^{12-13}$ Als de ziekte niet tijdig wordt herkend en behandeld, geeft de door ijzer geïnduceerde activatie van "stellate cellen" aanleiding tot fibrose vorming en uiteindelijk progressie tot levercirrose en het ontwikkelen van een hepatocellulair carcinoom. ${ }^{14}$ Levercirrhose en hepatocellulair carcinoom zijn de meest voorkomende doodsoorzaak bij niet behandelde $\mathrm{HH}$ patiënten. Andere complicaties van gevorderde $\mathrm{HH}$ zijn diabetes, veroorzaakt door ijzerstapeling in de alvleesklier, cardiomyopathie en hartritmestoornissen, veroorzaakt door ijzerstapeling in het hart, impotentie en hypogonadotroop hypogonadisme, veroorzaakt door ijzerstapeling in de hypofyse en testis en artropathie en arthritiden met primaire betrokkenheid van $2^{\text {de }}$ en $3^{\text {de }}$ metacarpo-phalangeale gewrichten. Sommige manifestaties zoals vermoeidheid, pigmentaties van de huid en leverfibrose, kunnen met adequate behandeling afnemen, andere complicaties, eenmaal opgetreden, zijn onomkeerbaar. ${ }^{15-16}$ Behandeling in een vroeg stadium kan complicaties van ijzerstapeling voorkomen. De levensverwachting van adequaat behandelde patiënten verschilt niet van de populatie zonder deze aandoening, mits de ziekte is gediagnosticeerd voor de ontwikkeling van diabetes en cirrhose. ${ }^{17-19}$

Voor het stellen van de diagnose zijn verhoogde waardes van serum ferritine (SF) en transferrine saturatie (TS) van belang. De diagnose wordt bevestigd met genetische onderzoek naar de p.C282Y mutatie. Patiënten die negatief zijn voor deze mutatie maar bij wie ijzerstapeling in de organen is aangetoond, dienen te worden onderzocht op bijzondere mutaties. Bij patiënten die homozygoot zijn voor de p.C282Y mutatie is genetische screening bij volwassen eerste graads familie leden geïndiceerd. ${ }^{20}$ Een leverbiopsie is niet langer nodig voor het bevestigen van de diagnose, maar wordt wel geadviseerd voor de stadiëren van de graad van fibrose, mits de SF waarde boven $1000 \mu \mathrm{g} / \mathrm{I}^{21}$ is. Tegenwoordig worden "magnetic resonance imaging" (MRI) technieken gebruikt voor het evalueren van de hoeveelheid ijzeropslag in organen. Echter er zijn meer prospectieve studies en gestandaardiseerde protocollen nodig voordat de toepassing van MRI in diagnostiek en de evaluatie van de behandeling standaard gaat worden.

Behandeling van $\mathrm{HH}$ is gebaseerd op het verwijderen van overmaat van lichaam ijzer en bestaat uit twee fasen, de initiële /depletie fase en de onderhoud fase. Het doel van de initiële fase is het verlagen van SF tot streefwaarden. Het doel van de onderhoudsfase is het handhaven van de streef SF-waarde tijdens een levenslange behandeling.

Voor het ontijzeren kunnen drie verschillende behandelmethodes toegepast worden: aderlating, erytrocytaferese en toedienen van chelatoren. De laatst genoemde optie 
wordt alleen gebruikt in geselecteerde groepen van patiënten, namelijk patiënten met een moeizame veneuze toegang of patiënten met bloedarmoede.

Aderlating is momenteel breed geaccepteerd als standaard behandeling en bestaat tijdens de depletie fase uit wekelijkse afname van $500 \mathrm{ml}$ volbloed. Het totaal aantal uit te voeren procedures varieert afhankelijk van de initiële SF waarde en de voorraad opgeslagen ijzer en kan oplopen tot meer dan honderd behandelingen in een periode van 2 jaar. In de onderhoudsbehandeling fase bedraagt het aantal behandelingen 2-6 per jaar. De meest voorkomende bijwerkingen van deze behandeling zijn moeheid, flauwvallen, pijn ter plaatse van de punctie, bloeduitstorting en bloedarmoede. Ongeveer $52 \%$ van alle patiënten in de initiële fase en $37 \%$ in de onderhoudsfase melden bijwerkingen van de behandeling. Zelfs $16 \%$ van de patiënten zou overwegen te stoppen met aderlatingen, mits een alternatieve behandeling beschikbaar zou zijn. ${ }^{22}$

Een van de alternatieven is het gebruik van erytrocytaferese, een selectieve afname van erytrocyten door middel van een afereseprocedure. Met deze behandeling is het mogelijk per procedure 300-1000 ml erytrocyten af te nemen, waardoor er significant minder procedures nodig zijn voor initiële ontijzeren in vergelijking met aderlating. Een bijkomend voordeel van deze behandeling is teruggave van plasma, witte bloedcellen en bloedplaatjes aan de patiënt. Om die reden is de behandeling geschikt voor patiënten met een verlaagd aantal bloedpaatjes of laag proteïne gehalte. Tot de mogelijkheden behoort ook compensatie van de afgenomen volume met fysiologische zout of colloïden. Hierdoor is de procedure ook geschikt voor patiënten met cardiovasculaire of hemodynamische problematiek.

In de laatste 20 jaar zijn er meerdere publicaties verschenen die wijzen in de richting van een hogere effectiviteit van erytrocytaferese. ${ }^{22-35}$

Het doel van dit proefschrift was om op een "evidence-based" manier de rol van erytrocytaferese in beide fasen van de behandeling te evalueren. Onze hypothese was dat deze behandelmethode het aantal benodigde behandelingen met ten minste $50 \%$ zal verlagen. Daarmee zullen bijwerkingen en behandelkosten dalen en kan de kwaliteit van leven en therapietrouw van patiënten stijgen.

In Hoofdstuk $\mathbf{1}$ is een overzicht gegeven van geschiedenis, pathofysiologie, diagnostiek, klinische verschijningsvormen en huidige behandelingen van hereditaire hemochromatose.

\section{Depletie fase van de behandeling}

Hoofdstuk 2 presenteert de resultaten van een pilot studie. Nieuw gediagnosticeerde patiënten met type $1 \mathrm{HH}(n=6)$, behandeld in de depletie fase met erytrocytaferese werden vergeleken met een historische controle groep $(n=6)$ van patiënten met type 1 $\mathrm{HH}$, behandeld met aderlating. In de groep behandeld met erytrocytaferese hebben 
we een reductie van bijna $70 \%$ in het aantal behandelingen en ook van de totale duur van de depletie fase kunnen waarnemen. Dit bevestigde dat erytrocytaferese superieur is aan aderlating. Bij deze studie dienen we de beperking in design, van een historische vergelijking van twee kleine patiënten groepen te verdisconteren.

In de periode tussen 2005 en 2008 hebben we een gerandomiseerde klinische trial (RCT) uitgevoerd, waarin we erytrocytaferese met aderlating in de depletie fase van behandeling hebben vergeleken. Het betrof een groep van 38 nieuw gediagnosticeerde patiënten met type $1 \mathrm{HH}$, homozygoot voor p.C282Y mutatie. De primaire uitkomst van deze studie was het aantal behandelingen dat nodig was om de targetwaarde van SF van $50 \mu \mathrm{g} / \mathrm{l}$ te bereiken. Secundaire uitkomstmaten van de studie waren: de totale duur van depletie fase, het optreden c.q. voorkomen van bijwerkingen, veranderingen in ijzerstatus en leverfuncties, kwaliteit van leven en kosten. De resultaten van deze RCT zijn in hoofdstuk 3 beschreven. We vonden dat het toepassen van erytrocytaferese, vergeleken met aderlating, het aantal behandelingen met $67 \%$ deed afnemen ( $57 \%$ na de correctie voor de initiële waardes van SF en het lichaamsgewicht), alsmede de behandelingsduur van de depletie fase met $42 \%$ (30\% na de correctie). De geobserveerde reductie van $67 \%$ (voor correctie) voor het aantal behandelingen komt overeen met de resultaten van onze pilot studie. Er bestond ongelijkheid betreffende initiële waardes van SF tussen beide groepen na randomisatie. Echter, ook multivariate analyse met correctie voor confounders, zoals de initiële waarde van SF en het lichaamsgewicht, bevestigde de conclusies van de univariate analyse. Achteraf een gestratificeerde randomisatie, betreffende initiële waardes van SF, bleek de beste oplossing voor eventuele toekomstige studies. Een post-hoc analyse van de data liet zien dat patiënten met lichaamsgewicht boven $76 \mathrm{~kg}$ de meeste baat hadden bij toepassen van erytrocytaferese. Gebaseerd op de uitslagen van deze studie hebben we voorstellen gemaakt voor behandel-regimes tijdens depletie fase van de behandeling.

\section{Geadviseerd behandel regime voor de depletie fase}

- Behandel procedures uitvoeren in een frequentie van eenmaal in de 2-3 weken, afhankelijk van de waarde van het hemoglobine gehalte.

- De hoeveelheid van de af te nemen erytrocyten individueel bepalen, afhankelijk van het totale bloedvolume van de patiënt (bepaald door geslacht, lichaamsgewicht en lengte) en de actuele hematocriet waarde van de patiënt.

- De minimale waarde van post procedure hematocriet instellen op een ondergrens van $30 \%$, bij voorkeur $32-34 \%$.

\section{IJzer parameters}

In de hoofdstuk 4 zijn de resultaten gepresenteerd van een retrospectieve observationele studie, waarin we serum ijzer parameters bij 12 mannelijke patiënten met type $1 \mathrm{HH}$ tijdens de depletie fase van de behandeling hebben vergeleken. Zes patiënten werden behandeld met aderlating en 6 met erytrocytaferese. Deze 
resultaten lieten zien dat gepersonaliseerde erytrocytaferese lijdt tot minder uitgesproken daling van het serum hepcidine. Dit kan klinisch relevant zijn en kan een verhoogde ijzer-resorptie veroorzaakt door de daling van hepcidine zelfs voorkomen. Verder liet deze studie zien dat erytrocytaferese leidt tot meer stabiele waardes van het hemoglobine gehalte tijdens de gehele behandelfase. Dit wordt veroorzaakt door een langere herstelperiode tussen twee opeenvolgende behandelingen. Al deze resultaten dienen te worden bevestigd in prospectieve studies.

\section{Het voorspellen van het aantal behandelingen}

In het hoofdstuk $\mathbf{5}$ presenteren we een predictie model, welke het aantal behandelingen inschat tijdens de depletie fase, bij het gebruik van aderlating of erytrocytaferese. Dit model is gebaseerd op de retrospectieve data van in totaal 97 nieuw gediagnosticeerde patiënten met type $1 \mathrm{HH}$, behandeld met aderlating (54) of erytrocytaferese (43) tot serum ferritine (SF) waarde tussen 50-100 $\mu \mathrm{g} / \mathrm{l}$. Wat betreft erytrocytaferese waren de initiële waarde van SF, initiële waarde van hemoglobine en lichaamsgewicht de beste voorspellers. Voor de aderlating waren dat de initiële waarde van SF en lichaamsgewicht. Dit model kan behandelaren en patiënten samen helpen om de meest effectieve behandelmethode voor een individuele patiënt te selecteren. Verder kan het model inzicht geven in kosteneffectiviteit van beide methodes bij de start van de behandeling. Omdat deze studie deels is verricht op retrospectieve data, is het nodig om het predictie model prospectief te valideren in de nabije toekomst.

\section{Onderhoudsfase van de behandeling}

De toepassing van erytrocytaferese in de onderhoudsfase van de behandeling is bestudeerd in een cross-over gerandomiseerde studie, uitgevoerd in de periode tussen 2008-2011 en beschreven in hoofdstuk 6. De resultaten laten zien, dat erytrocytaferese het aantal behandelingen per jaar met $42 \%$ doet afnemen en verlengt 2,3 maal het interval tussen twee behandelingen. Gebaseerd op deze resultaten hebben we adviezen opgesteld voor de onderhoudsfase van de $\mathrm{HH}$ behandeling.

\section{Geadviseerd behandel regime voor de onderhoudsfase}

- De frequentie van behandel procedures verlagen tot 1-3 procedures per jaar, soms is zelfs 1 procedure in 1,5 tot 2 jaar voldoende.

In het hoofdstuk $\mathbf{7}$ is een bijzondere casus beschreven: een patiënt in de eindfase van cardiomyopathie, veroorzaakt door cardiale siderose bij HH type 1. Deze patiënt werd succesvol behandeld met erytrocytaferese in combinatie met een kunsthart. Ondanks dat deze patiënt in de eerste instantie een kandidaat was voor harttransplantatie, was na ontijzering door middel van de erytrocytaferese zijn algehele conditie zodanig verbeterd, dat behandeling met transplantatie niet meer nodig was. Deze casus laat 
zien dat erytrocytaferese een goed verdraagbare behandeling is, zelfs bij de patiënten die hemodynamisch instabiel of gecompromitteerd zijn.

\section{Bijwerkingen van de behandeling}

In de beide gerandomiseerde studies beschreven in hoofdstuk $\mathbf{3}$ en $\mathbf{6}$ hebben we actief het voorkomen van de bijwerkingen gemonitord. In het algemeen leidt de toepassing van de aferese techniek tot verlaging van het aantal bijwerkingen. Dit is toe te schrijven aan het gebruik van fysiologisch zout voor het compenseren van het verwijderde volume van erytrocyten en aan de langere collectie tijd.

De meest voorkomende maar nog steeds zeldzame bijwerkingen bij het toepassen van erytrocytaferese zijn de reacties op het gebruik van citraat, dat als een antistollingsmiddel wordt toegepast.

Beide gerandomiseerde studies lieten geen significant verschil zien in het aantal bijwerkingen bij toepassing van erytrocytaferese, vergeleken met het aantal bijwerkingen tijdens behandeling met aderlating. Dit komt omdat bijwerkingen zeldzaam zijn en het aantal geïncludeerde patiënten beperkt was.

\section{Kosten}

Een echt obstakel bij de dagelijkse toepassing van erytrocytaferese wordt gevormd door de kosten van de behandeling. In de gerandomiseerde studie beschreven in hoofdstuk 3, lieten we zien dat kosten voor een enkele erytrocytaferese procedure ruim 3,5 maal hoger zijn dan kosten voor een aderlating procedure. Desondanks, zijn de totale kosten voor de gehele depletiefase, in dezelfde range, of zelfs lager, in vergelijking met aderlating. Dit is toe te schrijven aan een significante reductie in het totaal aantal behandelingen, reiskosten en kosten gerelateerd aan werkverzuim.

In de gerandomiseerde studie beschreven in hoofdstuk 6, waren de gemiddelde kosten per jaar onderhoudsbehandeling $€ 234$ bij de toepassing van aderlating, versus $€ 510$ bij de toepassing van erytrocytaferese. Dit verschil in kosten in onderhoud versus depletiefase van behandeling is te verklaren door het veel geringer aantal behandelingen. Ook speelt een rol het feit dat we in deze studie geen rekening hebben gehouden met kosten veroorzaakt door werkverzuim, dit ten gevolge van een grotendeels gepensioneerde populatie in deze studie.

\section{Voorkeur van patiënten}

Ondanks het gegeven dat er geen verschil werd waargenomen tussen kwaliteit van leven in beide studies, hadden patiënten wel een duidelijke voorkeur voor de behandeling met erytrocytaferese (81\%), zoals we hebben laten zien in hoofdstuk 6 . De belangrijkste redenen voor de keuze van erytrocytaferese waren: hogere effectiviteit en lagere aantal van de behandelingen, teruggave van resterende onderdelen van bloed aan de patiënt, minder belasting voor het lichaam en aders en betere algemene welzijn gevoel na de behandeling, in vergelijking met aderlating. 
Betreffende de behandellocatie koos de meerderheid van de patiënten voor de bloedbank (78\%). Onderbouwing voor deze keuze was persoonlijke aandacht, vriendelijk en professioneel personeel en rustige omgeving.

\section{Conclusie (hoofdstuk 8)}

Aderlating is nog steeds de meest frequent toegapaste behandeling van patiënten met $\mathrm{HH}$. Dit ondanks sterke aanwijzingen dat gepersonaliseerde erytrocytaferese een meer effectieve behandeling is dan aderlating met een goede balans tussen effectiviteit, tolerantie en kosten. De patiënt staat centraal en rekening houden met patiënten voorkeuren in behandeling is leidend.

In de toekomst zijn prospectief uitgevoerde gerandomiseerde studies nodig, om het effect van erytrocytaferese op het beloop van ijzerparameters te beoordelen. Daarnaast willen we in prospectieve studies, uitgevoerd in meerdere centra, ons predictie model valideren. 


\section{Referenties}

1. Van Bokhoven MA, van Deursen CThBM, Swinkels DW. Diagnosis and management of hereditary hemochromatosis. BMJ 2011;342:c7251

2. Trousseau A. Glycosurie, Diabète sucré. Clinique Médical de l'Hôtel-Dieu de Paris. 2nd edition, vol.2. Bailière, Paris. 1865:663-98.

3. Von Recklinghausen FD. Hämochromatose. Tageblat der Naturforschenden Versammlung (1889), Heidelberg, 1890:324.

4. Sheldon J. Haemochromatosis. Oxford University Press, London, UK. 1953.

5. Feder JN, Gnirke A, Thomas W et al. A novel MHC class I-like gene is mutated in patients with hereditary hemochromatosis. Nature Genetics. 1996;13:399-408.

6. Pietrangelo A. Hereditary hemochromatosis: pathogenesis, diagnosis, and treatment. Gastroenterology. 2010;139:393-408.

7. Allen KJ, Gurrin LC, Constantine CC et al. Iron-overload-disease in HFE hereditary hemochromatosis. New Engl J Med. 2008;358:221-230.

8. Krijt J, Cmejla R, Sykora V, Vokurka M, Vyoral D, Necas E. Different expression patern of hepcidin genes in the liver and pancreas of C57BL/6N and DBA/2N mice. J Hepatol. 2004;40:891-896.

9. Desgrippes R, Lainé $F$, Morcet J, Perrin M, Manet $G$, Jezequel C, Bardou-Jacquet $E$, Ropert M, Deugnier $\mathrm{Y}$. Decreased iron burden in overweight $\mathrm{C} 282 \mathrm{Y}$ homozygous women: Putative role of increased hepcidin production. Hepatology. 2013;57(5):1784-92.

10. Park $\mathrm{CH}$, Valore EV, Waring AJ, Ganz T. Hepcidin, a urinary antimicrobial peptide synthesized in the liver. J Biol Chem. 2001;276(11):7806-10.

11. Ganz, T. Hepcidin, a key regulator of iron metabolism and mediator of anemia of inflammation. Blood. 2003;102:783-8.

12. Swinkels DW, Aalbers N, Elving LD, Bleijenberg G, Swanink CM, van de Meer JW. Primary hemochromatosis: a missed cause of chronic fatigue syndrome?, Neth J Med. 2002;60:429-433.

13. Janssen $\mathrm{MCH}$, Swinkels DW. Hereditary haemochromatosis. Best Pract Res Clin Gastroenterol. 2009;23:171-183.

14. Barton JC, Edwards CQ, Phatak PD, Britton RS, Bacon BR. Iron toxicity. In: Barton JC, Edwards CQ, Phatak PD, Britton RS, Bacon BR. Handbook of Iron Overload Disorders. Cambridge, England: Cambridge University Press, 28-33.

15. Bomford A, Williams R. Long term results of venesection therapy in idiopathic haemochromatosis. QJM.1976;45:611-623.

16. Falize L, Guillygomarc'h A, Perrin M, Lainé F, Guyader D, Brissot $P$, Turlin B, Deugnier Y. Reversibility of hepatic fibrosis in treated genetic hemochromatosis: a study of 36 cases. Hepatology. 2006;44:472477.

17. Milman N, Pederson P, á Steig T, Byg KE, Gradual N, Fenger K. Clinically overt hereditary hemochromatosis in Denmark 1948-1985:epidemiology, factors of significance for long-term survival, and causes of death in 179 patients. Ann Hematol. 2001;80:737-744.

18. Niederau C, Fisher R, Pursuchel A, Stremmel W, Haussinger D, Strohmayer G. Long-term survival in patients with hereditary hemochromatosis. Gastroenterology. 1996;110:1107-1119.

19. Wojcik JP, Speechley MR, Kerstesz AE, Chakrabarti S, Adams PC. Natural history of C282Y homozygotes for hemochromatosis. Can J Gastroenterol. 2002;16:297-302.

20. Porto G, Brissot P, Swinkels DW, Zoller H, Kamarainen O, Patton S, Alonso I, Morris M, Keeney S. EMQN best practice guidelines for the molecular genetic diagnosis of hereditary hemochromatosis (HH). Eur J Hum Genet. 2016;24:479-495.

21. Brissot P, Ball S, Rofail D, Cannon H, Wu Jin V. Hereditary hemochromatosis: patient experiences of the disease and phlebotomy treatment. Transfusion. 2011;51:1331-1338.

22. Conte D, Brunelli L, Bozzani A, et al. Erythrocytapheresis in idiopathic haemochromatosis. Br Med J. (Clin Res Ed) 1983;286:939.

23. Zoller WG, Kellner H, Spengel FA. Erythrocytapheresis. A method for rapid extracorporeal elimination of erythrocytes. Results in 65 patients. Klin Wochenschr. 1988;66:404-9.

24. Conte D, Mandelli C, Cesana M, et al. Effectiveness of erythrocytapheresis in idiopathic hemochromatosis. Report of 14 cases. Int J Artif Organs. 1989;12:59-62. 
25. Kellner H, Zoller WG. Repeated isovolemic large-volume erythrocytapheresis in the treatment of idiopathic hemochromatosis. Z Gastroenterol. 1992;30:779-83.

26. Kohan A, Niborski R, Daruich J, et al. Erythrocytapheresis with recombinant human erythropoietin in hereditary hemochromatosis therapy: a new alternative. Vox Sang. 2000;79:40-5.

27. Muncunill J, Vaquer P, Galmes A, et al. In hereditary hemochromatosis, red cell apheresis removes excess iron twice as fast as manual whole blood phlebotomy. J Clin Apher. 2002;17:88-92.

28. Mariani R, Pelucchi S, Perseghin P, et al. Erythrocytapheresis plus erythropoietin: an alternative therapy for selected patients with hemochromatosis and severe organ damage. Haematologica. 2005;90:717-8.

29. Fernandez-Mosteirin N, Salvador-Osuna C, Garcia-Erce JA, et al. Comparison between phlebotomy and erythrocytapheresis of iron overload in patients with HFE gene mutations. Med Clin. (Barc) 2006;127:409-12.

30. Wijermans $\mathrm{P}$, van Egmond L, Ypma $\mathrm{P}$, et al. Isovolemic erythrocytapheresis technique as an alternative to conventional phlebotomy in patients with polycythemia rubra vera and hemochromatosis. Transfus Apher Sci. 2009; 40:137.

31. Poullin P, Lefevre PA. Effectiveness of therapeutic erythrocytapheresis to achieve iron depletion in hereditary type 1 hemochromatosis: Report of 30 cases. Transfusion Clinique et Biologique. 2011;18: 553-8.

32. Řeháček V, Bláha $M$, Jirušová $H$, Černohorská J, Papoušek $P$. Therapeutic erythrocytapheresis in the initial treatment of hereditary hemochromatosis. Acta Medica. 2012;55(4):180-185.

33. Evers D, Kerkhoffs JL, Van Egmond L, Schipperus MR, Wijermans PW. The efficiency of therapeutic erythrocytapheresis compared to phlebotomy: A mathematical tool for predicting respons in hereditary hemochromatosis, polycythemia vera, and secondary erythrocytosis. J Clin Apher. 2014;29:133-138.

34. Sundic T, Hervig T, Hannisdal S, et al. Erythrocytapheresis compared with whole blood phlebotomy for the treatment of hereditary hemochromatosis. Blood Transfus. 2014;12 Suppl 1:s.84-9.

35. Stefashyna O, Stern M, Infanti L, Holbro A, Tichelli A, Buser A, O'Meara A. Pattern of care of blood donors with early-uncomplicated hereditary haemochromatosis in a Swiss blood donation centre. Vox Sanguinis. 2014;106:111-117. 



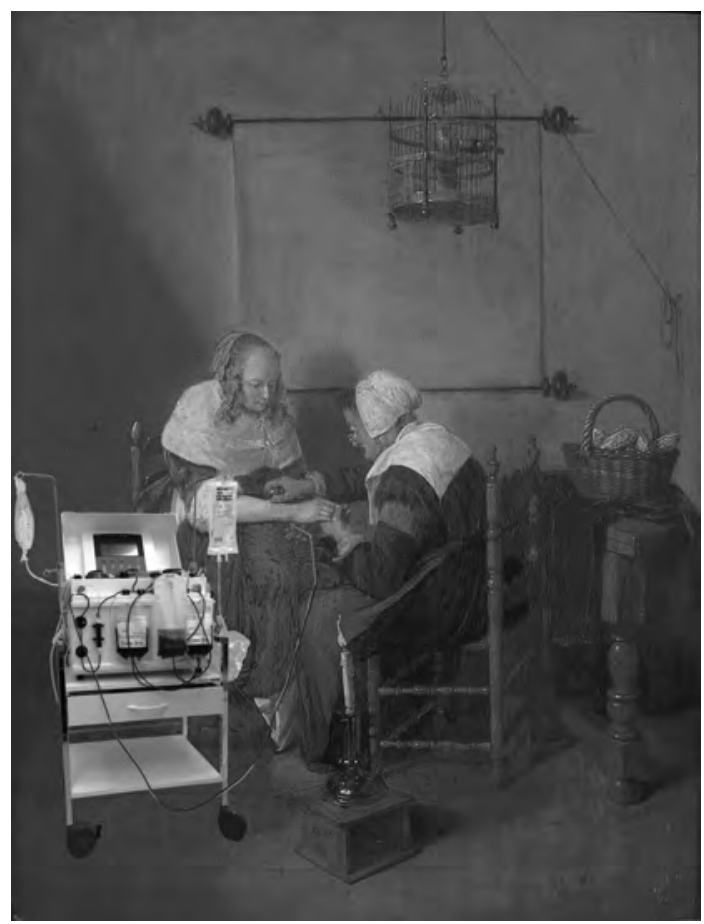

Valorization 



\section{Valorization}

Hereditary hemochromatosis $(\mathrm{HH})$ is the most common autosomal recessive disorder in the population of north European origin. The disease is characterized by increased iron absorption, leading to a progressive iron accumulation in tissues and organs with impairment of their function, especially of the liver, heart, pancreas, joints, skin and gonads as a result. The treatment, consisting of two phases (depletion and maintenance), is based on the removal of excess body iron. Start of treatment in early phase of the disease increases survival and decreases morbidity of patients. It is important to realize that life expectancy of $\mathrm{HH}$ patients on therapy equals that of the non-HH population but only when the disorder has been diagnosed and treated before the onset of cirrhosis and diabetes.

Despite many scientific discoveries and breakthroughs in the area of iron metabolism, treatment has remained the same for many decades. Phlebotomy is still the corner stone in the treatment. More recently erythrocytapheresis, a technique using apheresis equipment, has become an attractive alternative. With erythrocytapheresis selectively only red blood cells ( $R B C^{\prime}$ 's) are removed while valuable blood components such as plasma proteins, clotting factors, platelets, are returned to the patient. In general two different approaches are applied: first, a personalized approach based on individually adjusted volume of removed RBC's, and an approach removing a standard volume of RBC's.

In this thesis we have systematically evaluated whether a personalized approach with erythrocytapheresis has an added value in the treatment of $\mathrm{HH}$.

It was shown that personalized erythrocytapheresis leads to a significant reduction in the number of treatment procedures as well as in treatment duration in the depletion phase of treatment. Based on these results we have provided evidence for this method as treatment of choice. Indeed, our data have contributed to the advice of American Society For Apheresis (ASFA) to employ this method as a first line treatment for all $\mathrm{HH}$ patients.

Additionally, we have shown a significant reduction in number of treatment procedures and significant extension of inter-treatment interval using erythrocytapheresis in the maintenance phase of treatment.

Based on the data we have collected, a position paper and guide for the optimal treatment regimen for various groups of patients with $\mathrm{HH}$ has been written. In this guide we propose the use of erythrocytapheresis as a preferred treatment modality during both the depletion and maintenance phase of treatment.

While the scientific evidence has been generated, the next phase of implementation of erythrocytapheresis into routine care for $\mathrm{HH}$ patients poses several obstacles. The most important issue is related to the costs of erythrocytapheresis in comparison to phlebotomy. Our randomized trial has shown that the use of erythrocytapheresis in the depletion phase of treatment is cost effective. This is based on costs reduction resulting from a considerable decrease in the number of treatments as well as a 
reduction in indirect costs related to the lower number of treatments resulting in lower travel costs and costs resulting from work absenteeism.

$\mathrm{HH}$ is a chronic disease and therefore treatment compliance is a highly important factor. Patient acceptance and patient preference are crucial factors in this respect. Our second randomized trial showed that erythrocytapheresis is preferred by the majority of patients (81\%). This preference may also have a positive effect on compliance during the lifelong maintenance treatment.

In an observational study we demonstrated that erythrocytapheresis may lead to a better recovery of hemoglobin and hepcidin at start of the next procedure compared to phlebotomy. This may be clinically relevant and may prevent an increase in intestinal iron uptake and an ensuing vicious circle of more frequent treatment procedures. However, measurements of serum iron parameters were performed only before treatment procedures and not on a scheduled interval and therefore the outcome of this explorative study needs to be confirmed in larger prospective studies. Furthermore, it would be of great benefit for both patients and physicians when at start of depletion treatment the total number of phlebotomy and erythrocytapheresis procedures could be predicted. Such a prediction could guide patients and physicians in process of shared decision making to choose for the most effective treatment modality, and will provide insight in cost-effectiveness for insurance companies. We have designed, and presented an algorithm to predict the number of needed treatment procedures during depletion phase of treatment. This algorithm will be incorporated into a generally available app which would allow healthcare professionals to easily apply this algorithm and follow the treatment as well as patients to follow their treatment and possible have a positive effect on compliance.

In this thesis we have provided evidence that personalized erythrocytapheresis is a very efficient treatment modality with a good balance between effectiveness, tolerability and costs. These arguments are in favor of erythrocytapheresis over phlebotomy as a first line treatment in hereditary hemochromatosis. 


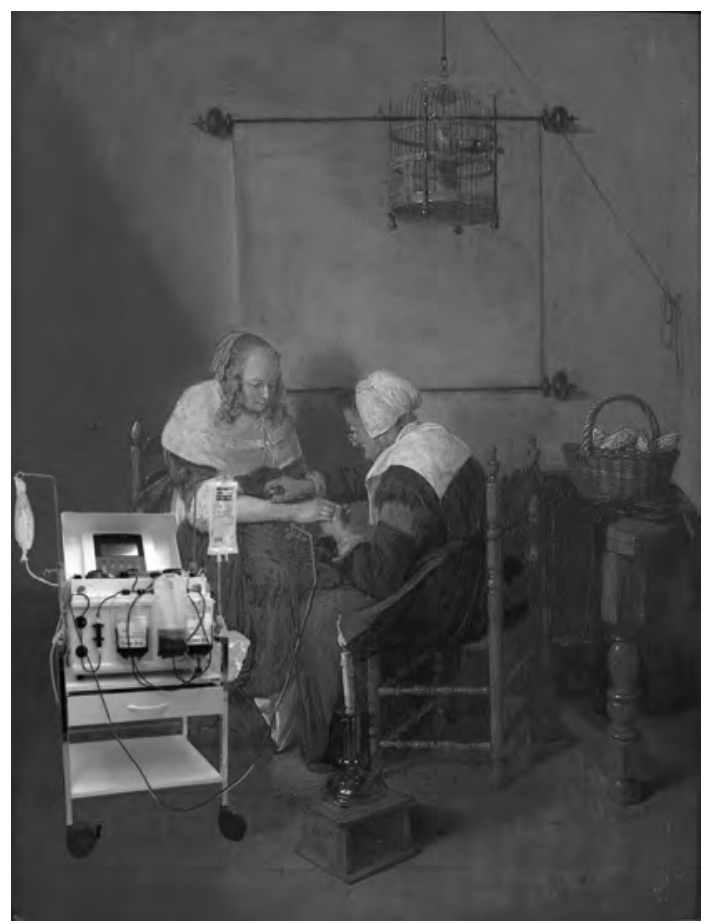

Dankwoord 



\section{Dankwoord}

$\mathrm{Na}$ vele jaren van onderzoek is het zover, de resultaten zijn gepubliceerd, mijn proefschrift is af en ik kan beginnen aan het dankwoord.

Aan het begin van dit onderzoek was er geen intentie om te gaan promoveren. Het enige doel dat ik had was om een erytrocytaferese als een nieuwe, patiëntvriendelijke, behandelmethode te testen en te bewijzen dat deze methode een toekomst heeft. En dat is gelukt. Daarom allereerst heel veel dank aan alle hemochromatose patiënten. Zonder jullie samenwerking en vertrouwen was er geen onderzoek en dus ook geen proefschrift geweest en op dit moment ook geen betere behandeling.

Verder ben ik veel dank verschuldigd aan Cees van Deursen. Cees jij was de eerste behandelaar die instemde om zijn patiënten te laten behandelen met erytrocytaferese. Heel erg bedankt voor het vertrouwen dat je vanaf het begin in dit onderzoek had, bedankt voor je adviezen met betrekking tot de gepubliceerde artikelen en voor het altijd luisteren naar al mijn vragen. Op jouw advies heb ik ook patiënten van mijn uiteindelijke co-promotor Ger Koek betrokken bij onze onderzoek.

Beste Ger (Koek), jij was de eerste die met het idee kwam dat dit onderzoek proefschriftwaardig is. Ik nam het eerst niet echt serieus en ik dacht "laat hem maar praten". Maar uiteindelijk heb je gelijk gekregen en mij zover gekregen, dat er nu een proefschrift klaar is. Nu kan ik je alleen bedanken dat je dat gedaan hebt en mij gesteund hebt in tijden dat ik echt dacht dat het niet al die stress en moeite waard was.

Heel veel dank ben ik verschuldigd aan mijn huidige promotor, professor Masclee. Geachte professor Masclee dankzij $U$ is het echt zover gekomen. $U$ hebt het mogelijk gemaakt dat ik een eigen spreekuur met hemochromatose patiënten kreeg, hetgeen een cruciale rol speelde in het hele onderzoekstraject. Van dit spreekuur en mijn hele patiëntengroep heb ik eigenlijk het meest genoten en hoop dit nog lang te doen. Uiteindelijk heeft $U$ een strak schema opgezet om dit jaar alles af te ronden en te promoveren en hebt $U$ gezorgd dat dit schema ook daadwerkelijk behaald werd. Ik kon altijd vragen om advies met betrekking tot gepubliceerde artikelen en ondanks uw drukke agenda kwam dat advies altijd heel snel. Ook daarvoor heel erg bedankt.

En dan alle steun die ik bij Sanquin kreeg. Het begon met Wim de Kort, die mij een functie van manager voor onderzoek en opleiding heeft aangeboden en er toen ook bij vertelde dat het fijn zou zijn als ik meer actief onderzoek zou doen. Zo is het eigenlijk allemaal begonnen. Wim bedankt, dat je mij deze mogelijkheid gaf. Daarna kwam Viera Novotny, een hele prettige collega en baas, die het vanzelfsprekend vond dat ik ruimte kreeg voor mijn patiënten spreekuur en voor mijn onderzoek. Viera heel erg bedankt voor alle steun en hulp, het was heerlijk jou als baas en collega te kunnen meemaken. En zo kom ik bij mijn huidige co-promotor en mijn baas bij Sanquin, Marian van Kraaij. Marian je hebt mijn begeleiding heel serieus genomen, zorgde voor strakke schema's en bood vooral heel veel hulp bij het meedenken over de opzet van 
onderzoeken, corrigeren van artikelen en goed tijdmanagement. Heel erg bedankt voor al je hulp en steun.

Verder wil ik alle leden van de beoordelingscommissie, professor Bekers (voorzitter), professor Anneke Brand, Professor Piere Brissot, professor Schouten, en dr. Wim Hameeteman bedanken voor de tijd en moeite die ze hebben genomen om mijn proefschrift door te lezen en te beoordelen. Dear Professor Brissot, I highly appreciate your enthusiasm with which you have agreed to participate at the defense of my thesis and I am also very pleased that you were willing to give a lecture during our symposium.

Ik kan zeker niet vergeten een heel belangrijke collega, een ongelooflijk fijn mens, die het mede mogelijk heeft gemaakt dat ik als internist in Nederland aan de slag mocht en later alle geheimen van de aferese techniek aan mij toevertrouwde, Bob Sybesma. Het is erg jammer dat hij er niet meer bij kan zijn. En zo kom ik ook bij de hele groep van internisten, hematologen en mdl-artsen in het Merwede Ziekenhuis in Dordrecht, waar ik mij in de periode tussen 1994-1996 heel erg thuis voelde en mijn registratie als internist in Nederland behaalde. Allen heel erg bedankt voor de steun die ik toen kreeg. Ook nog een bedankje aan Alberdina Dullemond-Westland, een internisteoncologe en vooral een aangenaam persoon. Zij heeft mij veel geholpen bij mijn eerste baan in Nederland in het Maria Ziekenhuis in Tilburg. Beste Alberdina, bedankt voor al je steun en hulp.

En nu alle collega's, en dat waren er heel wat, die meewerkten aan alle verrichte studies. Ik hoop dat ik niemand vergeet. Ik begin met Paul van Noord, een prettige collega die vanaf het begin hielp met de statistiek en opzet van studies, hij heeft veel uren doorgebracht in Maastricht bij het opzetten en uitwerken van onze SPSS bestanden. Paul heel erg bedankt voor al je hulp en steun. Vanaf onze eerste Pilot Studie was Ans Nillesen, een bijzonder elegante en vriendelijke aferese assistente, heel professioneel bezig bij de technische ondersteuning, het uitvoeren van procedures en het contact met de patiënten. Ans jij stopte halverwege onze onderzoeken in verband met je wel verdiende pensioen, maar wij en vooral de patiënten misten je erg. Ellen Franken en Judith Heeremans waren nauw betrokken bij het opzetten van bestanden en contact met patiënten, beiden inmiddels bezig met andere werkzaamheden. Ik dank jullie voor alle ondersteuning. Later en tot het slot nam Ellen Reuser al deze taken op zich. Ellen ik ben je heel erg dankbaar voor al het verrichte werk met betrekking tot administratie, patiënten contacten, technische ondersteuning en het uitvoeren van aferese procedures. Zonder jullie alle vier waren deze studies niet mogelijk geweest. De laatste jaren kregen we steun en hulp van het BAT-team, Marian Klijn Velderman, Astrid van der Griendt en alle afname dames: Ingrid, Karin, Hélène en Sjan. Daarvoor heel erg bedankt.

In Nijmegen kreeg ik veel steun en hulp van professor Dorine Swinkels en Mirian Janssen, ik ben jullie erg dankbaar voor alle hulp en de zeer prettige samenwerking, Dorine voor de kritische meetings met als doel het onderzoek scherp te formulieren en de publicaties zo goed mogelijk aan te leveren, Mirian voor heel veel hulp bij 
includeren van patiënten en het kritische doorlezen van publicaties. Later kwam Alexander Rennings erbij, Alexander ook bedankt voor al je hulp bij het aanleveren van patiëntgegevens voor het predictie model. In Sittard heeft Laurens Bos geholpen met het includeren van patiënten, heel erg bedankt ervoor. In Leiden en Den Haag kon ik rekenen op hulp van Jean-Louis Kerkhoffs en Dorothea Evers, jullie beiden erg bedankt. En nu alle statistici en epidemiologen van de universiteit en de afdeling KEMTA in Maastricht, Brigitte Essers, Fred Nieman en Bjorn Winkens. Zonder jullie was het afronden van onderzoeken niet mogelijk geweest. Beste Brigitte, heel erg bedankt voor alle hulp bij de kostenberekeningen, evaluaties van vragenlijsten en kritische aanvullingen bij beide publicaties. Geachte collega Nieman, bedankt voor alle hulp bij de statistische evaluatie van onze beide studies en alle geduld bij het uitleggen van het gebruik van multivariate analyse. Beste Bjorn, jou bedank ik voor de hulp bij de statistische verwerking van onze tweede studie, de prachtige grafieken en vooral de hulp bij het opzetten van het predictie model. Jij toonde enorm veel geduld bij het uitleggen van voor mij vaak te moeilijke termen. Verder dank aan Rogier van den Braak, de financiële man achter Sanquin, die ons heeft geholpen met prijsberekeningen van aderlating- en erytrocytaferese-procedures. Ook bedankt voor alle hulp aan Paul Menheere bij de grafische verwerking van trends in onze hepcidinestudie en het meedenken over de verwerking van alle resultaten van deze studie. Dezelfde dank ook aan Rabin Neslo, die leverde prachtige plaatjes voor dezelfde studie.

Hemochromatose-patiënten lijden vaak aan gewrichtspijnen. Daarom hebben we de hulp van professor Annelies Boonen ingeroepen. Geachte professor Boonen heel erg bedankt voor alle goede adviezen met betrekking tot het gebruik van vragenlijsten, hulp bij de interpretatie van deze lijsten en het kritische doorlezen van het artikel.

Tijdens het uitvoeren van mijn patiëntenzorg werd ik geconfronteerd met een patiënt in een eindstadium van cardiomyopathie die we met erytrocytaferese konden helpen tot volledige herstel. Bij het verwerken van de gegevens van deze patiënt in de vorm van een publicatie hebben de collega's uit het Utrechtse UMC, Nicolaas de Jonge, Corinne Klöpping, Karin van Galen en Aryan Vink en de collega's van het Twents MC, Elly Wajon en Willem Smit, samen met Cor van Bree en het BAT-team van Sanquin geholpen. Hartelijk bedankt jullie allemaal.

Alle stafleden van afdeling gastro-enterologie en hepatologie, wil ik bedanken voor een heel fijne omgeving die ik kon ervaren tijdens mijn aanwezigheid op deze afdeling. Ik ben een beetje een vreemd eendje als algemeen internist tussen jullie maag-darmlever-artsen, maar toch voelde ik me niet vreemd en daarom bedankt aan jullie allemaal. Beste Yolande Keulemans, je bent inmiddels vertrokken, maar ik wil je toch bedanken voor alle hulp bij mijn eerste uren op de polikliniek. Je was een hele fijne collega. Beste Wim Hameeteman, enkele jaren hebben we op de poli in de kamers naast elkaar gezeten, ik kon altijd bij je aankloppen bij vragen betreffende mdlproblematiek, waarvoor heel erg bedankt. Beste Joanna Kruimel, je bent altijd zeer 
aardig en behulpzaam gebleven toen ik regelmatig Ger bezocht op de kamer die jullie samen delen.

Beste Elly Mares en Mietsie Tijssens, heel erg bedankt voor jullie hulp bij het regelen van alle afspraken, hulp bij alle brieven en alle aardige woorden en hulp die ik van jullie altijd kreeg. Beste Tiny Wouters, bedankt voor je hulp met lay-out en alle praktische zaken bij de totstandkoming van mijn proefschrift.

Alle collega UTG'ers, bedankt jullie allemaal voor alle morele steun en hulp die ik van jullie kreeg. Saskia, voor alle geruilde diensten, toen ik tijd te kort kwam in de laatste fase van mijn proefschrift; Jacques en Henk, voor alle begrip en goede gesprekken in te drukke tijden; Judith en Cynthia, voor alle steunende woorden; Bert voor alle begrip met mijn werkzaamheden; Leo voor je leuke presentaties over hoe je een studie wel of niet moet opzetten; Hans voor alle steun met betrekking tot de aferesewerkzaamheden; Peter, voor jouw support bij onze regionale opleidingsactiviteiten; Fikreta en Jessy voor jullie bereidheid altijd te helpen met de moeilijke logistiek m.b.t. zeldzame uittyperingen; Rianne, jouw steun als onze nieuwe manager; Cor en Roland, voor ondersteuning van erytrocytaferese werkzaamheden in het noorden; Anja en Francis voor de morele steun. Ellen, voor alle je hulp met het Kennisplatform, regelen van agenda en afspraken en een luisterende oor bij alle problemen. Karin en Christien, voor jullie hulp met dienstroosters; Ingrid je hulp met ICT problematiek.

Alle Maastrichtse collega's van de afdeling uitgifte en klantenservice, Patrick, Angèle, Anja, Christian, Hong, Nadja, Patricia en Sya, bedankt voor begrip en een fijne sfeer, aan onze kant van de Bloedbank. Het is altijd leuk met jullie tijdens alle feestjes op de Bloedbank.

Dames van de afdeling van bloedinzameling, Margot van de Leemput en Manon Theunissen bedankt voor alle begrip die jullie met ons hadden tijdens alle therapeutische afnames, die vroeger nog op jullie grondgebied gebeurden.

Collega's donorartsen, Armand Snel, Saba Karomi, Wouter Hamstra en alle andere, die betrokken zijn geweest bij de begeleiding van patiënten met hemochromatose, bedankt voor jullie hulp en professionaliteit. Anna van Kleef bedankt voor het regelen van alle logistiek omtrent aanwezigheid van de artsen tijdens deze afnames.

Beste Lizzy (van Pampus) jij bedankt voor alle steun, een altijd luisterend oor en de interesse die je altijd toonde. Ik mis zeker onze gesprekken uit de periode toen je nog in Maastricht werkzaam was.

Beste Evelien (Pijpers) en Patricia (Stassen) het was erg gezellig met jullie op de kamer. Heel erg bedankt voor alle steun.

En nu mijn familie, die mij de hele tijd door dik en dun gesteund heeft. Beste Ferdie bedankt voor alle steun, hulp met tabellen en grafieken, hulp bij interpretatie van studies en vooral voor al die keren dat je mijn computer weer aan praat kreeg toen die zogenaamd niet meer werkte. Ik heb enorm veel steun van je gekregen en zal dat hopelijk nog lang krijgen. Beste Juraj, je kreeg soms een boze moeder aan de lijn die enige stress op jou afreageerde, sorry daarvoor. 
Moja drahá mamička a Alenka, vy ste ma vždy podporovali a tešili sa z každého úspechu, začo vám patrí obrovská vd'aka. Najviac sa zo všetkého radoval môj drahý otecko, ktorý velkú čast svojho života venoval výskumu. Žialbohu nám ho zákerná choroba zobrala a nemôže sa tešit $z$ tohto úspechu, ale viem určite že by bol strašne rád a hrdý, nielen na mňa ale aj na vás obidve, ako to všetko zvládate bez neho. 



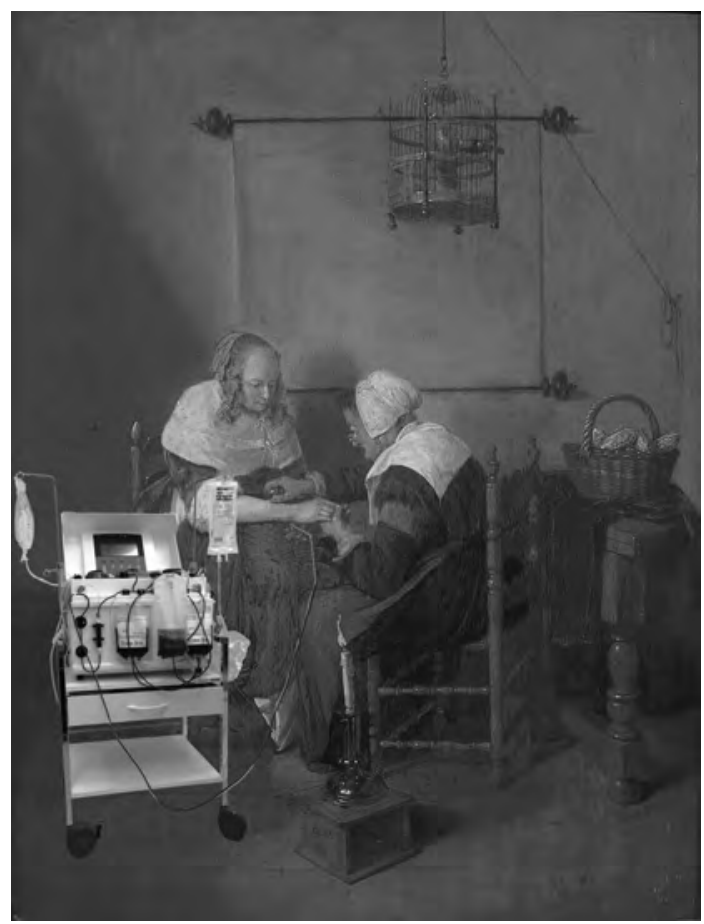

Curriculum vitae 



\section{Curriculum vitae}

Eva Rombout-Sestrienkova was born on December 15th 1956 in Zlate Moravce, Czechoslovakia. After finishing her secondary school training, Gymnasium, in 1976, she started her medical education at Comenius University in Bratislava, Czechoslovakia. In 1982 she graduated at the medical school and started working at the Department of Internal Medicine at the Hospital in Piestany (Czechoslovakia, now Slovakia). In 1985 and 1990 she was registered as a Specialist in Internal Medicine (first and second degree respectively) in the register of the Slovak Medical Chamber. From 1990-1991 she was working as a head of the Department for Internal Medicine and Geriatrics in the Hospital in Piestany. In 1992 she moved to Netherlands and between 1993-1996 she worked at the Department of Internal Medicine of the Maria Hospital in Tilburg followed by the Merwede Hospital in Dordrecht. In 1996 she registered as a Specialist in Internal Medicine in the register of KNMG and started working at the Blood Bank South-Limburg in Maastricht. In 2003 she was registered as a Specialist in Transfusion Medicine in the register of KNMG. From 2000-2002 she was working as a Manager at the Department for Medical affairs at the Blood bank South-Limburg, and from 2002-2007 as a Manager at the Department for Research and Education from Sanquin Blood bank Southeast region. From 2007 she works as a Transfusion specialist at the Department of Transfusion Medicine at the Sanquin Blood bank.

In 2008 she started her scientific project with the aim to improve the quality of life of patients with hereditary hemochromatosis, eventually leading to this thesis at the Division of Gastroenterology and Hepatology at the Maastricht University Medical Centre. She performed her research first under supervision of associate professor $\mathrm{dr}$. Ger Koek and professor dr. Peter de Leeuw , later professor dr. Adrian Masclee. 



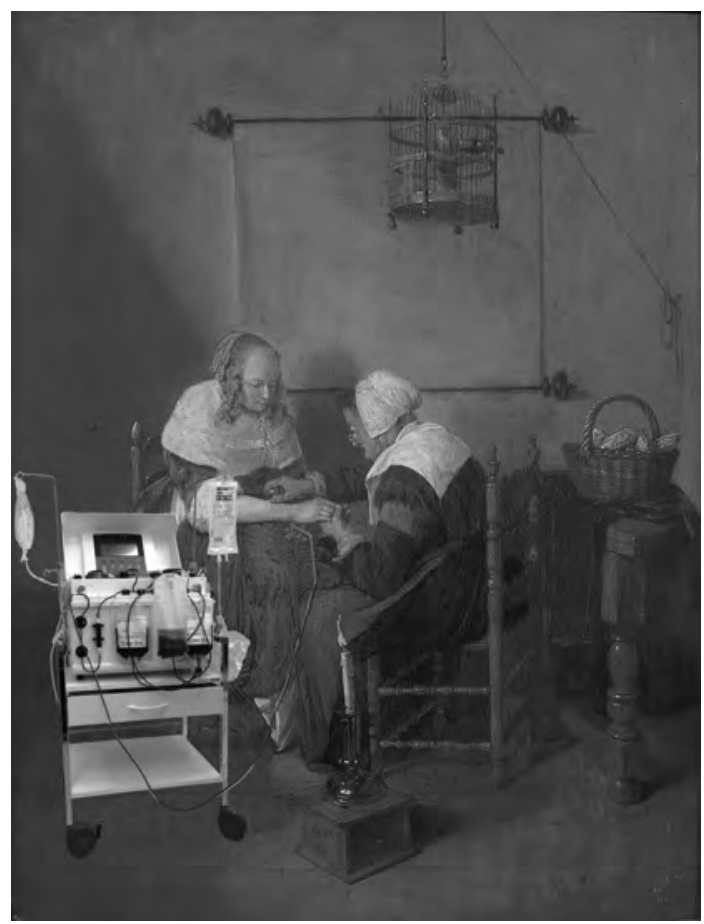

List of publications 



\section{List of publications}

1. Rombout-Sestrienkova $E$, van Kraaij MG, Koek GH. How we manage hereditary haemochromatosis. Br J Haematol. 2016, Epub ahead of print.

2. Rombout-Sestrienkova E, Koek GH, Neslo R, van Kraaij M, Menheere PP, Masclee A, Swinkels DW. Course of iron parameters in HFE-hemochromatosis patients during initial treatment with erythrocytapheresis compared to phlebotomy. J Clin Apher. 2016 Feb 16. doi: 10.1002/jca.21451.

3. Rombout-Sestrienkova E, Winkens B, Essers BA, Nieman FH, Noord PA, Janssen MC, van Deursen CT, Boonen A, Reuser-Kaasenbrood EP, Heeremans J, van Kraaij $\mathrm{M}$, Masclee A, Koek GH. Erythrocytapheresis versus phlebotomy in the maintenance treatment of HFE hemochromatosis patients: results from a randomized crossover trial. Transfusion. 2016 Jan;56(1):261-70.

4. Rombout-Sestrienkova E, De Jonge N, Martinakova K, Klöpping C, van Galen KP, Vink A, Wajon EM, Smit WM, van Bree C, Koek GH. End-stage cardiomyopathy because of hereditary hemochromatosis successfully treated with erythrocytapheresis in combination with left ventricular assist device support. Circ Heart Fail. 2014 May;7(3):541-3.

5. Rombout-Sestrienkova $E$, van Deursen $C T$, Janssen $M C$, van Kraaij MG, de Leeuw PW, Koek GH. Erythrocytapheresis for hereditary haemochromatosis. Ned Tijdschr Geneeskd. 2012;156(26):A4745

6. Rombout-Sestrienkova E, Nieman FH, Essers BA, van Noord PA, Janssen MC, van Deursen CT, Bos LP, Rombout F, van den Braak R, de Leeuw PW, Koek GH. Erythrocytapheresis versus phlebotomy in the initial treatment of HFE hemochromatosis patients: results from a randomized trial. Transfusion. 2012 Mar;52(3):470-7.

7. Luten M, Roerdinkholder-Stoelwinder B, Rombout-Sestrienkova E, de Grip WJ, Bos $\mathrm{HJ}$, Bosman GJ. Red cell concentrates of hemochromatosis patients comply with the storage guidelines for transfusion purposes. Transfusion. 2008 Mar;48(3):43641.

8. Rombout-Sestrienkova E, van Noord PA, van Deursen CT, Sybesma BJ, NillesenMeertens AE, Koek GH. Therapeutic erythrocytapheresis versus phlebotomy in the initial treatment of hereditary hemochromatosis - A pilot study. Transfus Apher Sci. 2007 Jun;36(3):261-7. 
9. Curvers J, van Pampus EC, Feijge MA, Rombout-Sestrienkova E, Giesen PL, Heemskerk JW. Decreased responsiveness and development of activation markers of PLTs stored in plasma. Transfusion. 2004 Jan;44(1):49-58.

10. Fransen EJ, Rombout-Sestrienkova E, van Pampus EC, Buurman WA, Reutelingsperger CP, Maessen JG. Prestorage leucocyte reduction of red cell components prevents release of bactericidal permeability increasing protein and defensins. Vox Sang. 2002 Aug;83(2):119-24. 


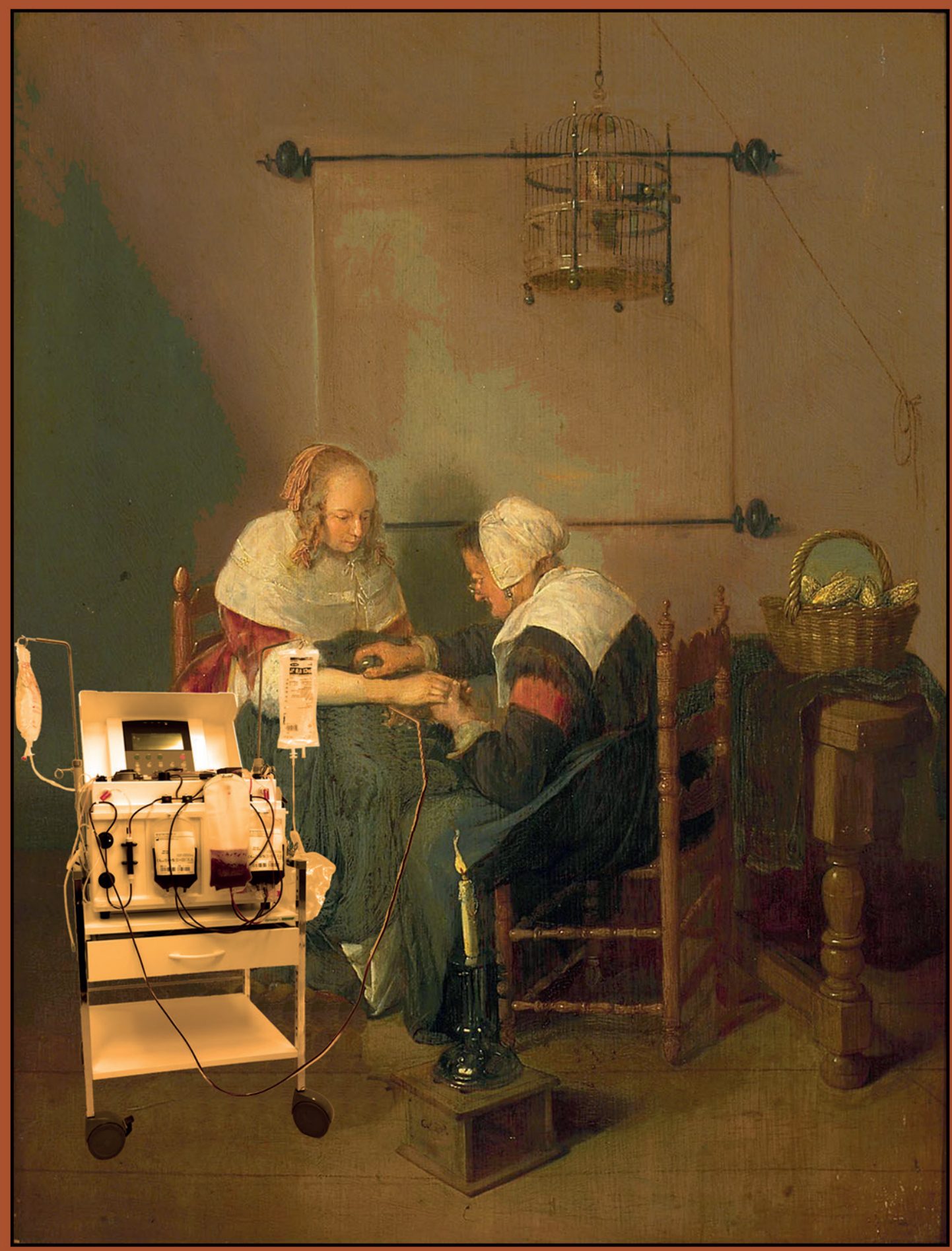

